
e. 
Dedicated to Marianne, Paul and Etienne for your understanding, tolerance and support during our stay in Het Groot Begijnhof 54/1. 


\section{STRATEGIC MANAGEMENT SUPPORT TECHNOLOGIES IN THE PUBLIC SECTOR}

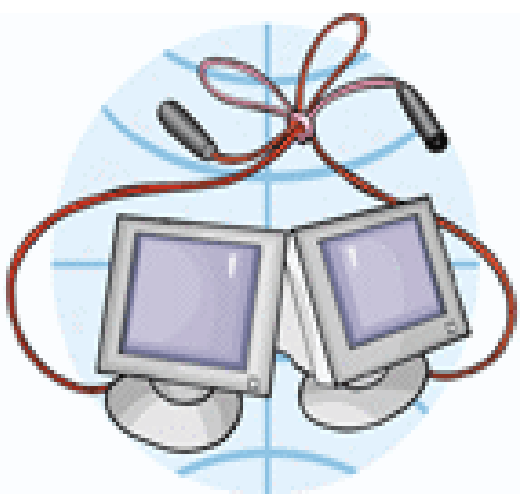

Report on the use of electronic back-office technologies to improve capacity building for good governance outcomes in the public sector

by

\section{Fanie Cloete}

Professor of Policy Analyses

School of Public Management and Planning

University of Stellenbosch

March 2003 
Published by SUN ePRESS, a division of AFRICAN SUN MeDIA, Victoria Street, Stellenbosch, SOUTH AFRICA 7600

ISBN: 978-1-919980-05-8

e-ISBN: 978-1-919980-27-0

DOI: $10.18820 / 9781919980270$

First Edition 2003

No part of this book may be reproduced or transmitted in any form or by any electronic, photographic or mechanical means, including photocopying and recording, or by any information storage and retrieval system, without prior written permission by the publisher.

Digitally printed by US Printers, Stellenbosch

e-Book packaged for SUN ePRESS by Cape Multimedia Systems

All rights reserved

(c) Prof Fanie Cloete, University of Stellenbosch, 2003 
"Decision-making at ... high levels of government ... is often portrayed as rational decision processes. But in fact, decision-making involves managing issues that are forced on decision-makers with varying and shifting priorities. Issues circulate continuously; they enter and exit through participants and are resolved in the sense that they dissolve or go away or are overtaken by other issues. The issues are themselves complex, poorly defined, interdependent... Information is voluminous but unreliable and qualitative." - Lauden \& Lauden 1998:596

"... informatization is radically changing the 'business processes' of public administration. The automation of implementation processes ... is not only blurring organizational boundaries..., it is also changing the organization chart of public administration... In a more fundamental sense it is transforming the bureaucratic structures and processes that have dominated it for ages. The organization of public administration of the next millennium will not be bureaucratic but infocratic..."

- Snellen \& Van de Donk 1998:16 


\section{ACKNOWLEDGEMENTS}

Research for this report was undertaken during 2001 and 2002 in Stellenbosch in South Africa and in Leuven in Flanders, Belgium. I spent the last half of 2001 at the Catholic University of Leuven for this purpose, together with my family. We had a wonderful time in Leuven and will always cherish these memories. The time spent at the Public Management Institute (PMI) in Leuven and my field visits around Europe contributed towards the visit being a productive and intellectually stimulating exercise for me; I gained access to new materials established new networks and contacts, made various new research outputs and gained important new insights through observation, the perusal of documentation and the exchange of ideas in personal discussions. I was received at the PMI in a very cordial and friendly manner, and for all practical purposes was accepted as a full member of the Institute during my stay here.

I want to extend my sincere gratitude to all the members of the Institute (especially to Geert Bouckaert, Marlene Brans and Christel Vandeurzen) for their assistance to me during this period. I have made many new friends and will continue to expand the research project in co-operation with the PMI, as stated above.

The financial assistance of the First Rand Foundation and the University of Stellenbosch towards this research is hereby also gratefully acknowledged. Opinions expressed in this report and conclusions arrived at are, however, those of the author or the sources referred to, and are not to be attributed to any of the above organisations.

\section{Fanie Cloete}




\title{
STRATEGIC MANAGEMENT SUPPORT TECHNOLOGIES IN THE PUBLIC SECTOR
}

\begin{abstract}
The objective of this paper is to summarise the need for and potential applications of selected user-friendly, state-of-the-art electronic policy support tools to promote more successful strategic policy management, which will in turn improve sustainable service delivery outcomes in the public sector.

Recent international research findings on good governance indicate inter alia the following trend: a general acceptance that a strategic management approach focused on committed actions to achieve realistic implementation objectives is needed to improve service delivery outcomes. This necessitates inter alia effective information use and management; a dramatic world-wide increase in the availability of digitised policy-related data and highpower-capacity computer systems to manipulate that data; a resultant dramatic increase in the reliance on electronic management information systems in well-developed and relatively successful policy systems to monitor, co-ordinate, implement and assess the effectiveness of policy implementation programmes, and an increasing reliance on more user-friendly and less technically complicated and more visual and command-driven electronic decision-support systems to optimise multi-criteria policy decision-making in order to promote effective policy implementation and service delivery.
\end{abstract}

In many developing countries the current state of affairs with regard to the above strategic trends in more developed countries is not good. The main problems are: frequent incidences of policy failure, attributed primarily to ineffective or bad policy implementation; weak policy implementation capacity and service delivery results; low levels of policy decision-making-related knowledge, experience and skills, especially electronics and management information systems, and low appreciation of the utility and potential of such aids; information gaps and uncertainties that lead to a general policy 
paralysis, which should be transformed into policy activism in order to improve policy implementation and service delivery results.

In order to improve the positive impact of public policy outputs in developing states, the success rate of the government's public policy outcomes needs to be significantly increased. The experiences of different nations where electronic output and outcome support tools have been used or are in use to achieve a better success rate with public policy design and implementation are important in this regard. The adoption and use of more user-friendly but effective electronic management support systems will not necessarily guarantee policy and service delivery success. It is assumed that these decision aids will, however, maximise the potential for improved or more successful results, if they are applied appropriately and effectively.

Elementary electronic management assessment tools can be used effectively to improve the success rate of public services delivery. Policy implementation and review could be enhanced through the use of specialised electronic performance management and assessment tools. No single, integrated package of this nature currently exists. If developed, it could be beneficial to public policy outcomes, especially in the developing world, to expose the officials concerned to the utility of MSS tools. 


\section{CONTENTS}

$\begin{array}{lr}\text { Foreword } & 1\end{array}$

1. Research problem and objectives 3

$\begin{array}{lll}\text { 2. Changing perspectives on public management } & 7\end{array}$

3. The IT revolution in public management 25

4. Electronic public management support in comparative perspective $\quad 49$

5. Conclusions and recommendations 75

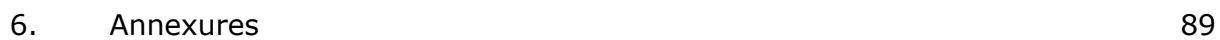

6.1 Research methodology and programme 89

$\begin{array}{lll}6.2 & \text { Interviews } & 97\end{array}$

6.3 Selected electronic management support tools 101

$\begin{array}{lll}6.4 & \text { Suggested course outline } & 109\end{array}$

$\begin{array}{lll}7 . & \text { Bibliography } & 115\end{array}$ 


\section{FOREWORD}

In 1998 the Presidential Review Commission on the Transformation of the South African Public Service (the PRC) identified a series of normative, structural and functional defects in the existing South African public service. The Commission recommended a series of significant reforms to attempt to improve the process of strategic governance in general and public services delivery in particular in South Africa. A crucial element of the recommendations was the reshaping of the strategic electronic decision-making and management capacity of central government (see Malabie 1998).

The author participated in the research that led to the PRC report and expanded that research during a six-month research programme in South East Asia in 1998, where the contributions of the so-called South-East Asian "Tigers" (Singapore, Malaysia, Thailand, Indonesia and the Philippines) were assessed to determine which factors contributed to their varied levels of public services delivery performance over the past decade. A model for improved public services delivery in developing countries was formulated on the basis of the comparative contemporary literature on Good Governance, combined with the experiences of the Tiger countries.

The above research report was subsequently published in book format (Cloete 2000). One of the crucial research findings in this book was that there was a need to improve strategic management processes in government in order to promote good governance by reducing the levels of uncertainty and risk in decision-making, which frequently led to either policy indecision and stagnation or bad decisions or implementation strategies. This generally necessitates higher-quality policy planning, implementation and assessment processes in the public sector. It also became clear during that research project that the current evidence and outcomes-based approaches to governance in turn necessitates much more rigorous attention to information accumulation, analysis and assessment in order to build up factual evidence and records of the results of policy interventions. 
These insights coincided with the growth spurt in the global IT industry that led to the recommendations of the PRC in this regard. Many governments declared their commitment to establishing e-governance systems, including governments in lesser-developed countries. The traditional literature and teaching on public policy analysis, however, did not keep pace with these new developments. This led to the author's decision to embark upon a research programme on the use of strategic management support technologies in the public sector in order to upgrade the capacity for good governance outcomes, especially in lesser-developed societies. This report is the result of the first stage of that research programme, which started during the author's sabbatical leave in Europe during the second part of 2001.

More details about the research methodology, schedule and programme are provided in Annexure 1. 


\section{CHAPTER 1}

\section{RESEARCH PROBLEM AND OBJECTIVES}

\section{INTRODUCTION}

This study is concerned with the use of technology to improve capacity building in the public sector in developing countries in order to maximise the potential for good governance outcomes in those societies. The research problem and objectives will be briefly summarised in this chapter, followed by a summary of changing perspectives on management. The identification of a management assessment framework to accommodate these changing perspectives on management will be undertaken in Chapter 2, while Chapter 3 summarises the implications of the fast-growing information revolution for public management and Chapter 4 compares the role of electronic management support tools in selected public management settings in Europe. A summary of the conclusions of the study is set out in Chapter 5, followed by various annexures containing more details about the research methodology, interviewees and programme followed, as well as a bibliography.

\section{PROBLEM IDENTIFICATION}

Recent research findings on the impact that the global information technology revolution has so far had on the state of governance in industrialised states indicate the following trends:

回 frequent incidences of policy failure, attributed primarily to ineffective or bad policy implementation;

回 a general acceptance that a strategic management approach focused on committed decisions and actions to achieve realistic implementation objectives is needed to improve service delivery outcomes; 
回 a general acceptance that this in turn necessitates inter alia more effective information use and management for strategic decision-making and monitoring;

回 a dramatic world-wide increase in the availability of digitised policy-related data and high-power-capacity computer systems to manipulate such data;

回 a resultant dramatic increase in the reliance on electronic management information systems in well-developed and relatively successful policy systems to make appropriate strategic choices, monitor, co-ordinate, implement and assess the effectiveness of those policy choices; and

回 an increasing reliance on more user-friendly and less technically complicated and more visual and command-driven electronic decision-support systems to optimise multicriteria policy decision-making in order to promote effective policy implementation and service delivery.

In South Africa as well as in other developing countries the current state of affairs with regard to these strategic trends in more developed countries is not good. The trends are:

回 weak policy implementation capacity and service delivery results (the South-East Asian Tiger cub countries, developing countries in general and SA in particular);

回 low levels of policy decision-making-related knowledge, experience and skills in SA, especially electronics and management info systems, and low appreciation of the utility and potential of such aids;

回 information gaps and uncertainties that cause a general policy paralysis, which should be transformed into policy decisional activism in order to improve policy implementation and service delivery results.

In order to improve the positive impact of public policy outputs in developing countries, including South Africa, the quality of public policy-related processes in government clearly needs to be significantly increased. Answers will therefore be sought to the following research questions: 
回 What electronic internal management support (back office) systems are predominantly used in the public sectors in the different countries, by whom, how widely and for what purposes?

回 How effective are these practices, i.e. what is their impact on public sector policy processes and outcomes?

回 What other similar or new systems are under development or contemplated to facilitate good governance in this way?

回 How relevant are they for, and how appropriately can they be utilised to enhance, good governance processes and outcomes in South Africa and other developing countries? 


\section{RESEARCH OBJECTIVE}

The objective of this research programme is to investigate the nature, availability, use and possible application in South Africa and other developing countries of various user-friendly, state-of-the-art electronic policy management support approaches and aids in use in selected strategic public management units in Europe during 2001.

A variety of electronic government initiatives are in progress or are under development in highly developed countries like the United Kingdom, the Netherlands, Belgium, France and Germany, as well as in leading nations in the developing world, like Brazil, Mexico, India and Singapore. Many of these aids can be similarly applied, customised or expanded in developing countries like South Africa to improve the success rate of public services delivery by increasing the accuracy and scope of information available to policy managers and by providing them with support tools for better and faster data comparison, analysis and assessment.

The broad hypothesis for this study is that the appropriate use of electronic management support aids has the potential to promote more successful strategic policy decisions, implementation strategies and policy assessment processes, which in turn may improve public service delivery outcomes. 


\section{CHAPTER 2}

\section{ChANGING PERSPECTIVES ON PUBLIC MANAGEMENT}

The emerging use of information technologies in the public sector will be briefly contextualised in this chapter against the background of the international development of the discipline of Public Administration and Management. The main considerations conducive to the current rapid spread of various information technologies in public management will be summarised and assessed in order to understand the nature of the new developing integrated management paradigm more accurately.

The study of Public Administration in its earliest form started in the classical Greek period with a normative approach in the form of philosophical debates and qualitative assessments of the values underlying good government (democracy, liberty, authority, etc.). At the start of the modern nation-state era, Montesquieu initiated a legalistic, structural approach to government by identifying different analytically distinct and functionally specialised organs of state, which together comprise the instruments of government (legislative, executive and judicial organs).

In the early twentieth century Woodrow Wilson refined this approach by explicitly distinguishing political from administrative institutions, while scholars like Weber, Taylor and others started to focus increasingly on the functioning of the administrative or bureaucratic policy implementation institutions of the state. Planning, organisation, staffing, training, control and budgeting (POSTCORB) were identified as characteristic policy implementation functions of, or sub-processes within, bureaucracies. This functional approach lead in the early 1950 s to attempts to develop more rigorous methodologies for the analysis of public sector institutions and processes and the establishment of a fully-fledged, more quantitative policy sciences approach to public administration that was well represented by scholars like Laswell and Dror. 
The desire for greater methodological rigour required the availability of massive volumes of high-quality data and more complex data-analysis and assessment techniques in order to make valid comparisons and analyses, and to draw valid conclusions. The compilation and processing of high volumes of data only became feasible after mass production of mainframe computers in the 1960s, and more specifically after the spread of individual personal computers since the mid-1980s. This growing awareness of the importance of information in government also stimulated the cybernetics approach to public administration in the early 1970s. The premature emergence of the quantitative and cybernetics approaches to the study of public administration, before the introduction of the personal computer, resulted in these approaches being overtaken by other emerging approaches, because the conditions to enable their full development were not favourable enough at the time. They needed more appropriate mass-produced hardware and software systems than the few mainframe computers that were available at the time.

In addition, a perceived over-emphasis on the study of methodological, institutional, procedural or instrumental aspects of public institutions, processes and policies, and growing dissatisfaction with the results of government interventions in society eventually lead to a normative backlash in the form of a more explicit value-laden, issue-based approach to public policy contents and outcomes rather than institutions, processes and methodologies. More explicit foci started developing instead on specific issues of community, racial and gender participation in policy processes, transparency, accountability, ethics, the fairness of redistributive outcomes, developmental objectives, ecological preservation, etc. In order to assess the impact of government on individuals, interest groups and communities, however, more detailed information is required about their needs and wants, and about public policy objectives, action plans, resources and outcomes. This new issue-based approach therefore increased the need for more and better information, and consequently also the need for more sophisticated technologies to collect, process and assess such information. 
This micro-level approach to the study of public administration issues eventually developed into a distinct post-modernist approach to public administration that denied the validity of over-generalisations and emphasised instead the contextual uniqueness of public administrative systems. The post-modernist approach has, however, so far not achieved widespread support, although its expansion into fully-fledged complexity and quantum theories of organisations is steadily gaining ground (Kiel 1994, Evans 1996; Overman 1996; Pascale 1999; Cooper, Musso \& Oztas 2001). In contrast, rapid globalisation processes, driven by a similarly fast-growing information technology revolution, and the increasing realisation during the early 1980 s that contemporary government is not delivering the goods as it is supposed to do, stimulated the development of the prevailing inter-related New Public Management (NPM), Network and Governance approaches to public management. It also created more favourable conditions for the cybernetics approach to government to return with a vengeance.

The reigning New Public Management approach developed as a reaction against the focus of the traditional Public Administration discipline on the input-related structures and functions of government that did not seem to produce the anticipated results in terms of social development in industrial societies (Kettl \& Milward 1996:4; Hood 1995). As a result of the perceived inefficiencies of the traditional public administration system, the NPM promotes the adoption by the public sector of generic and liberal free market-oriented business management principles. It also promotes the voluntary transfer of the public sector's non-core functions to the private or voluntary sectors, either through full or partial privatisation exercises, joint or partnership ventures, or agency or outsourcing contracts. In this way the state can gain access to other resources in society in addition to those under its direct control and it can improve the quality of public services by allowing other service providers to deliver specified services better than it can do itself.

This approach blurs the distinction between the public, private and voluntary sectors by postulating that many principles of management are generic and applicable to both public and business-oriented organisations. It has brought about a paradigm shift in the way that 
the role of the state in society is perceived. It changed Public Administration into Public Management (see, for example, Pollitt \& Bouckaert 2000:8). It has become an influential approach that has taken root across the world and is still expanding in its application in different societies. NPM scholars disagree about the ideal new boundaries between the traditional sectors in society (Rhodes 1997:47). It has even been alleged that the NPM approach has extended the role of the state in society rather than restricted it, because of its gaining access to, and its regulation and control of, both profit making and voluntary agencies as proxies to achieve its objectives (Durant 1998:212, Smith 1998:51). A contrasting conclusion about the current nature of public organisations can, however, be drawn from the development of the network approach to public affairs, discussed below.

The NPM approach to service delivery entails a series of changes in traditional government focus, structure, functioning and organisational culture in the public sector. These changes include a change from an input-, resource-focused administration to an output-, resultsbased management system. The new approach is based on performance contracting and promotion, accompanied by a change from rough, superficial, qualitative assessments (or guesstimates) of the outcomes of service delivery to more accurate and precise quantitative measurements of policy outputs and/or outcomes, where possible and feasible. This necessitates the use of appropriate electronic methodologies to compile, analyse and assess the data needed for this purpose. Until recently computer technologies were not yet sufficiently developed to do this.

Another change brought about by the NPM is a more transparent, accountable and participatory public policy process. The characteristic of this process is that direct, vertical, regulatory, bureaucratic control of service quality is replaced by indirect, horizontal, ex post quality control by empowered customers/ consumers, citizens or the partners in a policy network. This necessitates more effective co-ordination of interactions among the various members of policy networks. More sophisticated technologies are also needed for this purpose. 
A last impact of NPM on traditional management practices that is relevant for this study is the change from simple cash budgeting and accounting methods as well as annual financial planning cycles to more complex accrual budgeting and accounting practices and multi-year financial planning cycles. This is normally accompanied by a rise in influence of economists, accountants, financial and strategic managers with the appropriate economic, financial and accounting skills in the public policy process. This shift in focus also necessitates more sophisticated methods of financial planning and control.

Weaknesses in the NPM approach (see Cloete 2000) led to the governance approach to public affairs. Kooiman defines governance as "... the patterns that emerge from governing activities of social, political and administrative actors..." (1993:2). According to Kooiman (1993), these patterns form the emerging outcomes which constitute a more abstract framework at a higher level for day-to-day governing activities. Governing is defined as "... those purposeful activities of social, political and administrative actors aimed at guiding, steering, controlling or managing aspects or facets of society" (Kooiman 1993:2). Inherent in Kooiman's definition of governance is the idea of public-private interactions within a network of relationships aimed at achieving desired objectives for society (see also Smith 1998:59). Strategies such as intergovernmental management (IGM) in different forms are increasingly needed to manage these complex relationships (Rhodes 1997:56; Peterson 1998; Durant 1998:233), while different new theories of complexity, including chaos and quantum theories, are increasingly relied on to explain various aspects of these interactions (Overman 1996:487).

The World Bank assumes that good governance implies a liberal free market-orientated democracy (World Bank 1994, Leftwich 1993 \& 1994; Williams \& Young 1994:87). Although the World Bank places a strong emphasis on the development of a free market economy, it sees the political elements of good governance as predictable, open, transparent policy-making processes, a professional bureaucracy, an accountable executive, a strong, participative civil society and a culture of acceptance of the rule of 
law. The World Bank regards these attributes as positive influences on sustainable socioeconomic development to reduce poverty globally (World Bank 1994: vii).

"Governance is the result of interactive socio-political forms of governing" (Rhodes 1997:51). Where the NPM's conception of governance blurs the distinction between public and private sectors, this conception of governance blurs the distinction between state and civil society (Rhodes 1997:57). Self-organising networks have been criticised as biased towards the status quo and the protection of vested interests, and of running the risk of creating autonomous organisational entities independent of government: "...governing without Government" (Rhodes 1997:59). Supporters defend them as instruments to develop society and empower its citizens, i.e. as instruments of good governance, because they also empower civil society rather than only big business. Savitch declares that "complex society is informally and increasingly run by public authorities, community-based organisations (CBO's), public-private partnerships, the privatization of public services and inter-local agreements" (1998:261).

Since its creation, the use of the term governance has therefore started to change over time. In an attempt to supplement the defects of the liberal, free market-based NPM approach, some scholars started to propagate the importance of enhancing the capacity not only of the public and private sectors, but also of the increasingly important voluntary sector, or civil society. This change in focus led to the conceptualisation of self-organising networks providing services by means of any permutation of government, the private and voluntary sectors (Rhodes 1997:53). This led to a more refined prescriptive focus on facilitating the complex interaction between these sectors rather than on what each of them should be responsible for (Toonen 1998; Rhodes 1997:46). These developments are logical outcomes of the new information society's focus on information-based services, which has already started to replace the industrial society's focus on production and consumption of goods, and which has already ushered in the age of globalisation (Peterson 1998:306; Savitch 1998; Smith 1998:54). 
The NPM and governance approaches have therefore also stimulated the development of the network approach to public affairs by highlighting the fact that traditional public policies and functions are increasingly designed and performed by networks of diverse, autonomous public, private and developmental institutions brought together around, and loosely bound together by, the same or related interests, instead of being controlled solely by the public sector (e.g. Mandell \& Steelman 2001). In this network view of the relationship between public and other institutions, the public sector does not necessarily control the networks that it participates in, but it has to rely on persuasion or bargaining in some cases in order to get its way. "The network character of society, which always has been an empirical reality, is now being honoured politically and electronically. The pyramidal design of the political system no longer is adequate to deal with this." (Frissen 1998:37). The vertical bureaucratic authority and control that the public sector exercises in traditional public administration, therefore, has given way to a process of horizontal consultation, persuasion, bargaining and co-ordination in order to achieve the desired results.

This network perspective on the role of the state in contemporary society is based on another paradigm shift: the perception of a fundamental loss of control by the public organisation sector over its monopoly on the provision of public services, because of its inability to provide those services in the required way, in favour of a loose network of institutions and interest groups working together to provide the required services. From this perspective the public sector is just another player competing with other players for influence in the game of public services delivery.

The development of the network approach to public management has also revived interest in the earlier post-modernist approach, now more clearly articulated in the form of the complexity perspective on organisations, mentioned above (e.g. Kiel 1994, Evans 1996; Overman 1996). Clarke explains the causal linkage between strategic information systems management and the complexity approach as follows: "... what is required in IS strategic planning is not the forecasting of some repetitive pattern or predictable event, 
but the 'forecasting of discontinuities'... The answer is not to attempt to forecast such discontinuities, since such forecasting is clearly impossible, but to react once they are identified. Similarly, an over-reliance on hard data may lead to an ignorance of the soft information on which so many decisions need to be taken." (Clarke 2001:39). This linkage will be further explored in the next chapter, where the role of information technology in management will be assessed.

It is clear from the brief summary above of the historical development of consecutive perspectives on public management that distinct causal linkages exist between the dominant NPM approach, the steadily growing network approach and the newly emerging complexity and quantum approaches to organisational structure and behaviour. The linkage between these approaches and the most recent theoretical development, the emerging integrated management approach based on the full utilisation of new technologies in management, will be assessed in Chapter 3.

\section{A MORE APPROPRIATE PUBLIC MANAGEMENT ASSESSMENT FRAMEWORK}

As mentioned in passing above, the implementation of the currently dominant NPM, network and governance perspectives on public management necessitates inter alia a more rigorous conceptual model of the public policy process and more extensive and sophisticated use of technologies in order to achieve the good governance outcomes envisaged in these contemporary perspectives.

The public policy process is conceptualised for the purposes of this study as the interaction of decisions and actions of various policy actors (individuals, interest groups or organisations in the public, voluntary and private sectors) either with the purpose of achieving stated public policy objectives or which unintentionally affect a public policy issue or sector. 
The public policy process can be divided into two broad analytically distinct phases. They are firstly a design phase, consisting of policy issue review and awareness, issue structuring and prioritisation, as well as policy agenda setting, option generation and assessment, and culminating in decision-making on a preferred policy. The second phase is the implementation phase, where the public policy design/blueprint/framework is transformed from unwritten ideas or concepts, or from a written document, into visible consequences in society. These phases cannot be separated from each other in a watertight way and design does not necessarily precede implementation. In most cases they are parallel processes, because even in the implementation phase, refinements or adaptations need to be made to policy plans as a result of design defects which have not or could not have been foreseen in the design phase.

Good governance is prescriptively conceptualised here as the achievement by a democratic government of the most appropriate developmental policy objectives to develop its society in a sustainable way by mobilising, applying and co-ordinating all available resources in the public, private and voluntary sectors, domestically and internationally, in the most effective, efficient and democratic way. This working definition contains both a normative and a utilitarian approach.

Developmental policies are public policies which succeed in raising the quality of life of a society's citizens. The objective with sustainable development in this sense is to achieve a self-sustaining improvement in medium- to long-term life quality. This inevitably implies a coherent systemic integration of development initiatives, resulting in a structural, functional and cultural consolidation of a new way of life - in fact the creation of a development culture in society.

Sustainability is based on the original idea of sustainable use of environmental socioeconomic resources immortalised by the Brundtland Commission in 1982, but the concept has an additional applied meaning here. Sustainability will be used in this document to refer to the institutional and functional durability of public policy programmes. Sustainable 
governance refers to the durability of service of a required quantity and at a required level of quality over an extended period. It therefore implies a thorough assessment of all resource implications of service delivery, the incorporation of the results of such assessments into the design of service delivery strategies and continuous access to the resources needed for sustainable service delivery.

Sustainability in this sense does therefore not only mean the availability of sufficient finances to provide the services needed, but refers more comprehensively to the overall capacity of the organisation to deliver such services and adapt to changing circumstances over an extended period of time, maintaining or preferably improving the service concerned. Sustainability therefore also includes the notions of flexibility and resilience in the face of setbacks. The term is also applicable in a political context. Political sustainability refers to dedicated political commitment: continuous support by political decision-makers for the programmes concerned, not only through consistent rhetoric, but also backing their words up with consistent actions (Brinkerhoff 1992; Brown 1998).

A balanced and integrated programme of development in all policy sectors is a prerequisite for the sustainability of policy implementation (Blunt 1990). Skewed development does not contribute to sustainability. It obstructs it. The negative consequences of high gini coefficients in states like South Africa, Brazil, India, etc. illustrate the point.

Sustainability should therefore not be interpreted as only of environmental and socioeconomic relevance, but should be conceptualised holistically to include also political, institutional and managerial dimensions.

In terms of the new public management focus on sustainable developmental outcomes, scholars are generally in agreement that more attention should be given to the integrated results of government activities. To ensure optimum results, it is therefore even more important to improve and integrate policy design, implementation and evaluation processes than to provide only better policy input and decision support. This is especially 
the case in more developed societies, where long periods of experimentation with different policy options have already resulted in optimal policy programme designs. Policy implementation, however, can still be improved in most cases. In addition, it has become clear that even governments in highly developed systems do not always know to what extent they have been successful with their policy programmes; this may be a result of insufficient or inappropriate attempts at measuring and evaluating the consequences of their policy processes and the policy products that result from those processes. This evidence-based or outcomes-based approach to governance necessitates a more rigorous approach to the study of management. It necessitates the compilation, comparison, analysis and assessment of more accurate data on all aspects of management in order to determine whether these management outcomes were positive, negative or neutral in terms of the objectives of promoting sustainable development in society. This is only possible with the assistance of the powerful data-capturing, analysis, presentation and assessment tools that are increasingly becoming available as a result of the global information revolution currently sweeping the world.

The conceptual approach to policy management summarised earlier and the results of an empirical survey about public performance measurement conducted by Bouckaert, Hoet \& Ulens (2000) will be used as points of departure for the design of a systematic conceptual classification of co-ordinated policy management activities that need to be assessed in an integrated way in order to improve governance outcomes. The focus will be on policy management and not on resource management per se, although the effects of good or bad resource management have to be taken into consideration in the assessment of policy outcomes and processes. This focus covers large parts of the overlapping policy evaluation, performance management and performance measurement sub-fields in the public sector.

As a result of the change in analytical focus from public administration functions to governance outcomes, there has been a substantial increase in the existing body of knowledge on performance management and measurement over the last few years. One of 
the most recent and authoritative summaries of these topics has concluded that there is a surprising similarity in the objectives of the new surge towards determining good governance outcomes. After a detailed comparative survey of performance measurement in the public sectors of eight highly developed countries across the world, Bouckaert, Hoet \& Ulens (2000:3) concluded that these governments normally assess their performance in order to:

1 increase savings on their expenditure budgets;

- improve their functioning (efficiency, effectiveness and quality of services); and

- improve their accountability towards their legislatures or other constituencies (see also Pollitt \& Bouckaert 2000:159).

It is interesting to note that normative aspects of public management do not feature explicitly in their conclusions. The above motivations are all of a highly utilitarian nature. They also found that different aspects of management performance are measured, including inputs, activities, outputs, users, results and impacts (Bouckaert, Hoet \& Ulens 2000:107), and that different types of services are measured, including:

1 tangible services (roads, houses);

- non-tangible personalised services (education, health); and

b non-tangible ideal services (advice, co-ordination) (2000:144).

Public management inherently consists of a government's response to the way it perceives its role in society. From a service delivery systems perspective, one can identify public management activities as a conversion of resources into public policy outcomes to address perceived public policy problems (e.g. the delivery of selected services) in a preferred way. Linked to this is an important developmental problem-solving approach that has clear normative implications. These approaches imply that a government pursues selected combinations of normative and utilitarian goals in order to transform society into what it believes to be a better place (see Cloete \& Wissink 2000, Chapter 1). One can distinguish 
various public policy products as the end results of various public policy processes in society.

The overall goal with the assessment of public management performance must then be to determine whether both the end products and the processes through which they came about comply with the required or preferred standards set for them. The performance assessment framework below may be useful to systematise the different dimensions that need to be assessed.

\section{Policy products}

The outputs and outcomes of public management processes are the most important objects for evaluation. The assessment task here is obviously to determine the progress towards goal achievement, i.e. what are the policy programme and project objectives, what are the real outputs and how big is the gap between them? This focus also satisfies the effectiveness criterion stressed and summarised well by Bouckaert, Hoet \& Ulens (2000:107). This type of assessment could also measure the various impacts of the policy programme on the different policy environments within which it plays out in the short, medium and long term. In this way the relationship between policy intention and achievement, or policy objectives and outcomes, can be determined. Examples of such impact indicators are summarised in Cloete \& Wissink 2000, Chapter 11. Increasingly indicators for sustainable development across policy sectors are being devised (e.g. Hart 1999; Bell \& Moore 2000; OECD 2000a \& 2000b).

Both normative and utilitarian aspects of policy products can further be assessed, depending on the needs within a given context. They include the following examples that do not constitute closed lists, but only summaries of the more obvious management performance dimensions that need to be assessed. They should be expanded and customised for different management assessment contexts. 


\section{Normative dimensions}

回 To what extent is the result in the public interest? This necessitates an operational conceptualisation of the public interest.

回 How equitable is the resource allocation? This in turn necessitates an operational definition of equity.

回 To what degree did the programme succeed in citizen empowerment (social, economic, political, technological)?

回 To what extent did the programme promote democratic or other values?

\section{Utilitarian dimensions}

回 To what extent did the government fulfil its protection, regulation (stability/customer satisfaction), social development and welfare (quality of life/ level of development) and economic growth imperatives through the programme concerned?

回 To what extent did the programme satisfy the programme objectives, needs and preferences in its society? How feasible therefore were the policy objectives and outcomes, and of what quality were they (see Bouckaert \& Vandeweyer 1999)?

回 How affordable are the services in the short, medium and longer terms?

回 What, and how sustainable, are the impacts of the policy products concerned generally in the longer term in the various sectors (social, economic, political, managerial, technological, environmental) and overall (both objectively and subjectively determined)?

\section{Policy Processes}

Although policy products as the main objectives of governmental activities are the primary foci of policy management assessment, management process assessment is just as crucial. This entails an evaluation of the way in which resources or systemic inputs have 
been converted into policy outputs and outcomes. Contrary to many popular beliefs, there are also crucial normative elements inherent in management process assessment. The different assessment dimensions that are relevant here are discussed below.

\section{Normative dimensions}

回 The main question in this regard is probably how legitimate/democratic were the processes through which the policy products came into being and how representative of the main stakeholders in the issues concerned were they?

回 To what extent did the policy management processes acknowledge/promote the rights and duties of citizens?

回 How transparent, tolerant and participatory were these processes?

回 How responsive and accountable were these processes towards the main political and financial constituencies who gave the mandates concerned?

回 How equitable and fair were the processes concerned?

回 How professional \& ethical were they?

\section{Utilitarian dimensions}

回 Probably the most important assessment dimension here is the degree of efficiency and productivity of the policy process in the conversion of resources into outputs. The main objective here would therefore be to determine whether there was an optimal use of all resources (including people, finances, supplies, time, etc.), with the objective of decreasing the costs for the organisation concerned of producing the required service/product (Bouckaert \& Auwers 1999:13 prefer to talk of an increase in savings) and simultaneously increasing the quality of such service/product (Bouckaert \& Vandeweyer 1999).

回 Various aspects of effectiveness are also relevant here, as Bouckaert, Hoet \& Ulens have indicated (2000:107). 
回 The flexibility of the policy processes to allow for mid-stream changes in direction as a result of unforeseen circumstances is also a relevant factor to be considered.

回 The extent of entrepreneurialism/innovation/creativity in the design and delivery of policy processes and products can be assessed.

回 The quality and sustainability of the overall policy system that has been created, and the extent of strategic and operational integration and co-ordination for purposes of continuous improvement is another crucial element for process assessment.

The above policy management assessment framework contains elements that overlap in some cases, making it more difficult to measure and assess isolated effects accurately. This is, however, the nature of social research and the difficulty can be minimised only through careful and systematic controlling of variables, where feasible.

Various conceptual and analytical management performance assessment models have been developed over time that combine elements of the above framework for the purpose of assessing different management dimensions. One of the most popular contemporary models is the Balanced Scorecard (BSC) model, designed by two American academics to improve business excellence and popularised by the Harvard Business School (see Bouckaert \& Auwers 1999:39). The model consists of a combination of the following four dimensions of management: profit, client satisfaction, internal organisational processes, and continuous learning for the sake of improvement of results. The model proposes a measuring instrument to assess to what extent organisations have succeeded in achieving better results in those areas. Because the BSC model has been developed specifically for the business sector, its application in the public sector is not always satisfactory (Bruggeman \& Vereecken 1999).

Another recent approach that has been developed is the Public Service Excellence Model (PSEM), which is the most comprehensive attempt so far to design an evaluation approach explicitly for the contemporary public sector in more developed societies 
(Publicfutures 1998). It is an adaptation of the original business-focused EFQM model developed by 14 European countries who are members of the European Foundation for Quality Management and has the explicit objective of improving public policy programme outcomes through the improvement of the strategic management processes in public sector agencies (Publicfutures 1998; Bouckaert \& Auwers 1999:33). It places an ambitious, comprehensive focus on the whole service delivery system and attempts to improve literally all the elements of that system, analogous to the management assessment framework summarised above. The PSEM identifies and attempts to measure performance in 14 categories, using 83 different criteria. The performance categories are:

- Six Performance Enablers: Policy and governance, strategy and plans, leadership, resources, processes and people;

- Six Organisational results: Resource results, efficiency results, people results, service reporting, service outputs and service satisfaction; and

- Two Programme results: Programme outcomes and programme satisfaction (Publicfutures 1998).

As in the BSC approach, the emphasis of the PSEM is also primarily on the utilitarian dimensions of policy management, under-emphasising the normative dimensions involved. The elements of the BSC model have also largely been incorporated into the new PSEM.

A third distinct public management assessment model that has gained support recently is the Belgian MAPE model, devised by Bouckaert and his colleagues (see Bouckaert \& Auwers 1999:22). Like the PSEM, the MAPE model is also basically an input-output model. It also focuses on the total public policy management system and emphasises its four distinct functional dimensions: inputs, throughputs, outputs and outcomes (see also Pollitt \& Bouckaert 2000:13). It is, however, analytically more streamlined and flexible than the PSEM model, because it does not restrict itself to the specified performance categories in the PSEM. The foci identified in the PSEM will probably also be the main foci in the application of the MAPE model, although it can be customised better to take different 
organisational contexts in account. The MAPE model also focuses on the total management assessment framework summarised above (see Van Sprundel 2000 for an application of the approach in Belgium), and it similarly under-emphasises the normative elements of the framework.

As the recent developments regarding the PSEM and MAPE approaches have indicated, a trend towards more comprehensive, macro-level, strategic assessment of both public sector management processes and products can be discerned (see also McGee \& Prusak 1993:182). This trend also includes a focus on the integration of policy management processes with evaluation processes in order to create an integrated and continuous assessment system instead of the traditional add-on and periodic evaluation that is frequently not taken seriously (e.g. Marr, Erlhoeffer \& Neely 2000). There is a clear trend towards an integration in the business sector of Activity-Based Costing \& Management $(A B C M)$ and Enterprise Resource Planning and Management (ERPM) approaches with general financial management systems (e.g. Gurowka 2001; Pollitt 1999). A significant number of Fortune 500 companies have already moved or are moving in this direction. This is clearly an emerging best practice and, if the public sector wants to be a competitive service provider, it has to follow suit. The objectives and scope of management assessment will, however, differ from agency to agency and each exercise has to be custom-designed in order to achieve the desired results, depending on what one wants to assess.

A thorough integrated assessment of the different dimensions of the policy process as summarised above is only feasible with the assistance of the latest technology. The next question is therefore inevitably what the contribution of electronic policy management assessment tools can be to facilitate and perhaps even improve the quality of answers sought for the above types of questions. 


\section{CHAPTER 3}

\section{THE INFORMATION TECHNOLOGY REVOLUTION IN PUBLIC MANAGEMENT}

"Information technology has irreversibly changed the business world. The ways organizations perform their operations and market their products have all changed dramatically since the serious introduction of information technology in the mid-1950s" (McGee \& Prusak 1993:3. See also Owes, Welson \& Abell 1996).

The brief summary in Chapter 2 of the main developments in the study of the role of the public sector in society highlighted the changing perspectives that have developed over the past century about the nature and focus of public management. These changing perspectives have been stimulated by crucial changes in the environment within which public sector organisations operated. Recent global trends that have a far-reaching cumulative impact on current public management practices and outcomes include the following: 


\begin{tabular}{|c|c|c|}
\hline SECTOR & TREND & CONSEQUENCE \\
\hline Demographic numbers & Increasing & Error impact larger \\
\hline Cultural diversity & Increasing & Higher uncertainty \& risk \\
\hline Social mobility & Increasing & Higher uncertainty \& risk \\
\hline $\begin{array}{l}\text { Globalisation \& International } \\
\text { communications }\end{array}$ & Increasing & $\begin{array}{l}\text { Need for quick decisions } \\
\text { Error impact larger }\end{array}$ \\
\hline Systemic complexity & Increasing & Higher uncertainty \& risk \\
\hline Environmental integrity & Decreasing & Error impact larger \\
\hline Resource availability & Decreasing & Error impact larger \\
\hline Political stability & Decreasing & Higher uncertainty \& risk \\
\hline $\begin{array}{l}\text { Management effectiveness \& } \\
\text { efficiency }\end{array}$ & Increasing & $\begin{array}{l}\text { Need for better analysis \& assessment } \\
\text { tools }\end{array}$ \\
\hline State capacity & Decreasing & Decision support tools needed \\
\hline Educational levels & Increasing & Higher quality decisions needed \\
\hline Citizen expectations: & Increasing & $\begin{array}{l}\text { Faster, transparent, higher-quality } \\
\text { decisions needed }\end{array}$ \\
\hline Rational democratic values & Increasing & $\begin{array}{l}\text { Rational, transparent, higher-quality } \\
\text { decisions needed }\end{array}$ \\
\hline State capacity & Decreasing & Appropriate decision-support tools needed \\
\hline Information needs & Increasing & $\begin{array}{l}\text { Range of options larger } \\
\text { Need for better \& faster analysis \& } \\
\text { assessment }\end{array}$ \\
\hline $\begin{array}{l}\text { Economic consumerism \& } \\
\text { competition }\end{array}$ & Increasing & Range of strategic options larger \\
\hline Technological development & Increasing & $\begin{array}{l}\text { Powerful, user-friendly management- } \\
\text { support tools available }\end{array}$ \\
\hline IT costs & Decreasing & Affordable decision-support tools available \\
\hline
\end{tabular}

(Adapted from Turban \& Aronson 2001:7) 
The above trends have lead to a situation where an increasing relevance of information technology for Public Management has become an established fact, accompanied by unprecedented progress with the development of increasingly cheaper but increasingly powerful and versatile computer hardware and software systems (Estabrooks 1995; Milner 2000; Kettl 2001).

As summarised earlier, various consecutive approaches to the study of public management have identified or emphasised the need for more effective ways of dealing with information in public management. The NPM's outputs/outcomes focus has stimulated a need for "evidence-based" policy-making. This implies the availability of effective methodologies to identify, monitor, record, compare, measure and assess outputs and outcomes. The compilation, analysis and assessment of information for these purposes can only be done effectively with the use of the latest IT support tools, as a result of the huge volumes of data that have to be processed and the complexity of these analyses. It is therefore not possible to implement these approaches to governance effectively without the optimal use of IT.

Whatever the different conclusions that one can draw about the role of the state in services delivery from these diverse perspectives, one common element in the quantitative, issue-based, NPM, governance and network approaches to public management remains the increasing salience of information technology for purposes of planning, decision-making, communication, implementation, co-ordination, assessment, control and other desired elements of good governance outputs and outcomes.

\section{NATURE OF THE IT REVOLUTION IN PUBLIC MANAGEMENT}

"Information technology" (IT) is an umbrella term referring to electronic, computerised aids that facilitate the compilation and systematisation of un-systematic data into information (see also Heeks 1999:15). These tools normally refer to computer technologies such as individual personal computer hardware and software programmes 
and networks. IT is frequently linked to communication technologies such as telephones, fax machines, dial-up modems, different media technologies and the intangible but increasingly powerful internet and e-mail technologies, and then referred to as ICTs (information and communication technologies). ICT is also increasingly linked to the newly emerging field of Knowledge Management, and is then referred to as IKCTs. This acronym is a comprehensive umbrella term that refers to information, knowledge and communication technologies. These IKCTs include all of the above technologies as well as web browsers and search engines to synchronise and optimise the transformation of systematic information into interpreted and later internalised knowledge about different issues.

IT is just another management tool that promotes office mechanisation or automation such as the now traditional file, ledger, spreadsheet, ball-point pen, telephone, fax machine and typewriter. Like the above tools, it can be used to improve management processes and outcomes, or it can be abused to achieve personal gain or other extraorganisational objectives. It is, however, a much more sophisticated tool that has already changed the nature of management fundamentally, in contrast to the other tools mentioned above, especially those IT tools used for strategic management support purposes.

A range of general and more specialised electronic management support tools (also frequently referred to as management support systems (MSS's) have developed over the last few years. They hold much promise for the improvement of government performance, if they are applied correctly. MSS is a collective umbrella term referring to a set of distinct tools or sub-systems designed and used to support different managerial activities (Finlay 1994:40).

An MSS normally includes one or more of the following sub-systems (see also Klein \& Methlie 1998:6): 
回 A transactions processing system (TPS): This is an electronic management support system or a range of such tools designed to implement, keep track of and record transaction processing (e.g. resource facilities and office automation tools such as word processing, databases, spreadsheets, presentation aids, e-mail, internet, etc.). It is descriptive in nature and comprises the electronic equivalent of the traditional research, planning and bookkeeping systems in an organisation used to run the organisation (Fidler \& Rogerson 1996:49; Turban \& Aronson 2001: 23).

回 A management information system (MIS) is an analytical operational management tool based on the TPS, designed to summarise the results of the organisation's transactions in order to monitor results, control activities, assess and plan ahead (Watson, Houdeshel \& Rainer 1997:10; Turban \& Aronson 2001:23).

回 An executive information system (EIS) is an even more specialised strategic analytical MIS designed to summarise selected macro-level trends and processes in the organisation for the benefit of top managers in order to enable them to monitor and manage more effectively the strategic direction in which the organisation is moving (Marakas 1999:185; Duffy 1998:30).

回 A decision-support system (DSS) can be conceptualised as a specialised analytical planning-support system intended to improve the quality and outcomes of managerial decisions by facilitating more systematic and accurate identification, analyses, assessments and linkages of different policy problems, resources, objectives, solutions, costs, benefits, risks, probabilities, priorities, processes, outputs and outcomes (see also Dutta, Wierenga \& Dalebout 1997:72; Finlay 1994:37; Lootsma 2000a). Sometimes one finds that the term DSS is used in a much wider sense to refer to MSS functions (Turban \& Aronson 2001:13/14). In this study, though, the above narrower conception of a DSS will be adopted, while MSS will be used as the more comprehensive term. Lauden \& Lauden (1998:597) capture the distinction between a DSS and an MIS as follows: "... a DSS is not only an application , but a generalised capability for addressing decision makers' needs. Unlike an MIS, a DSS 
does not simply involve a routine, steady flow of data, but instead can be flexibly responsive to new situations by using data and analytic models (even spreadsheets) to work through the consequences of decisions and assumptions".

回 An expert system (ES): This is a very specialised DSS that is normally applied to wellstructured routine decision issues where all crucial variables are known and where discretion is minimal or well circumscribed (e.g. who qualifies for specific pensions) (Marakas 1999:225; Svensson 2001). These systems are used to automate or computerise decisions, eliminating the human element in such decisions (Finlay 1994:231; Turban \& Aronson 2001:17; Snellen, Van de Donk \& Baquiast 1989).

回 An artificial neural network (ANN): This is a sophisticated DSS operating on the basis of fuzzy logic and having the ability to learn from previous experiences, using a pattern-recognition approach to problem solving (Turban \& Aronson 2001:18).

回 A knowledge management system (KMS): This type of IT system deals with data as part of a more comprehensive knowledge system (Davis \& Naumann 1999:343; Turban \& Aronson 2001:18).

回 An enterprise resource planning system (ERPS): This type of system integrates the operational processes in an organisation in order to enable production staff as well as managers to achieve more effective and efficient outputs. These systems then form an integral part of a more comprehensive MIS or EIS (Turban \& Aronson 2001:19).

回 A supply-chain management system (SCMS): This a more specialised ERPS, focusing only on the supply-chain processes involved in manufacturing (Ayers 2001; Turban \& Aronson 2001:19).

The need for electronic management support is increasing rapidly. Recent international research findings on good governance indicate inter alia the following trends (e.g. Lauden \& Lauden 1998; Snellen \& Van de Donk 1998): 
回 a general acceptance that a strategic management approach focused on committed actions to achieve realistic implementation objectives is needed to improve service delivery outcomes;

回 an acceptance that this in turn necessitates inter alia effective information use and management;

回 a dramatic world-wide increase in the availability of digitised policy-related data and high-power-capacity computer systems to manipulate that data;

回 a resultant dramatic increase in the reliance on electronic management information systems in well-developed and relatively successful policy systems to monitor, coordinate, implement and assess the effectiveness of policy implementation programmes; and

回 an increasing reliance on more user-friendly and less technically complicated and more visual and command-driven electronic decision-support systems to optimise multi-criteria policy decision-making in order to promote effective policy implementation and service delivery (see also, for example, OECD 1998).

In line with the above trends, various specialised niche software packages have been developed over the last few years to support back-office public management processes (see Annexure 6.2). The knowledge explosion in this regard and the recent expansion in electronic hardware and software applications that facilitate e-government have, however, taken place so rapidly that these tools are either still relatively unknown or have not yet been integrated into mainstream public management processes in many developed countries.

In many developing countries the current state of affairs with regard to the above strategic trends in more developed countries is not good (Berman \& Tettey 2001; Peterson 1998). An authoritative management scholar has remarked: "Decision-making at these high levels of government ... is often portrayed as rational decision processes. But, in fact, 
decision-making involves managing issues that are forced on decision-makers with varying and shifting priorities. Issues circulate continuously; they enter and exit through participants and are resolved in the sense that they dissolve or go away or are overtaken by other issues. The issues are themselves complex, poorly defined, interdependent... Information is voluminous but unreliable and qualitative" (Lauden \& Lauden 1998:596).

The trends regarding public management outputs and outcomes in developing societies are:

回 frequent incidences of policy failure, attributed primarily to ineffective or bad policy implementation;

回 weak policy implementation capacity and service delivery results (Tiger cubs, developing countries in general and SA in particular);

回 low levels of policy decision-making-related knowledge, experience and skills, especially electronics and management information systems, and low appreciation of the utility and potential of such aids; and

回 information gaps and uncertainties cause a general policy paralysis, which should be transformed into policy activism in order to improve policy implementation and service delivery results.

In order to improve the positive impact of public policy outputs in developing states, the success of public policy-related decisions and follow-up actions in government need to be significantly increased. Success is for purposes of this paper conceptualised as visible, concrete progress in policy decision-making and implementation towards achieving sustainable good governance along the lines summarised above (see, however, also Alavi \& Joachimsthaler 1992; Sanders \& Courtney 1985). Against the background of the global electronic revolution, the experiences of different nations where electronic decision and implementation support tools have been used or are in use to achieve a better success 
rate with public policy design and implementation are important in this regard (Heeks \& Bhatnagar 1999:56).

This study follows an explicit rational policy decision-making approach to public management that combines elements of a policy sciences approach with an NPM/ governance approach as well as an integrated management approach in order to accommodate the above changing environmental conditions within which public management currently operates. The approach that is followed in this study therefore regards public management as a series of both simultaneous and sequential decisions by governing elites whether to intervene in society or not. If a decision is taken to intervene, then the decision entails deciding what to do (policy or strategy options are devised, compared and considered against various implicit or explicit criteria), how to do it, when and by whom, followed up by later decisions whether to accept the results, or again intervene in specific ways to change the results in order to achieve good governance outcomes.

Complex policy design and implementation decisions with multiple policy objectives that may be contradictory need to be prioritised in terms of different and potentially also contradictory decision criteria. The adoption and use of more user-friendly but effective electronic management support systems for this purpose have the potential to maximise more successful results if they are applied appropriately and effectively (see Foroughi, Jelassi \& Perkins 1991). However, these tools will not necessarily guarantee success, because they do not take a decision out of the hands of the decision-maker. They only allow such a person to take better informed decisions, hopefully more aware of the main implications of those decisions.

\section{USES OF ELECTRONIC MANAGEMENT SUPPORT TOOLS}

General electronic management support tools can be used in different ways. Such toolkits can be especially useful at different stages of the policy process to consider more 
systematically what to do, how to do it and what variables should be considered. These include:

回 Situation analysis, problem identification and structuring (e.g. by using the tools Decision Explorer, STRADSPAN, Thinktools. See also Regan \& Holtzman 1995; Rosenhead 1996).

回 Options analysis and assessment (e.g. V.I.S.A, Thinktools, Definite, SOS, electronic spreadsheets - see Kirkwood 1997; Lotfi \& Pegels 1996; Ragsdale 1995; Winston \& Albright 1997; THRIPP 2000; Lootsma 1997, 1999a, 1999b).

回 Option selection/choice (Thinktools, V.I.S.A, SOS - see Goodwin \& Wright 1991).

回 Implementation strategies and tactics (e.g. electronic spreadsheets and various project management software packages as well as on-line electronic service delivery systems like the internet).

回 Evaluation and impact assessment (Workbench, Definite, Impact Explorer, Thinktools).

回 Process and product analysis, assessment and support: Specialised negotiations support software has, for example, become available over the last few years (The-artof-negotiating, Negotiator Pro and WinSquared), as well as output and outcome assessment software in the form of various business intelligence toolkits (e.g. PBViews, CORVU, QPR, etc.).

回 Single work-station, network and on-line web-based support systems: These tools include decision-support as well as assessment aids. Such negotiation support systems include, for example, Ventana Group Decision Support Systems Smart Settle, Inspire and WebNS. They can support both back-room negotiation planning and the front-room conducting of the negotiations proceedings in an interactive way. 
These tools are useful in the following ways:

回 Guiding individual decision-makers step by step through transparent, standardised processes to reach decisions without their relinquishing control over those processes;

回 Guiding small groups of decision-makers step by step through transparent, standardised processes to reach collective decisions, again without losing control over those processes. In this case the groups are taken through strategic policy or implementation strategy-planning processes that culminate in collective decisions (Impact Explorer see Lauden \& Lauden 1998:600; Finlay 1994:139; De Vreede, Jones \& Mgaya 1998 Dennis, Valacich, Connolly \& Wynne 1996; Easton, George, Nunamaker, \& Pendergast 1990; Mabin, Menzies, King \& Joyce 1997; Salo 1995; Schuuring \& Feenstra 1998);

回 Prompting decision-makers to consider important variables like alternative objectives, solutions (see Parkinson 1995), costs, benefits, risks and priorities before making choices, and providing technical assistance on how to do this (DecisionPro, Definite, VISA, Decideright, SOS - see Zeleny 1982:488);

回 Providing specialised technical electronic research tools for modelling or determining objectives, scenarios, costs, benefits, risks, probabilities, priorities, etc. (e.g. DecisionPro, IDecide, Thinktools, SOS, SIMUL8, V.I.S.A (see Belton 1999), various applications of GIS software, illustrated in Batty \& Xie 1994; Da Villa \& Panizzolo 1996; Hawkins 1994; Hirschfield, Brown \& Bundred 1995; Karnavou \& Mikelis 1994; Martin 1991; McIntyre 1994; Taylor 1991; Walker \& Young 1997; Yeh \& Li 1997);

回 Providing decision-makers with pull-down menus or hot links leading to background information or templates of standardised formats for useful information such as:

1) definitions

1 policy requirements

1 provisos 
- documentation such as contracts, forms, legislation, etc.

(e.g. Workbench, Definite);

回 Drafting automatic reports, tables (including budgets), graphs or graphics containing the above information in a user-friendly written or even visual presentation format that can be integrated into other administrative and secretarial office automation toolkits (e.g. Decideright).

\section{CRITERIA FOR SELECTING ELECTRONIC MANAGEMENT TOOLS}

In order to be of optimal use, electronic policy management tools should in principle comply with a set of criteria that could include the following objectives. These objectives may, however, be contradictory in some cases.

回 Simplicity: because of the frequently low levels of electronic literacy among public officials, especially in developing countries, the simpler the user interface is, the better (see also Finlay 1994:37; Sprague \& Watson 1986:8; Duffy 1998:32). This means that the use of simple concepts and clear command prompts guiding users step by step through the programme will enhance a programme's utility instead of the use of statistical tables and a reliance on more advanced electronic literacy levels of users (e.g. the built-in capability to print customised reports, visual presentations and background information such as definitions, technical specifications, legislative requirements, etc.).

回 Cost: inexpensive MSS tools will for obvious reasons be more popular.

回 Hardware requirements: computer memory and general capacity are perpetual constraints on decision-support systems. The less capacity needed, the more application potential the MSS tool will have, especially in developing countries.

回 Access \& maintenance: access to MSS tools, training opportunities and the maintenance and upgrading of those tools are essential in order to apply the tools 
concerned optimally. Off-the-shelf software is therefore potentially more useful than specially designed software that needs specialist maintenance and upkeep.

回 Visual images: MSS tools with strong visual and graphic capabilities will have a better impact for presentation purposes in developing countries, where the levels of literacy are traditionally low (Finlay 1994:37, 250; Van Os 1994; Nordbotten \& Crosby 1999).

回 Specificity: MSS tools that can be applied to achieve specific objectives are preferred to tools that can only indirectly resolve specific questions of concern (e.g. tools that are customised for application in the public sector will obviously be more useful than more generic tools focused on management in general).

回 Versatility/flexibility: MSS tools that are able to address more than one problem, can be applied in different settings for different purposes, and that do not need specialised training are preferable to tools that don't conform to these require-ments (Sprague \& Watson 1986:8). The more multi-functional these tools are, the more useful they will be (e.g. the capability to access specialised technically complex resources online in other databases or on the internet).

回 Compatibility: the level of compatibility and integration of MSS tools with other programmes is essential to optimise application potential. Compatibility with existing mainstream business applications is therefore essential (Duffy 1998:32).

回 Transparency: the desire of decision-makers to retain control over the decisionmaking process necessitates tools that are relatively transparent and simple in order to achieve legitimacy in the perception of the decision-maker.

回 Scientific rigour: the more rigorous the scientific base of the tool, the more reliable it would be, i.e. tools that provide both qualitative and quantitative analytical and assessment capabilities in addition to more straightforward recording, describing, monitoring, tracking, systematising, reporting and presentation abilities will be more useful than tools which have fewer features of this nature. 
The ideal would be to develop a single, integrated toolkit that can be used for different purposes in different stages of the policy process. No single MSS of this nature currently exists, probably inter alia as a result of the technological requirements (e.g. speed, power, memory) and the conceptual complexities involved in the development of such a programme, the financial implications and most probably also as a result of a still inadequate mainstream appreciation of the need for and the utility of such a tool.

There are, however, various existing electronic management assessment tools that contain one or more of the assessment dimensions mentioned above and also comply to a greater or lesser extent with the major criteria for such tools summarised here. References to a few of the most interesting tools of this nature and the way in which they can be used for purposes of policy management as well as for education and training are contained in Annexure 6.4.

\section{BENEFITS AND CONSTRAINTS OF THE IT REVOLUTION IN PUBLIC MANAGEMENT}

\section{The benefits}

Heeks (1999:18) identified the main positive impacts of IT on an organisation's outputs as:

\footnotetext{
- cheaper results;

- more results;

, quicker results;

- better results; or

r new results.
}

An authoritative empirical assessment of the consequences of IT in public management concluded inter alia that "...IT provides a faster and more precise knowledge of operating conditions and results. Secondly it reduces the scope for indeterminacy in the behaviour of 
employees. Thirdly it unifies previously segmented control systems and thereby increases the potential for a comprehensive and balanced assessment of performance" (Bekkers \& Frissen 1992:487).

Other experts have commented that technology can "... make it more feasible to collect and store detailed data about business events that can be summarised and presented in operational rather than financial detail to managers that are far removed from the events. Whether this is relevant or irrelevant for an organization does not depend on technology capability but on decisions about how measurements will be used in management processes" (McGee \& Prusak 1993:199). They suggest that the application of IT in an organisation can be optimised if the following guidelines are followed:

Different studies (e.g. Finlay 1994:173, Turban \& Aronson 2001:9-10, 15-16; Bellamy \& Taylor 1998:47, 54,59) have confirmed that the appropriate use of IT in management has in the past led to:

1 faster decisions;

, increased productivity;

1 simplifying complexity;

b increased quality outputs;

- competitive advantages;

1 cost reductions;

bvercoming cognitive limits.

At its first meeting in July 2002 the UN Committee of Experts on Public Administration adopted a report by its Secretariat on the capacity of the public sector to support the creation and application of knowledge, innovation and technology for development. In that report the role of technology in administrative reform is summarised in the following way: "E-government has tremendous transformative potential if used in support of good governance objectives, and can significantly change the way in which government 
approaches its mandate, solves developmental problems and interacts with other government agents, citizens and business. It can give rise to a new paradigm of governance: one that places citizens at its centre, responds to their needs and expectations, and is based on the tenets of transparency, accountability and participation" (UN-CEPA 2002a:3).

The President of the World Bank referred recently to the following results of e-government in India: "getting a licence to drive in a matter of hours, instead of six months [and] transferring property in a day instead of a year with lots of bribes" (Wolfensohn 2001:2).

In a summary of empirical research undertaken by various researchers into the impact of EISs in management, Duffy (1998:31) identified the consistent benefits experienced by a range of users, consultants and developers of EISsas:

- better responsiveness to organisational changes

better satisfaction of changing user needs;

- better problem identification and resolution;

better management co-ordination; and

better strategy formulation.

Bellamy \& Taylor also state that "(T)he new information flows made possible by the new technologies offer significant benefits. First, they offer massive economies of scope, leading to substantially reduced costs of service provision. Second, they offer the possibility of more holistic services, leading to much enhanced service quality for individual consumers. However, they also threaten to dislocate well- established information-handling processes within the existing organizational domains of government, and pose severe challenges to the actors who control and depend on those domains. Hence it is not surprising that information-based innovations - for example those associated with process re-engineering - frequently excite defensive strategies designed to 
frustrate the emergence of new information-mediated relationships" (1998:153. See also Bellamy 2000).

\section{The constraints}

Significant constraints on the optimal use of IT in public management have so far delayed the full realisation of the above potential benefits that IT may have in public management. These constraints can be summarised in the following analytical categories:

\section{回 Technological constraints}

The potential of IT to improve management outcomes had been identified as early as the mid-1950s, when the first computers were developed for managerial purposes. Those technologies were, however, primitive, expensive and extremely complicated and therefore user-unfriendly for lay managers. IT was regarded as a specialist tool to be operated by experts. This quickly dampened the initial expectations of how technology could improve management in practice. Each new development or invention (e.g. the mainframe, the network, personal computers, mobile computers, optical fibre, officemanagement software, personal digital assistants, etc.) again revived the initial expectations, but the pace of technological development did not match the pace of rising expectations. The result was consecutive waves of disappointment in the failure of technology to bring about the high levels of improvements expected, despite the relatively rapid rate of technological development that was achieved.

The uneven development of computer hardware and software products and a lack of uniform standards aggravated the disappointments, because promises created by some technological breakthroughs were dashed by bottlenecks in other crucially related areas (e.g. fast processors but slow bandwidth and powerful new software but old legacy hardware that could not run those programmes).

Technological constraints are still crucial today (Heeks \& Davies 1999:33; PCIP 2002:6), especially in the form of an absence of sufficiently powerful hardware infrastructure in 
some organisations and even in regions like Africa (e.g. Norris 2000). As will be evident later, however, the current state of technological development, both in hardware and software terms, does not present the most important constraint on general use any longer. This outcome is now more the result of other constraints.

\section{回 Financial and political constraints}

Although the cost of technological upgrading has been markedly reduced over time, financial constraints are still crucial obstructions to the full adoption of technology in many public sector organisations, especially in developing countries, where opportunity costs in favour of massive spending on social services frequently swing government decisions away from technological projects. Again, however, experience has shown that a lack of funds is not the major obstacle to technological modernisation. In the end very subjective political prioritisation determines the direction of government spending (UN-DPEPA 2001:2; PCIP 2002:12). It is difficult for governments, especially in developing societies, to justify spending on computers in the face of very visible abject poverty in the streets (Wolfensohn 2001:1).

Another political constraint is the understandable political concern about privacy and security in new technological applications (Heeks \& Davies 1999:43). The current state of security of financial transactions in electronic banking, however, is an indication of rapid progress in this field.

\section{回 Psychological constraints}

Ironically, both a personal psychological fear of or aversion to technology and the enthusiastic adoption of technology as a panacea for all ills are serious obstacles to successful implementation of new technologies in government.

The psychological resistance against learning a new technology (which can also be translated as leaving one's personal comfort zone) is a very powerful driving force behind opposition to such administrative modernisation (Clarke 2001:144). It implies more effort, 
a possible loss of control, an entry into uncharted waters and the possibility of personal failure for many well-established managers who do not want to take such personal and professional "risks" (Watson, Houdeshel \& Rainer 1997:237; Clarke 2001:142; Heeks \& Davies 1999:32; PCIP 2002:18). The result is at worst open and even hostile opposition to such ideas, at best lukewarm support mainly at the rhetorical level, or different combinations of these reactions. Ignorance of, or inexperience in, the potential contributions of technology to administrative modernisation (Heeks \& Davies 1999:26) is frequently linked to a mental resistance against the introduction of new technologies. These factors are probably the main obstructions to successful implementation of such projects. Such psychological resistance frequently manifests itself in different types of arguments as to why technological modernisation is unnecessary or even detrimental to the operations of the organisation (Watson, Houdeshel \& Rainer 1997:237).

The opposite situation may, however, also obstruct success. Technological enthusiasts may proceed too rapidly with IT innovation projects, without due consideration of the implications of - and with insufficient or bad planning for - the implementation of such projects (Heeks \& Davies 1999:29; Heeks \& Bhatnagar 1999:56).

\section{回 Organisational constraints}

Personal unwillingness to adopt new procedures have a significant organisational impact if such obstructive attitudes exist at strategic locations within an organisation. Bureaucratic inertia and organisational cultures protecting existing power bases and other vested interests are powerful forces of opposition to modernisation and change in any organisation (Verbeken \& Pallemans 2000; Pratchett 1999). "The major change necessary is a cultural or social change in working procedures and habits, and failure to recognise this has caused the failure of many such projects" (Clarke 2001:143).

Bad policy design and implementation are also significant explanatory factors for the failure of new IT projects in government (Heeks \& Bhatnagar 1999:56). 


\section{回 Social constraints}

The characteristics of developing societies are normally major factors inhibiting successful IT projects in such societies. These characteristics include very low levels of literacy, accompanied by an absence of sufficient levels of technological infrastructure, leading to serious blockages on access to new technologies (PCIP 2002:6; Norris 2000; Cloete \& Wissink 2000: Chapter 3).

A combination of the above potential constraints on the successful introduction of new technologies in government indicates the formidable opposition that technological modernisation faces, if one or more of the above considerations are present. Successful implementation of such projects requires an expert in participatory change management (Clarke 2001:143; Watson, Houdeshel \& Rainer 1997:242) as well as the commitment and full support of at least three key managers in the organisation concerned for the project: the political decision-maker, who can mobilise and deliver full political support, the administrative manager, who can mobilise and commit all the required resources for the project, and the IT manager. who can mobilise and commit the expertise required (Bannister 2001a. See also Watson, Houdeshel \& Rainer 1997:374).

\section{IMPACT OF THE IT REVOLUTION ON PUBLIC MANAGEMENT}

Heeks distinguishes three types of impacts that IT can have on an organisation:

- IT can support existing activities;

- IT can replace, change or supplant existing processes; or

- IT can create or innovate new activities in the organisation (1999:17).

An authoritative study published a decade ago already concluded that the impact of IT on organisations can be distinguished in 3 consecutive stages: first, automating the organisation, then informatizing it and lastly transforming its values, structures and 
core processes into a new type of organisation (Scott Morton 1991; Bellamy \& Taylor 1998:38).

The first discernible impact of IT on organisations can be traced back to the 1950s, when TPSs were developed to facilitate and eventually even automate simple, routine transactions (Fidler \& Rogerson 1996:49; Finlay 1994:37; Turban \& Aronson 2001:21). That was followed by the development of primitive office automation systems in the 1960s, and DSSs and MISs in the early 1970s. The conceptualisation of DSSs is generally attributed to an IT specialist with the name of Scott Morton, who first conceptualised it at the time as an "interactive computer-based system which helps decision-makers utilize data and models to solve unstructured problems" (Gorry \& Scott Morton 1971:55). During the 1980 s DSSs were transformed into more sophisticated MISs, EISs and ESs (Sauter 1997).

The IT revolution and the impact of globalisation have stimulated the development of the informatisation approach to public management from the middle 1980s onwards, after the successful debut of the personal computer in industrial societies. It resuscitated in another form the cybernetics approach of the early 1970s, which was largely unsuccessful because of the primitive state of understanding of the IT revolution at that stage. Ackoff summarised the main reasons for this failure as inter alia a series of misconceptions that designers and developers of MISs at the time held, including the misconception that, if managers have more information, their decision-making will improve (Fidler \& Rogerson 1996:50). It is now clear that it is not necessarily a lack of information that obstructs better decision-making, but a lack of knowledge about what information is needed and to use the available information optimally.

In its current form informatisation postulates that the requirements of contemporary public management and the availability of new technologies necessitate fundamental changes in the traditional role of information technology in management. "The drastically increased capacities to collect, store, aggregate, analyze and present data for instance in 
the form of key-figures, monitoring information, electronic models and geographic information systems enable a systematisation and rationalization of policy-making processes" (Snellen \& Van de Donk 1998:18). Informatisation is an umbrella term referring to a complex series of interrelated phenomena resulting from the increasing, and in many cases uncoordinated, adoption of different technologies in public sector organisations, including the following developments (Frissen \& Brussaard 1992 not in Bibl:1; Van de Donk \& Meyer 1995:230):

回 the increasing introduction of different types of information technologies at different levels in public sector organisations for a variety of reasons;

回 increased and new flows of information, resulting in new processes developing in public sector organisations as a result of the use of the new technologies;

回 changes in the organisational structures of the public sector as a result of these developments;

回 the increasing salience and rapid growth of an entirely new type of expertise in public sector organisations around IT; and

回 new ways of looking at the phenomenon of public management as a result of these new developments (i.e. the development of new organisational value and cultural systems).

The latest research results on the informatisation paradigm indicate that instead of being one resource supporting good management (in addition to financial resources, human resources and other resources), information technology is increasingly integrated into every dimension of management in order to comply with the ever-increasing demands for good governance. "ICTS contribute to an integration of the stages of policy making and policy implementation, while giving ... more possibilities to determine, control, and monitor the policy implementation stage" (Snellen \& Van de Donk 1998:18). 
Turban \& Aronsen comment that the current situation is that EIS's "which started in the mid-1980s in large corporations, have spread around the globe, have become affordable to smaller companies, and are serving many managers as enterprise-wide systems". They conclude that in the late 1990s the focus of stand-alone EIS moved from "executives" to "enterprise" in the form of web-based support systems serving everyone in the organisation (2001:16), while group support systems and ANNs also started to gain popularity during this period. Marakas (1999:205) comments that "The trend towards the integration of applications and technologies into seamless enterprise-wide systems, bodes well for the future", while other experts predict that the EIS of today may develop into an Executive Intelligence System in future (Watson, Houdeshel \& Rainer 1997). Other authors have commented that "(R)e-engineering business processes with ICTs promises to secure major efficiency gains which will ... (bring) about significant improvements in the quality of services" (Bellamy \& Taylor 1998:63).

Informatisation inevitably leads to transformation of an organisation's structures, functioning and eventually also its value systems as the last and highest-order impact of technology applications. Two of the most prominent international scholars in this field "believe that we are witnessing major changes in both practice and theory of Public Administration" (Snellen \& Van de Donk 1998:19). They agree with Finer (1997) that automation technologies have already started over the last century and a half to change the core business of government in fundamental ways and allege that as far as ICTs in public administration are concerned, we are witnessing an acceleration of such a development (1998:19. See also Bellamy \& Taylor 1998:34).

It is clear that IT is increasingly bringing about a paradigm shift in management by fundamentally blurring the boundaries between strategic and operational management and integrating these processes by changing traditionally consecutive management processes into simultaneous and parallel processes, and by establishing direct, empirical and measurable linkages between policy objectives, implementation programmes and project outcomes (see McGee \& Prusak 1993:174). This happens as a consequence of the 
digitisation and integration of all management processes into a single or more than one highly compatible databases, and the use of integrated management support software, including enterprise resource management, business intelligence tools and business process re-engineering strategies (Taylor, Snellen \& Zuurmond 1997).

It may therefore be more appropriate to refer to this new perspective as an Integrative Approach to Public Management (Heeks 1999:30; Bellamy \& Taylor 1998:151). The bulk of this study will be devoted to assessing the nature and potential impact of this integrative approach on public management (see also McGee \& Prusak 1993:173; Robson 1997).

Private sector management consultants have so far played a crucial and constructive role in these developments (see KPMG 2001; Accenture 2001; EIU 2002).

The electronic governance capacities of the individual European case studies selected for this study are summarised in Chapter 4. 


\section{CHAPTER 4}

\section{ELECTRONIC PUBLIC MANAGEMENT SUPPORT IN COMPARATIVE PERSPECTIVE}

The term e-government has been coined to refer to the new IT-based paradigm in contrast to the traditional paper-based approach to government. It refers to various government functions based on electronic systems and includes for the purposes of this study internal e-management (the use of electronic back-office support systems within public sector organisations like TPS, EIS and other general MSS) as well as external e-delivery (the provision of public services to the public through electronic front-office delivery systems (e.g. through the use of smart cards, e-mail, internet and other ICTs, both for political and administrative purposes), both in the form of e-democracy and e-services. (See also European Commission 2002; PCIP 2002:6). These analytical dimensions of e-government can be represented visually as follows:

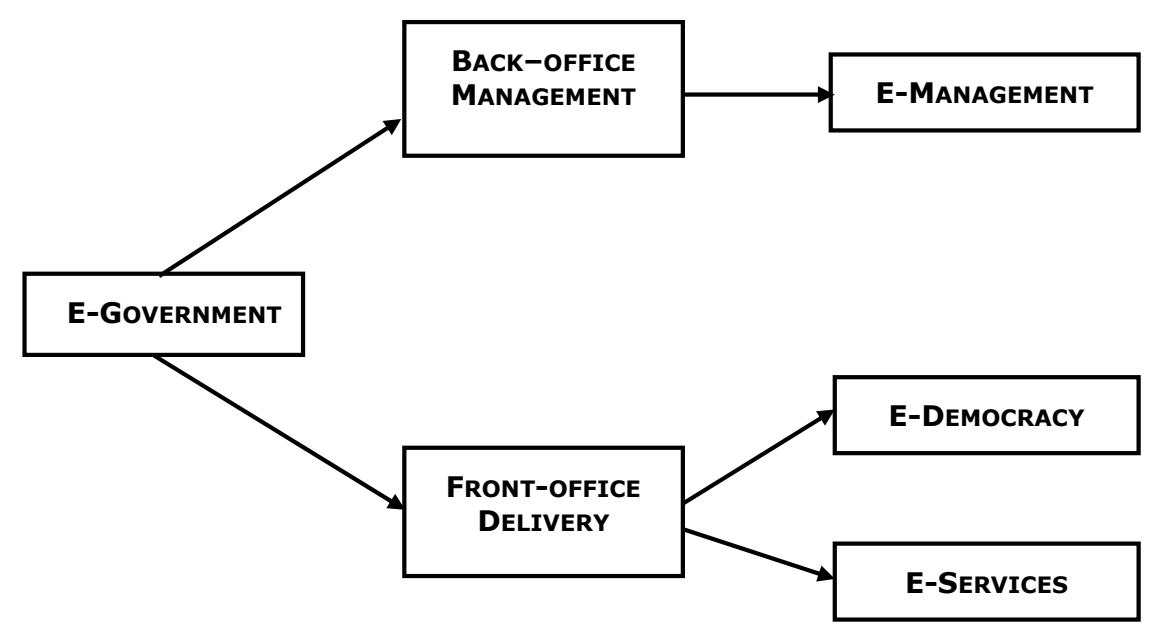




\section{Dimensions of electronic government}

As stated at the outset, the empirical focus of this research project is on internal e-management rather than on external e-delivery. The study concentrates on the varying degrees to which electronic back-office management-support tools have been adopted in public sector settings in selected European countries. In Chapter $\mathbf{1}$ the specific research questions to be investigated were formulated as follows:

回 What electronic internal management-support (back-office) systems are predominantly used in the public sectors in the different countries, by whom, how widely, for what purposes and why?

回 How effective are these practices, i.e. what is their impact on public sector policy processes and outcomes?

回 What other similar or new systems are under development or contemplated to facilitate good governance in this way?

回 How relevant are they for, and how appropriately can they be utilised to enhance, good governance processes and outcomes in South Africa and other developing countries?

The case studies that were selected were Belgium, the Netherlands, France and the United Kingdom. Annexure 6.1 contains the reasons why they were selected and how the data used in this assessment were compiled. A few attempts to provide conceptual frameworks for the assessment of electronic government across the world will be summarised before more detailed assessments are undertaken of the four case studies.

\section{MODELS TO ASSESS ELECTRONIC GOVERNMENT CAPACITY}

The existence of an appropriate level of electronic infrastructure (e.g. appropriate electronic work-stations linked into effective and reliable electronic networks with access to relational databases) and an accompanying appropriate level of electronic literacy 
among intended users of these systems (e.g. standardised, integrated computer-based work routines and processes throughout organisations and appropriate competencies of users to use these systems for the purposes for which they are intended) are prerequisites for the effective maintenance of both internal, back-office systems and external frontoffice systems. Different models to compare the experiences of states in this regard are available. A useful summary of some of the most important comparative assessments that have been made so far can be found in Bridges 2003. Four different models that seem the most appropriate for the purposes of this study are summarised below.

\section{The UN-DPEPA Model}

The United Nations Division of Public Economics and Public Administration (UN-DPEPA) has developed an authoritative, primarily input-based model of what it calls the E-government Index of UN Member States (UN-DPEPA 2001). The model's objective is to define UN member states' e-government environments and their capacity to sustain online development, and to establish a permanent yardstick against which progress can be assessed. It will therefore be regularly updated (UN-DPEPA 2001:v). E-government is narrowly defined in the index as "utilizing the internet and the world-wide web for delivering government information and services to citizens" (UN-DPEPA:1).

Key e-government criteria in the UN model are:

回 the state of a country's telecommunications infrastructure (PCs, internet hosts, online population, TVs, telephones);

回 the strength of its human capital in the IT field ( Human Development Information Access Indices and urban/rural population ratio);

回 the proven strength of political will and commitment of the national leadership to egovernment(including web presence, dedicated national e-government teams and implementation of strategic plans); and 
回 proven shifts of policy and administrative priorities to promote e-government (especially in critical sectors like education, health, labour/employment, welfare/social services and financial services) (UN-DPEPA 2001:11, 25-27).

The report states explicitly that "(f)ull-fledged commitment to e-government implies that a country's leadership recognizes the fact that information has become a social and economic asset just as important and valuable as traditional commodities and natural resources. Information benefits the most the individuals and industries which have unimpeded access to its acquisition, and the self-determination to convert essential data into knowledge" (UN-DPEPA 2001:2). The 2001 e-government profile that emerged from the model is shown on page 55 .

The 2001 e-government index is comprised of four categories of states:

- High e-government capacity scores $2.00-3.25$

- Medium e-government capacity scores $1.60-1.99$

- Minimal e-government capacity scores $1.00-1.59$

D Deficient e-government capacity scores below 1.00

Geographic leaders are $($ mean $=1.63)$ :

- North America (2.62): the USA (3.11)

1 Europe (2.01): Norway (2.55)

b South America (1.79): Brazil (2.24)

1 Middle East (1.76): Israel (2.26)

- Asia (1.38): Singapore (2.58)

- Oceania (2.59): Australia (2.60)

- Caribbean (1.34): The Bahamas (1.79)

- Central America (1.28): Costa Rica (1.42)

- Africa (0.84): South Africa (1.56) 
2001 UN E-GOVERNMENT PROFILE

\begin{tabular}{||l|l||}
\hline UN member states & $\mathbf{1 9 0}$ \\
\hline - with a government website presence & $169(88 \%)$ \\
\hline - with a national government website & 84 \\
\hline - with sub-national government websites & 84 \\
\hline - with single-entry government portals & 36 \\
\hline $\begin{array}{l}\text { - with online transaction capacity } \\
\text { Emerging stage: Establishment of an official, static online government } \\
\text { presence on the web }\end{array}$ & 17 \\
\hline $\begin{array}{l}\text { Enhanced stage: Expansion of government sites and services with more } \\
\text { dynamic content }\end{array}$ & $65(34,2 \%)$ \\
\hline $\begin{array}{l}\text { Interactive stage: Download of documents, e-mail to and from officials } \\
\text { and general interaction with government via the web }\end{array}$ & $55(30 \%)$ \\
\hline $\begin{array}{l}\text { Transactional stage: Online payment for services and other transactions } \\
\text { Seamless integration stage: Full integration of e-services across } \\
\text { administrative boundaries }\end{array}$ & $17(9 \%)$ \\
\hline \hline
\end{tabular}

(Source: UN-DPEPA 2001:1)

According to the UN-DPEPA report, the UK is at number 7 with a score of 2.52 , the Netherlands at 8 with 2.51, Belgium at 12 with 2.39 and France at 14 with 2.33 (2001:7). South Africa is at the top of the minimal capacity category. It is on the verge of the medium capacity category and probably fits better into that category. Only 7 other African countries are categorised in the minimal category. They include

Nigeria, the Ivory Coast and Botswana, which are all far down on the list, barely out of the deficient category (UN-DPEPA 2001:7). All other African states are in the last category.

Other conclusions in the report are that:

- e-government progress correlates with development progress; 
- a lack of co-ordination within national e-government programmes obstructs the effectiveness and efficiency of such programmes;

- online services should be seen as complementary to traditional services rather than replacing them;

- increased access to the web does not translate into increased use;

- government to business (G2B) services are frequently prioritised to the detriment of government to community (G2C) services;

- single-access portals are significant yardsticks;

- e-services are probably more cost effective than other services, but this cannot be proven yet; and

- national e-government teams and public awareness campaigns are rare (UN-DPEPA 2001:4).

\section{The Accenture Model}

Accenture Management Consultants recently developed an explicit output-based model to measure the progress towards overall maturity of e-government initiatives across the world. E-government is conceptualised in this model in a narrow sense only as electronic public service delivery systems, in line with the prevailing global bias towards front-office technologies. In a slightly adapted form, however, the model can also be useful to assess back-office technologies in government.

The developers of the model identified 22 countries in 2001 that seemed to be the most progressive in the field of e-governance maturity, as they defined it. Overall maturity of e-government is conceptualised in the model as a combination of two sub-indices:

回 Service maturity (low, marginal or moderate). Service maturity measures the level to which a government has developed an online presence. The number of 
services presented online (service maturity breadth) is distinguished from the level of completeness or comprehensiveness of each offering (service maturity depth).

回 Delivery maturity (low, marginal or moderate). Delivery maturity measures the sophistication/level of complexity of delivery mechanisms such as single-point entry, customer intention design, customer relationship management techniques, portal capability and additional value-added services. Complexity starts out with simple one-way passive dissemination of information that is regarded as a low-level of sophistication activity, through one-way interaction from the public to government, to mutually active, full electronic transaction and completion of the service intervention (Accenture 2001:5).

Overall maturity classification categories are (from high to low) (Accenture 2001:7):

回 Innovative leaders: standing apart from other countries due to the high number of mature services offered online (Canada, US and Singapore);

回 Visionary followers: countries that started strongly with a sound online services base and are progressing towards delivery maturity (Norway, Australia, Finland, Netherlands \& UK);

回 Steady achievers: countries with a large breadth of services with the potential for more depth and progressing steadily towards more depth and delivery maturity (New Zealand, Hong Kong, France, Spain, Ireland, Portugal, Germany \& Belgium);

回 Platform builders: countries with low levels of well-designed, sustainable online services and a good potential to increase the breadth, depth and complexity of their electronic offerings (Japan, Brazil, Malaysia, South Africa, Italy \& Mexico).

It is significant that four of the 22 identified countries are normally classified as developing societies: Brazil, Malaysia, South Africa and Mexico, while those countries that are on top of this e-government listing are classified as highly developed in terms of World Bank and UN development indicators. 
Both the Accenture and UN models have strong front-office biases that reflect the current global e-government profile.

\section{The Economist Model}

In 2002 the Economist Intelligence Unit (EIU) published in co-operation with IBM a White Paper consisting of E-readiness Rankings of the world's 60 largest economies. The EIU model is based on an index consisting of the following elements (EIU 2002:8-14):

回 Connectivity and technology infrastructure (25\%): telephone, PC and internet access, service reliability, affordability and quality, content security;

回 Business environment (20\%): business attractiveness, including social, political, economic and labour predictability, stability and growth;

回 Consumer and business adoption (20\%): size \& growth of e-business sector and support of government;

回 Legal and policy environment (15\%): regulatory framework to facilitate, protect and promote e-interaction;

回 Social and cultural infrastructure (15\%): general and internet literacy, innovation and entrepreneurship; and

回 Supporting e-services (5\%): technical and consulting IT services and standards.

The EIU model is basically also an input-based model. It ranks the Netherlands at number 2 (after the US), the UK at number 3, Belgium at number 16 and France at number 17. South Africa is ranked at number 33 out of the 60 states selected, just after Mexico, Poland and Malaysia, but ahead of Brazil and Argentina (EIU 2002:4-5).

\section{The Centre for Public Policy (CPP) Model}

In 2002 Prof. Darrell West of the Centre for Public Policy at Brown University in Rhode Island in the USA undertook a survey of the main features of 198 national e-government 
websites. E-government was defined for purposes of the study as "the delivery of information and services online via the internet" (CPP 2002:3). The model used was based on the following features that would assist an average citizen logging onto a governmental website (CPP 2002:4):

1 Contact information to find out who to call or write to in order to resolve a problem;

- Information materials;

- Types, scope and quality of services and databases;

- Features to facilitate the handicapped and non-native language speakers;

- Interactive features for public outreach; and

- Explicit re-assurances about security of data.

Like the Accenture model, the CPP model is primarily an output-based model of e-governance. The CPP study ranks the four countries used in this study as follows: The UK is ranked at number 9, France at number 24, Belgium at number 56 and the Netherlands unbelievably low at number 69. The Netherlands ranking is below Yemen at number 25, Cuba at number 33, Uganda at number 45, Kyrgyzstan at number 57 and Nepal at number 66 . South Africa is also rated only at number 83 .

Except for the Netherlands ranking, which is clearly an error, the CPP's ranking order of the other case studies is relatively similar to that of the other three models summarised above, although its assessment is clearly based on more formalistic requirements than is the case with the other assessments (especially regarding features to assist minority language speakers and the handicapped, and explicit statements about online security considerations). 


\section{European public sector electronic profiles - the front-office bias}

European governments generally spend varying portions of their budgets on the improvement of their ICT capacities (Heath 2001). There is a clear correlation between the levels of ICT-related spending and the progress made towards fully-fledged e-government. This is the result of the adoption of e-government visions at an early stage, followed by sustained commitment at political, administrative and financial levels of government, and the adoption and implementation of the strategically most appropriate strategies to achieve the desired results (Accenture 2001:8).

According to all the indices summarised above (with the exception of the obvious error regarding the Netherlands ranking in the CPP study and its more formalistic requirements), the four case studies are all close together at the top of the high e-government category. This means that they are all leading e-government nations. Both Accenture and the EIU rate the Netherlands as even more advanced in this field than the UK, while both France and Belgium lag behind them in many crucial respects. The Accenture model is preferred as a framework for assessment in this study, because of its more comprehensive scope and better explanatory powers. The inputs-based character of the UN model makes its assessment utility less useful than the output-based models.

\section{The Netherlands}

The 2001 Accenture report rates the Netherlands as the most progressive of the four cases, as a strong visionary follower of the front runners Canada, the US and Singapore. It has a well-considered strategy to turn its country into a "digital delta" (Netherlands 2000a \& 2000b) and has a strongly co-ordinated and synchronised effort underway to reach this objective in the short term. The Minister of the Interior has an explicit responsibility for ICT modernisation in the Dutch government. The programme started as a comprehensive programme in 1999 and already the Dutch e-government's single-portal website constitutes one of the most comprehensive sources of e-government currently available (Netherlands 1999). In 2000 the Dutch government spent 177 euro per capita on 
ICT-related public services (Heath 2001). A total of $58,07 \%(9,28$ million) of the Dutch population had internet access by February 2002 (NUA Netherlands 2002).

A range of functions can be accessed through that portal: from contact information to the contents of documents, including official administrative texts, legislative documents and correspondence, technical manuals and academic research papers. It is also one of the most refined systems developed so far for public interaction, especially at community level, and the target is to have all municipalities and $25 \%$ of all government transacting services fully online by the end of 2002. (www.e-envoy. gov.uk/publications /reports/benchmarkingV2/summary neth.htm, 3/4/2002)

Although the necessity of synchronising front- and back-office support systems has been recognised right from the start, there is still a strong bias towards external service delivery in the first stages of Dutch e-government. Concerns about electronic security and recordkeeping, however, have led to intensive efforts by the Dutch to establish reliable electronic identity registration, signature and archival back-office systems to support the expanding electronic front office systems (www.e-envoy.gov.uk/publications/reports/bench markingV2/summary neth.htm, 3/4/2002). In December 2001 the first concrete attempt to modernise policy decision support was made in the form of an overview of selected useful software programmes for purposes of problem identification, forecasting and options assessment (Netherlands 2001b). There is, however, no sign yet of any attempt to start using these decision support systems in a systematic manner throughout the Dutch public sector. The closest initiative in this regard is the development of the DEFINITE programme (Definite 2001) that was undertaken by the Institute of Environmental Management at the Free University of Amsterdam at the request of and in co-operation with the Netherlands Department of Finance for budgetary planning purposes. The product is now commercially available (Janssen 1991; Janssen \& Van Herwijnen). It is, however, ironic that there is no reference to Definite or to other products developed and used in the Netherlands public sector (Lootsma 2000b, Wijnmalen) in the dss overview referred to above (Netherlands 2001b). The use of such decision-support tools in the Dutch 
government seems to be sporadic and unco-ordinated in different line function departments where individuals have experimented with or introduced the use of different such tools that they personally like and find useful.

The progress that the Netherlands has made in European e-government circles can also be attributed to the strong emphasis on the informatisation of public administration in the various Departments of Public Administration and Management at different Dutch universities. These include the Erasmus University in Rotterdam, the Universities of Delft, Leiden, Tilburgh and Nijmegen, and the Free University of Amsterdam. There is a reciprocal relationship between academics and researchers in these institutions and government officials. In many cases academic research and application of ICTs in public management is further advanced in university think-tank contexts rather than in practice (e.g. De Vries 1992, 1994; Van de Donk \& Meyer 1995; Snellen \& Van de Donk 1998, Frissen \& Snellen 1990). Many of these academics are used as influential policy advisers on these issues. Examples include Prof. Ig Snellen of Erasmus University, who was the Chairperson of the Advisory Commission on ICT and Government, while Prof. PHA Frissen is the Deputy Chair of the Commission, with two other professorial colleagues also members of the Commission (Netherlands 2001c).

Dutch and British researchers and academics also dominate the activities and publications of the specialised research work groups on informatisation and the use of technology in public administration in Europe (see in addition to the above references also Bellamy \& Taylor 1998). This contributes to sustainable policy design and implementation. It is clear that the Netherlands is a generally acknowledged leader in this field and has all the features needed to maintain that position. The fact that it is a geographically small state, ethnically homogeneous, centrally governed and development-wise very wealthy and advanced contributes to the potential for success that the country exhibits. 


\section{The United Kingdom (UK)}

In the UK Prime Minister Tony Blair is personally behind the drive towards e-government. His vision is for a modern, efficient government that utilises the benefits of the latest technology to meet the needs of citizens, business and government (UK Cabinet Office 1999, 2000a; Accenture 2001:56). In 2000 the British government spent 209 euro per capita on ICT-related public services, the highest of the four case studies (Heath 2001). A total of $55,32 \%$ (33 million) of the British population had internet access by February 2002. (www.nua.com/surveys/ how many online/europe.html, 13/4/02).

The UK has by far the most ambitious e-government programme of the four cases. It intends having $75 \%$ of all government services in the UK online available by the end of 2002 and the remainder by the end of 2005 (UK Cabinet Office 2000b, 2001c, 2001d, 2001f). This plan will be funded by an allocation of 1 billion pounds sterling for egovernment projects for the three-year period April 2001 to March 2004 (www.eenvoy.gov.uk/publications/reports/benchmarkingV2/summary uk.htm, 3/4/2002). The Accenture report rated the UK as still behind the Netherlands as a visionary follower (2001:56). The UK's bigger population, surface area and decentralised government structure necessitates a much wider breadth of services to be provided. This has led to a lower score for the UK on the Accenture Maturity index, because most of the impressive number of governmental websites also mainly provide information rather than an opportunity for citizen interaction and completion of transactions (2001:57).

The government's single portal, www.open.gov.uk, is an effective comprehensive guide to government services, while another portal (www.ukonline.gov.uk) has been structured around life events (like the leading Singapore site in this regard, www.ecitizen.gov.sq) in order to make access easier for citizens who do not know which agency to contact for a specific service. The UK, however, now needs to advance to a higher level of electronic government maturity by increasing the delivery depth of its online services. This lack of sufficient progress in developing more mature delivery systems can be attributed to the 
reasons mentioned above, distinguishing the more complex UK situation from the simpler Netherlands environment.

Another reason, however, for the slower than expected e-government maturity rate is probably the lack of sufficient attention to the development of appropriate back-office systems to support these front-office services at the required levels (UK Cabinet Office 2000a, 2001a). Various initiatives to upgrade the back-office capabilities of government have been undertaken over the past few years (www.e-envoy.gov.uk/publications/ reports/benchmarkingV2/summary uk.htm 3/4/2002). They include projects aimed at improving the authentication and security of transactions, protecting privacy, assessing the potential applications of smart-card technology, improving electronic interoperability and establishing electronic records management systems (www.e-envoy.gov.uk/ publications ,3/4/2002, (UK Cabinet Office 2000c, 2001b, 2001e). These back-office support systems are, however, now developed either simultaneously with or after the development of those front-office electronic service delivery initiatives that they are supposed to support (see Margetts 1995 and 1999 for comprehensive overviews of the role of technology in the UK).

Electronic decision-, implementation- and assessment-support systems in the UK government are also either totally absent or in a rudimentary stage of development. It was, for example, impossible to identify key decision-makers in the British government who are responsible for the central promotion and co-ordination of back-office electronic decision-support tools in the British public sector. There is a full-time Electronic Envoy to the Prime Minister in the British Cabinet Office which has a complement of about 200 staff members. Their responsibility is to get all public services provided by the British government online by 2005, but back-office modernisation is not part of this brief (Aitken 2001). Various attempts to trace any person tasked with such responsibility failed. The reasons proposed by experts for this included the fact that the autonomy enjoyed by government departments in the UK has lead to decentralised experiments within departments and that there is no reason why this should be co-ordinated at central 
government level. Another explanation was the alleged threat perceived by politicians and bureaucrats of losing control over information and power once transparent decisionmaking aids are used (Perri 6, $2001 \mathrm{a}$ and b).

This cart-before-the-horse approach is a general phenomenon that has been observed across European states and is one of the most significant differences between Accenture's innovative leaders and this category of visionary followers. The Accenture report regards the UK as a potential innovative leader, if it can succeed in maintaining the momentum that it has already developed with its e-government initiatives.

\section{France}

France started with its e-government programme in 1997 under the personal supervision of Prime Minister Jospin. The initiative is also driven directly from the Prime Minister's office. At that time the government in France could not be reached on the internet. In October 2000, however, a single portal, "Service Public", was established (http://www.service-public.fr/etranger/english.html, 3/4/2002), providing public access to government services and documents (www.e-envoy.gov.uk/publications/reports/bench markingV2/ summary fra.htm. 3/4/2002).

In 2000 the French government spent 201 euro per capita on ICT-related public services (Heath 2001). The Prime Minister committed himself to the creation of 7000 additional public internet access points by 2002, while 5,5 billion francs were budgeted for public sector information systems and 600 million francs for the training of officials. Public internet access in 2001 was 26,28\% (15,65 million), still lagging behind countries like the UK and the Netherlands (www.nua.com/surveys/how many online/europe.html, 13/4/02).

Despite this fast increase in internet access points, however, slow progress has been made with higher-level use of these facilities, like interaction between citizen and government and also finalising transactions electronically. Electronic facilities are still mainly used for publishing information. The government's electronic service delivery target was only to 
provide public information about government services and documents by 2000 (www.eenvoy.gov.uk/publications/reports/benchmarkingV2/summary fra.htm, 3/4/2002).

France's service delivery maturity therefore scores relatively low on the Accenture index. This can be partly attributed to "... France's limited ability to couple technology with innovation and deeper reforms" (Accenture 2001:26), i.e. the absence of back-office modernisation. This problem has been acknowledged explicitly in interviews with senior French officials involved in these programmes (Marechal 2001; Field 2001; Courtine 2001). The Department of Finance and related agencies have made the best progress of all government departments in this regard (Marechal 2001; www.minefi.gouv.fr, www.netenterprises.fr, 3/4/2002).

Back-office management-support services are seriously neglect in France, as is the case also across all the case studies that were assessed (Field 2001). The French government has, however, thrown all its weight behind the e-government strategy and the designers of the strategy ascribe the slow progress so far to an intensive effort to upgrade back-office capacities better before proceeding to higher-level usage of its electronic capabilities (Courtine 2001). This is probably also partially due to the relatively low levels of electronic literacy in the French bureaucracy, compared to its counterparts in this study. An intensive effort is underway to increase the electronic literacy of public officials (Courtine 2001). An information society law project is also in progress in order to establish a legal framework to enhance electronic administration and security (www.internet.gouv.fr/english/textesref/ cisigb/fiche3gb.htm, 3/4/2002). Another significant strategy is to support open-source software (http://trans.voila.fr, www.atica.pm.gouv.fr, 3/4/2002). This will facilitate the dissemination of software toolkits to support public management processes.

The Accenture report classifies France as high on the Steady Achievers list and it is clear that the French government is following a different approach than the UK and the Netherlands by concentrating first on a consolidation of back-office capacity before proceeding to higher levels of external delivery. This seems to be a feasible strategy that 
has the potential for better longer-term success than the short-term external servicedelivery benefit strategy followed by the UK.

\section{Belgium}

The Belgian e-government initiative started in 1999 with a concerted effort by the Federal Government to put crucial governmental information online (Accenture 2001:18). The country is rated in the Accenture report as the last Steady Achiever in the field of egovernment, 5 places behind France and just ahead of Japan, which is the strongest electronic Platform Builder state. In 2000 the Belgian government spent 128 euro per capita on ICT-related public services (Heath 2001). A total of $33,14 \%$ (3,4 million) of the Belgian population were online in December 2001 (www.nua.com/surveys/how many online/europe.html, 13/4/02).

$\mathrm{E}$-government in Belgium has not yet reached the transactions stage. The overwhelming majority of its governmental websites provide mainly information. The government's single portal www.belgium.fgov.be provides effective access to governmental information in four languages. There is need, however, for a higher-level value-added approach to egovernment in Belgium, according to the Accenture report (2001:19). The Belgian federal government's Copernicus programme, which was launched in 1999, is aimed at modernising government in Belgium by focusing increasingly on online services delivery. "This policy development must be transformed into action. Belgium has crossed the first hurdle by having a well-articulated plan. Belgium has in place the key ingredients to make significant strides in e-government leadership - a solid platform of online information, a broad growthplan to follow, and a degree of commitment to the task at a federal level. As long astimetables and clear goals can be set and adhered to, Belgium is likely to make considerable progress in the next 12 months" (Accenture 2001:19).

The Accenture assessment recognises the efforts of the Belgian government's Copernicus programme to upgrade its back-office capabilities. This internal focus has clearly delayed 
progress with the development and expansion of more front-office services. The fact that the Accenture model scores Belgium the lowest of the four case studies can be explained within the context of the front-office bias of the model. As is the case with France, though, the greater attention of the Belgian federal government to the upgrading of its back-office capacity may prove to be more beneficial to the sustainability of the programme in the longer term.

Visits to Belgian government departments and interviews with officials in this field have indicated that serious efforts are in progress behind the scenes to ensure that the administrative backbone of the respective e-government systems in Belgium are operational before higher-level, front-end services go live. It is significant that the most advanced systematic effort that could be found among all four case studies at the end of 2001 to develop generic policy evaluation indicators across government was initiated in the Flemish regional government's Department of Planning and Statistics (Silon 2001; Flanders 2000 \& 2001. See also Heirbrant 1999; Hensmans 1999; Verdonck 1996). It is also significant that the best operational examples of Enterprise Resource Management and Business Intelligence systems to be found among the four cases were in the Belgian Federal Labour Bureau and in the Flemish Department of Welfare, Health and Culture (e.g. Bekaert 1997; Deblaere \& Vander Auwera 2000; Verdonck \& Van Wayenberge 1999).

A combination of factors can explain the Belgian case. The most significant of these probably include committed political and financial support by politicians and officials, a coherent, systematic vision of the future, the required technological infrastructure and the small size of the country and the population. The decentralised nature of the Belgian polity is both an advantage and a disadvantage in this regard. It enables the Flemish regional government, which is very committed to the establishment of e-government, to proceed rapidly with its programme, while the Walloon regional government, which is less committed to technological progress, is in danger of falling behind, unless it changes its strategy soon. 


\section{South Africa}

A total of $5,5 \%$ (2,4 million) of the South African population had internet access by February 2002 (www.nua.com/surveys/how many online/africa.html, 13/4/02). This represents the overwhelming majority of internet users on the African continent, as is evident from all the international studies mentioned above. The Accenture study regards South Africa as one of the 22 global e-government leaders (2001:52), probably mainly as a result of its totally dominant position in all sectors on the African continent (see Jensen 1999; http://www.africanconnection.org/, 3/4/02).

The South African government has further committed itself to e-government with a formal White Paper on the topic, a Ministry responsible for e-government and a full-time national team dedicated to achieving fully operational e-government by the end of 2005 at all levels of the public sector. The government already has an operational single-portal access to most central government services (http://www.gov.za/) and is currently in the second stage of e-government readiness. It already has an extensive array of government information and documentation electronically available, while sophisticated electronic community consultation initiatives are in place and many departments are already in the interactive transaction stage of service delivery (http://www.ICTinGovernment.co.za/, Humphries 2002, Benjamin 1999).

E-government is also not only under development at central governmental level. All nine provinces have sophisticated e-government systems either already in place or in various stages of development. The Gauteng provincial government, for example, has an initiative underway called Gauteng Online, which inter alia entails the incorporation of all provincial government stakeholders into the provincial portal, including the provision of computerised systems and internet access to all schools in the province in the immediate future (http://www.gauteng.gov.za/). Similarly, the Western Cape is breaking ground with its Cape Online project, which has the same objectives (PGWC 2001a:95; http://www.westerncape.gov.za/). The Western Cape Province is, after Gauteng Province, 
the largest internet user on the African continent (PGWC 2001b:8). Cape Gateway is the front-office project, Cape Change the back-office project, Cape Procure the pilot transactional completion project, Communities Online the external community stakeholders forum, and Cape Access and Cape Net the technological infrastructure coordination and development projects for these purposes (PGWC 2001b, Levin 2002).

Many of the nearly 300 local governments in the country also have sophisticated egovernment systems either already in place or in various stages of development. The City of Cape Town has announced in the first week of 2003 that it has put into operation the most sophisticated integrated strategic and operational information management system in Africa (see http://www/capetown.gov.za/; Cloete \& Needham 2002; Cape Town 2002). This system compares well with local government systems anywhere in the more developed countries of the world and contains many features that are at the cutting edge of local government management globally (Cloete \& Needham 2002). The metropolitan governments of Johannesburg, Durban and Tshwane (formerly Pretoria) are also gearing up to customise the Cape Town model for their respective contexts.

Plans for a comprehensive electronic gateway to South African (and even African) resources and services are at an advanced stage (see DPSA 2002; http://www.gateway.gov.za/; http://www.e-africa.com/). The South African Gateway vision is "to create seamless and continuous access (24/7/365) to information and services of the SA government, for all citizens and business users, through the use of appropriate technology" (DPSA 2002:11). It explicitly targets both back-office and front-office needs, and aims at effective integration of these activities over a period of three years (DPSA 2002:13).

The objective is to have a comprehensive, integrated single electronic portal access to public services information at all levels of government and governmental agencies operational by July 2003, including all governmental forms available for download in an electronic format (DPSA 2002:21). One year later, by July 2004, fully integrated 
interactive service transactions should be operational (e.g. registrations of births, deaths and companies, applications for ID documents, including secure payments for such services. By integration is meant the integration of legacy systems and not back- and front-office integration. This is the objective of the last phase that is due to be completed 18 months later, by December 2005 (DPSA 2002:23).

The SA Gateway schedule is extremely ambitious and it is doubtful whether it will be complied with, given the uneven state of e-readiness of government departments that is evident from the current government portal (http://www.gov.za/). Other constraints also obstruct full e-government readiness in South Africa. The most significant of these constraints include the typical constraints of developing countries: persistent, widespread general and computer illiteracy inside and outside the public service, a serious lack of technological infrastructure, especially in rural areas, and a lack of political commitment to implement fully the government's rhetorical support of e-government objectives in the face of growing disparities between rich and poor in the country and the approaching elections.

The South African government has high ambitions for e-government in the country, as is illustrated in the following extract from a presentation by a research officer in the government's IT Agency (Malema 2002): 


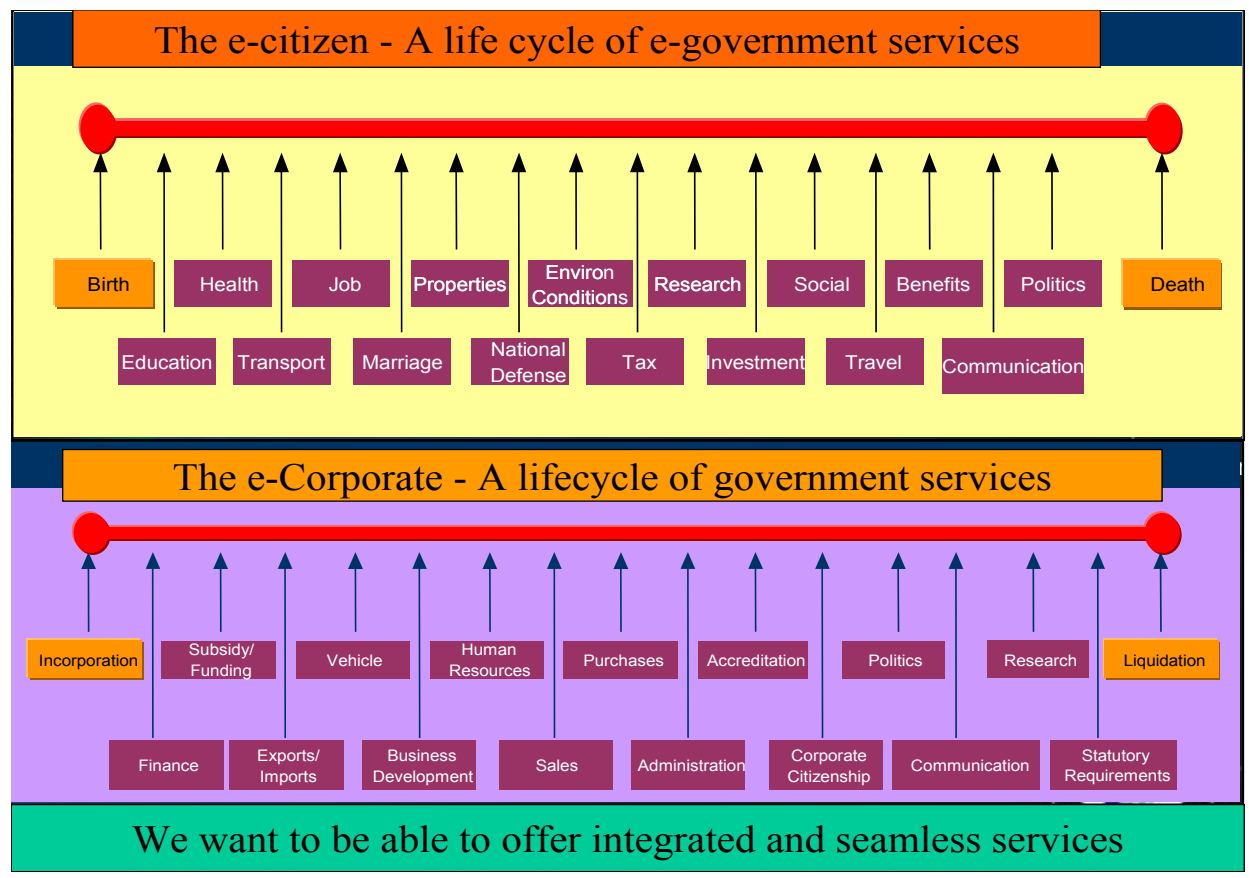

Envisaged e-government services in South Africa (Malema 2002)

The South African government is, in ironic contrast to the four European case studies, the only government encountered so far that has formally established a fully-fledged internal decision-support facility at the highest level of government (in the Office of the President). This facility is also available to all other government departments. It consists of 67 licences to use the powerful dss programme Thinktools in the South African government, under the professional guidance of the German development agency GTZ. Thinktools has inter alia been consistently used in the preparation of the World Economic Forum's meetings in DAVOS in Switzerland (see http://www.thinktools.com). Unfortunately this initiative was driven by a few individual bureaucratic elites in the South African government, who have now all left government since the establishment of the programme. 
The result is that the facility is currently still available, but totally under-utilised because it has not yet been structurally entrenched in governmental decision-making processes.

Whatever the obstacles to successful e-government in South Africa, it cannot be disputed that the country has built up a formidable lead in the field compared to others and that it stand a good chance of remaining among the front runners in e-government globally, if the SA government can continue to deliver on its commitments in this regard.

\section{Conclusions}

The Accenture report acknowledged that the digital revolution is expanding rapidly across the world, that it has already revolutionised the cutting edge of business management globally, and that it has started a paradigm shift in the way management is perceived and should be conducted in the business sector. However, it states explicitly that "no nation has demonstrated the level of sophistication of internet presence which is fast becoming the norm amongst leading private sector companies" (Accenture 2001:2. See also Estabrooks 1995).

Canada's status as Accenture's leading innovative leader in e-government is the result of its consistent commitment to a comprehensive government-wide programme of informatisation. The Canadian government "relies heavily on cross-departmental task forces to co-ordinate and communicate" (Accenture 2001:23). This distinguishes Canada from all other contenders in this field. Other innovative

approaches that set it apart from the rest include the development of sophisticated customer relationship management techniques and intentions-based designs for electronic services. These are electronic approaches that are standard in many successful e-businesses.

Although South Africa is not at the level of the four European case studies in terms of e-readiness, it is also not that far behind, as is clear from the status that it has been 
accorded in the four above-mentioned comparative studies. The most impressive results are reported by the Accenture study, where South Africa is one of only four developing countries that are regarded as global e-government leaders. It faces strong competition, however, in order to avoid falling below its place at the bottom of that list.

The four European governments in this research sample as well as South Africa have generally accepted that the nature of their government services will have to change fundamentally in order to keep pace with the advent of the digital or information age. The increasing use of IT in order to establish effective electronic front-office service-delivery systems (e-governance) in the public sector is therefore an important strategic objective of these governments, as is confirmed by Heath (2001). Massive amounts of funding are made available by European governments to establish online front-office services to the public and dedicated programmes to achieve these objectives are developing rapidly (e.g. Kablenet UK).

At the start of this research programme an important underlying assumption was that the relatively high levels of ICT-related spending by some European governments would have resulted in advances in the use or development of both electronic front-office and back-office systems in those countries. This assumption was proven wrong very soon after the empirical data compilation process started. Most of the research publications on e-government that were encountered focused virtually exclusively on the front-office component, especially the internet (e.g. Accenture 2001; European Commission 2002). The same happened in interviews conducted with key role-players in this field (see list of interviewees in Annexure 6.2).

An assessment of these sources indicated clearly that even the leading e-government countries defined their objectives virtually exclusively in terms of front-office technological progress and therefore allocated most of their resources to bringing their external servicedelivery systems online. Insignificant amounts of money are diverted to the upgrading of back-office management support systems. This has caused a notable scholar in the field to 
refer to this phenomenon as " the hollow e-state" (Heeks 2001). It was difficult and in some cases impossible to obtain hard data on back-office management-support modernisation in the public sector in the restricted time available for this research, compelling the researcher to make mainly qualitative assessments based on personal observations and interviews with key professionals in different policy sectors.

It is therefore clear that this area of research into the use of back-office managementsupport systems in government is a relatively new one that has not yet captured the attention of mainstream scholars. This is demonstrated well by two personal experiences during the research programme. The first illustration is the result of a content analysis of the papers presented at the meeting of the International Institute of Administrative Sciences' European Group on Public Administration's (IIAS's EGPA's) Working Group on New Technologies in Public Administration in Vaasa, Finland on 3-5 September 2001. Of the 33 papers presented at the workshop, only two focused on back-office technologies (including one by the author himself), while the rest all dealt with different aspects of the use of technology in external service delivery in the public sector (front-office applications like e-service delivery and e-communication with the public).

The European Commission has recently acknowledged that this skewed focus on frontoffice technologies cannot continue indefinitely by concluding in a significant Web-based Survey on Electronic Public Services in Europe conducted for it by Cap Gemini Ernst \& Young that "(c)omplex administrative procedures require important back-office reorganizations" and that "the online development of public services can be enhanced by ... extensive back-office reorganisations to transform complex transactions into simple procedures. This is a long-term operation [but] (i)f the back office is well prepared ... bringing services online can be done very quickly" (European Commission 2002:9).

The Commission also stated that "(t)his leads to the conclusion that the concept of e-government should focus more closely on the modernisation of government, and more 
particularly on the transformation of government authorities into customer-oriented service providers" (European Commission 2002:10).

It is clear that increasing external pressure on government agencies to change and growing evidence of the concrete benefits of e-management are starting to influence the perceptions of individual public sector elites of experimenting with emerging back-office technologies in isolated cases. European governments are increasingly realising that fullyfledged e-management (integrated back- and front-office technologies) is their only option to meet changing demands in their respective societies (e.g. Brittain 1992; Kroon 1997). 


\section{CHAPTER 5}

\section{SUMMARY OF RESEARCH FINDINGS AND RECOMMENDATIONS}

This exploratory study of the state of electronic management support tools in four European governments has produced the findings listed below.

1. The global IT revolution is causing a fundamental paradigm shift in management theory and practice all over the world.

2. This IT revolution has already taken firm root in large organisations in the business sector, under the driving force of private-sector management consultants, and is expanding rapidly to smaller enterprises.

3. The use of electronic management-support systems in Western European governments is, however, not as advanced as originally anticipated.

4. Although plans for electronic front-office service delivery of most public services are well advanced in most European governments, these attempts at e-governance are not sustainable without similar fundamental paradigm changes in supporting backoffice technologies.

5. A serious neglect of back-office technologies is evident throughout the European public sector.

6. The reasons for this neglect of back-office technologies by European governments include different combinations of political, social, cultural, psychological, bureaucratic and technological considerations.

7. A systematic improvement of back-office technologies in the public sector in more developed societies as part of a more comprehensive programme to improve good 
governance outcomes is needed in order for current e-governance initiatives to succeed.

8. Outcomes-based governance is only feasible if it is founded on a management approach and a system that fully utilises the current and future potential of IT to determine and assess results in real time. This means the strategic adoption and application of integrated management-support software and business intelligence tools as integral components of mainstream management processes.

9. The experience of the private sector in this regard is crucial for success in the public sector, obviously adapted to the specialised needs of the public sector, where necessary.

10. Appropriate commercial hardware and software products already exist to achieve desired objectives and can be customised relatively easily for specialised applications in the public sector (see e.g. Annexure 6.3).

11. In lesser developed societies successful applications of these back-office technologies are to a larger extent a prerequisite for successful e-governance than is the case in more developed societies.

12. In these lesser developed societies the adoption of cutting-edge back-office technologies, as suggested above, may also be the only way for some governments to deliver on their own policy objectives and undertakings, despite the significant constraints on successfully implementing such technologies.

13. The systematic adoption of, and the training of serving and prospective officials in the public sector in lesser developed societies in, the use of appropriate cutting-edge back-office technologies in the short rather than the medium term can facilitate and accelerate the mental consolidation of the new paradigm shiftin public management in those societies too. It can also assist with concrete capacity building for policy 
implementation in the public sector and access to the benefits of development through the international network society, although at a much slower and incremental pace than in more developed societies.

The early functional approach to public administration distinguished conceptually between strategic and operational management processes, as well as other analytically distinct and systematic sub-processes that follow each other to a large extent in linear or consecutive fashion (e.g. POSTCORB referred to earlier). The policy sciences approach in turn identified similar linear policy management stages, labelled policy formulation, implementation and evaluation, all designed as rational, systematic procedures to optimise intended outcomes.

IT is bringing about a paradigm shift by fundamentally changing the nature and order of the above management processes. Over the last decade new developments in IT have led to a blurring of the traditional conceptual boundaries between strategic and operational management as well as between the different conceptual stages of the policy management process. These IT breakthroughs have also started to change many management sub-processes into simultaneous and parallel instead of consecutive processes. Planning, implementation and assessment can now be done simultaneously and continuously, while re-designed integrated management processes can establish direct, empirical and measurable linkages between vision/mission statements, objectives, implementation programmes and outcomes, as well as between budgets, resource availability and control measures.

Now a paradigm shift is starting to take effect by the effective integration of these approaches, made possible only now by emerging ICTs, creating for the first time the conditions to fulfil the promise of public administration theory in practice. It is now possible to achieve a situation where "all the elements of corporate and information strategy are aligned, so that an organisation's information resource is placed to support that organisation's strategic and ultimately, operational activity"(Clarke 2001:91). 


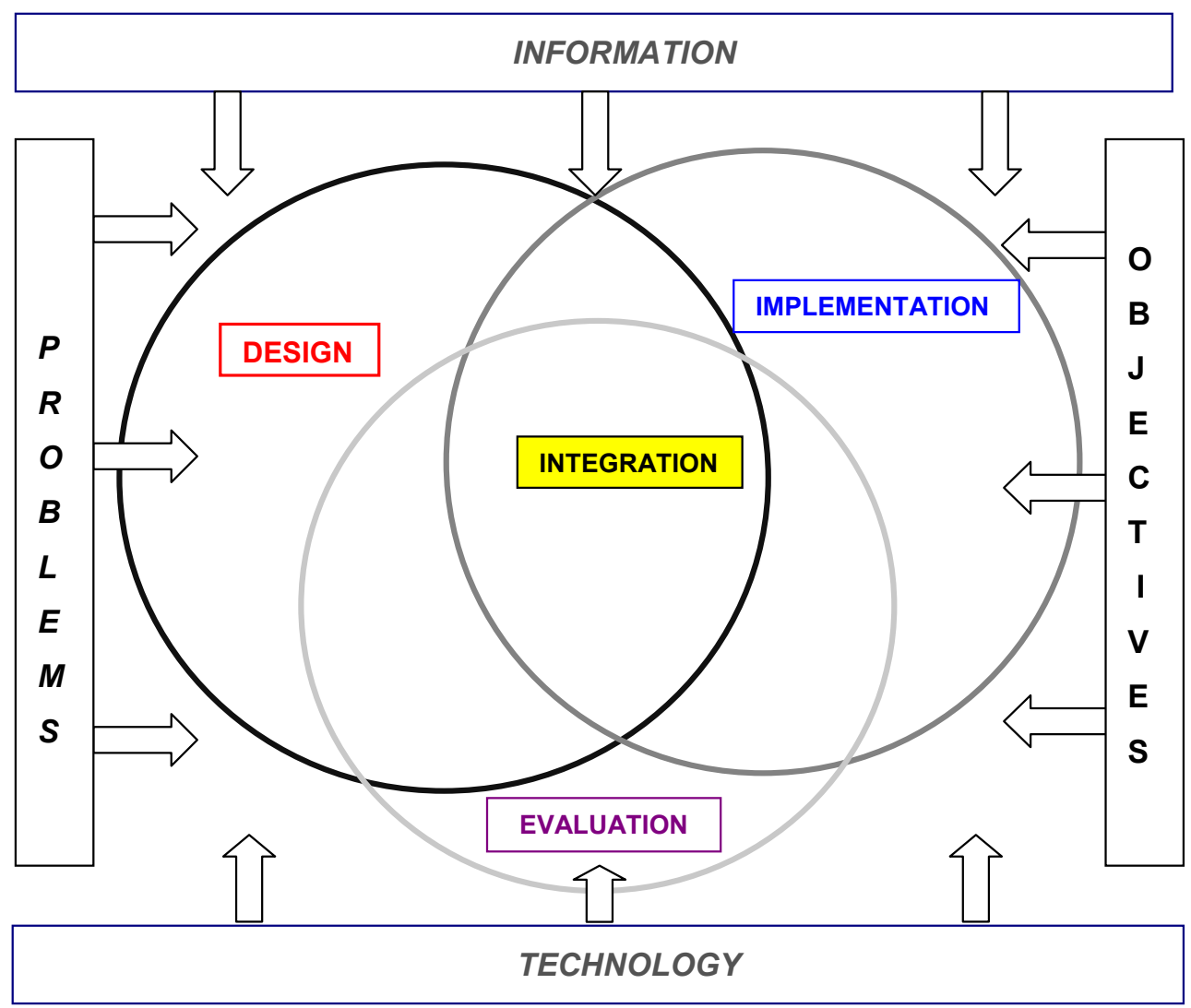

(Adapted from McGee \& Prusak 1993:8)

An empirical research study among EIS users, consultants and developers in South Africa in 1996 reported that the respondents identified the trends listed below in the expanding capacities of EISs (Duffy 1998:37. See also Watson, Houdeshel \& Rainer 1997:406):

- More user-friendly tools to make the human interface with technology more intuitive; 
- better identification of overall patterns, generation of solutions to problems and the preparation of formal reports;

- better integration with other management applications;

1 text manipulation capabilities;

- data warehouse and data mining capabilities (Gray 1999:99; Gray \& Watson 1998);

, object-oriented features;

- better use of multi- and hypermedia technologies (Watson, Houdeshel \& Rainer 1997:275);

- the use of intelligent agents to collect, analyse and distribute information; and

> individual and group support for everyone in the organisation (Watson, Houdeshel \& Rainer 1997:316).

Six years after the research findings reported by Duffy, many of the trends that had been identified have already materialised in new technologies that are freely available on the market. There was a dramatic increase in the use of knowledge and information technologies in society over the last decade and a general international trend towards a closer integration of information technology with virtually every policy sector imaginable (even to extent of placing electronic bar codes on refuse bags to determine contents and ownership for charging user fees). This implies that the public sector will have to keep up with these developments if it wants to fulfil the expectations of its citizens and provide public services of the required quality and quantity.

A general acceptance of this point of view has so far been delayed and complicated by:

- insufficient appreciation of the utility of such tools;

- open suspicion of and even deliberate resistance to the increased use of electronic tools in public management, linked to the complexity of digitising existing programmes; 
- low levels of computer literacy; and

- serious resource constraints in the face of different priorities, especially in developing countries.

The use of electronic management assessment tools can, however, provide important benefits as far as public management outcomes are concerned, including:

v the education of public officials in information technology, and through this,

- achieving more systematic management design, implementation and assessment of public programmes;

1 facilitating the development of a culture of performance;

- capacity building for more effective and efficient service delivery; and

1 fulfilling better the governance functions of the state.

A variety of electronic management assessment tools are currently available and are used or are under development in various countries to try to enhance the quality of public policy management outcomes (see Annexure 6.3). Of special importance for the new paradigm of integrated management are the so-called business intelligence tools like Corvu, PBViews and similar functionalities in more comprehensive enterprise resource managementsupport programmes. Unfortunately, it seems as if there is no single tool at the moment to undertake the tasks in the management assessment framework conceptualised above. The combined effect of still-developing technologies and the insufficient appreciation of the utility of such instruments, referred to above, has resulted in a situation that is not at the moment fully conducive to such developments. It is, however, an open question whether in ten years time public sector agencies and their staff will not be fully reliant on these instruments in order to do what they are supposed to do. Another open question is whether any government that does not embrace the new technologies for these purposes will be able to provide the required levels of services, or to compete with other service providers in an environment of open competition, or even survive as governments in future. 


\section{IMPLICATIONS FOR DEVELOPING COUNTRIES}

In order to improve the positive impact of public policy outputs in lesser-developed states, the quality of public policy designs and implementation needs to be assessed accurately. This can be facilitated by the use of user-friendly electronic policy management assessment tools. However, Lauden \& Lauden argue that users of MSS tools frequently "... have little or no computer experience, and no patience to learn a complex tool, so the interface must be relatively intuitive... To mimic a typical way of working, a good user interface should allow the manager to move back and forth between activities at will" (1998:594).

This conclusion is important, because it implies that even existing electronic MSSs or other software programmes designed for purposes of management support and that are widely used in more developed countries (like Microsoft Office and MS Project packages) are already too sophisticated and complex for general application in publicmanagement conditions in many developing countries. There is therefore a need for the identification or development of intermediate level MSSs for this purpose in order to expose middle-level officials to the benefits of such systems and induce them to migrate to more powerful and sophisticated systems like those mentioned above. Simultaneously, however, the overall strategic management outcomes of public sector organisations that already have a basic electronic infrastructure in place that operates satisfactorily can potentially be further enhanced by more sophisticated support tools. The UN Social and Economic Council's Committee of Experts on Public Administration now openly supports the promotion of egovernment across the world (including in developing countries) as an important instrument to implement the UN's Millennium Declaration and it also supports the development of analytical and policy tools for this purpose to promote good governance (UN-CEPA 2002b:10).

The combined effect of still-developing technologies, a lack of a critical mass of technological infrastructure and the insufficient appreciation of the utility of such 
instruments, referred to above, has resulted in a situation that is not at the moment fully conducive to widespread adoption of electronic management assessment-support tools in governments across the worlds, even in countries regarded as leading e-government advocates (Cloete \& Needham 2002). The situation in developing countries is even worse.

As stated above, it is an open question whether any government that does not embrace the new technologies will be able to provide the required levels of services, compete with other service providers in an environment of open, global competition, or even survive as a government in future. At the moment many governments in developing countries cannot meet the needs, expectations and demands of their citizens through their current servicedelivery programmes for the variety of reasons summarised above. Although there is no general agreement yet that electronic service delivery is more cost effective than traditional delivery systems, there are strong indications that this is the case (Heeks 1999:18). The Third Global Forum on Reinventing Government concluded in 2001 that egovernment can consistently improve the quality of life for citizens and can create a sharp reduction of costs and time (UN-DPEPA 2001:4-5).

"E-government must be given serious consideration also in the developing countries not only for its potential for stronger institutional capacity building, for better service delivery for citizens and business (thus increasing local social and economic development), for reducing corruption by increasing transparency and social control, but also for 'showing the way' to the civil society and business community" (UN-DPEPA 2001:5). The UN report on e-government further stated explicitly that decision-makers and public sector professionals were of the opinion that e-government "transforms governance like no previous reform or reinvention initiative. E-government potentially empowers individual citizens by providing them with an alternative channel for accessing information and services and interacting with government" (UN-DPEPA 2001:6). This statement obviously also refers to the crucial sustainable development objective of all developing governments. IT is from this perspective also used as an important development agent to induce citizens 
to become more literate in order to benefit from the advantages presented by technology (UN-HDR 2001; Bhatnagar 2001).

Governments that do not accept the emerging benefits of technology and still cling to their traditional delivery systems face a very stark range of choices. The first choice is to attempt to improve their current, traditional policy implementation capacities and mechanisms to the extent that they will be able to meet the needs, expectations and demands in their respective societies sufficiently to stave off political instability and loss of power. In most cases this objective of good governance is beyond their capacity, because of current systemic defects that they seem unable to reverse. Another complication is that the effects of globalisation inter alia necessitate the closure of the existing digital divide between wealthy and poor nations - a require-ment that is, in the short term at least, beyond the capacity of any government in a developing state to achieve.

The second choice they face is to accept the inevitability of insufficient performance and to try to stave off political instability for as long as possible through increasingly authoritarian actions and internal security operations. The course that the Zimbabwean government has been taking in the recent past is an illustration of this desperation to survive politically. This not sustainable good governance, but a recipe for national disaster.

The only feasible alternative for a government in a developing country to achieve good governance outcomes is to accept the inevitability of the global technological revolution and to initiate, as soon as possible, appropriate general literacy and specialised computer literacy programmes to reduce the digital gap between it and the industrial world (see also Grindle \& Hildebrand 1995). This implies a major paradigm shift in public policy and spending priorities to utilise technology optimally as a major policy instrument to facilitate the provision of basic services. In many cases technology-based services like distance education, electronic personal identification systems, internet-based services, etc., may prove to be the only way in which those governments will be able to meet their own service-delivery targets. These policy innovations are fast becoming delivery standards 
across the world. Developing nations cannot do without them if they want to provide sustainable good governance. The UN Social \& Economic Council's Committee of Experts on Public Administration stated explicitly in its first report that public sector organisations should become learning organisations with the objective of exploring "how to create a dynamic culture that could be conducive for the developing countries to 'leap-frog' over stages of development and to leap more rapidly the benefits of a nascent knowledge economy" (UN-CEPA 2002b:6).

A useful compilation of the main lessons one can learn from e-government experiences in developing countries, including both failures and successes, can be found at http://www.egov4dev.org (2003).

The most significant obstacle to the optimal use of technology in government is not resource related. It is a mental obstacle, namely an unwillingness to accept the inevitable impact of the global technological revolution on governance. Despite massive technological development aid that may be provided in future to developing countries that lag behind the technologically better-endowed states, the digital divide will not be reduced if accompanying mental paradigm shifts are not made in such countries.

\section{RESEARCH CONCLUSIONS}

The broad hypothesis for this study that was formulated at the start of this report was that the appropriate use of electronic management-support tools has the potential to promote more successful strategic policy decisions, implementation strategies and policyassessment processes that in turn may improve public service delivery outcomes. This hypothesis was broken down into four specific research questions, which were analysed and assessed in this report. These four research questions that formed the conceptual framework for this study can now be answered as follows. 
Firstly, it seems that, although all four states have advanced e-government programmes in place, electronic internal management-support (back-office) systems are not the primary focus of attention in any of the four case studies concerned. In all cases they are incidental to the development of external electronic service delivery systems (e.g. focusing on the development of back-office security systems to protect the integrity of electronic data transmissions and transactions, and for administrative record keeping and archival purposes). There is a general absence of any co-ordinated effort to develop these capacities in a systematic way to support better-quality policy design and assessment. The isolated use of electronic dss can in most cases be attributed to individual officials or consultants in autonomous departments that find such tools useful.

The main reasons for the lack of attention to this application of electronic managementsupport tools seem to be similar to the normally accepted reasons why the introduction of e-government is resisted in public sector organisations. Additional considerations for the lack of electronic decision-support use in government seems to include a lack of knowledge about the existence of the available utility programmes, unfamiliarity with the operation of the tools, a distrust of the normative bases of existing decision-support programmes and of the transparency of the processes resulting from the use of these programmes, and personal decision-making styles and mindsets that are not conducive to the use of these tools.

The second question was: how effective are these practices, i.e. what is their impact on public sector policy processes and outcomes? From the above conclusion it should be clear that the lack of a systematic, co-ordinated use of decision-support tools in the four case studies means that such tools have no significant impact on the state of public management in general in those countries. In the isolated cases where such tools have been successfully implemented, they have already had very important positive impacts on the immediate outcomes in their working environments (RVA 2001; Janssen 2001; Bannister 2001b). 
The third question was: what other similar or new systems are under development or contemplated to facilitate good governance? The results from this research allow only a negative response to this question. No significant new development work has been encountered in the various case studies, with the isolated exception of the Dutch case, where a single working paper on the internet has recommended experimentation with some of these tools (Netherlands 2001b). The probable reasons for this situation have been addressed above.

The last question was: how relevant is the European experience for the situation in South Africa and other developing countries? Earlier in this chapter that question was dealt with in detail. The only conclusion that can be reached here is that developing countries can and should learn from the emerging experiences in Europe, where increasingly "hollow estates" are developing that are in danger of imploding if they are not strengthened in the short term by more appropriate supportive electronic back-office systems.

Another conclusion is that the weaker public e-government capacity that currently exists in developing countries should probably (inevitably?) lead to a more logical sequence of egovernment strategies. Governments in developing countries do not have the luxury of choosing between a front-office or back-office bias. They are currently not able to provide the required levels of external services delivery to their respective constituencies via traditional delivery mechanisms. They therefore do not have a choice but to adopt a committed e-government strategy if they seriously want to deliver on their own good governance objectives. From a rational perspective they further do not have a choice but to upgrade their back-office capacities substantially before trying to provide effective external e-services. This deterministic constraint may prove to have a beneficial outcome in the end, enabling a more successful and hopefully sustainable e-government outcome.

It seems as if the research results support the initial hypothesis that formed the point of departure for this study, namely that the appropriate use of electronic managementsupport aids has the potential to promote more successful strategic policy decisions, 
implementation strategies and policy assessment processes, which in turn may improve public service delivery outcomes. These research results are of crucial importance to enhance the relevance of Public Policy and Management teaching in South Africa and other developing countries and to provide further opportunities for quality research into the application of new technologies in policy decision-making. New policy information management networks and partnerships have been created or strengthened at international level, and a new database of user-friendly electronic management-support systems, which are available for different applications in the policy process, has been established. The appropriate application of some of the software programmes listed in Annexure 6.3 will also improve policy decision-making and capacity building in the public sector, while their incorporation into training courses for managers in the public sector will illustrate their potential and pitfalls.

Training is still too fragmented and occurs within the context of the old paradigms. It deals mostly with the role of IT as a separate management resource, instead of integrating IT into all other line-function activities in a coherent, strategic way. Training must take place within the context of the new paradigm of integrated management (Heeks \& Davies 1999:44). An outline for an integrated management course for this purpose is suggested in Annexure 6.4.

These research results can therefore potentially have a direct impact on the improvement of public policy and services delivery at grassroots levels, especially in developing countries, as policy decision-makers at all levels are empowered to take more informed and confident decisions about complex policy issues by using the anticipated electronic management support systems appropriately. 


\section{ANNEXURE 6.1}

\section{RESEARCH MOTIVATION, METHODOLOGY AND SCHEDULE}

\section{Research Motivation}

The results of recent research initiatives into new approaches to public management consistently indicate that the current evidence and outcomes-based approaches to governance in turn necessitate much more rigorous attention to information accumulation, analysis and assessment in order to build up factual evidence and records of the results of policy interventions. This is only feasible through a much more sophisticated use of computer technology. The increasing growth spurt in the global IT industry led many governments to declare their commitment to establishing e-governance systems, including governments in lesser-developed countries. Traditional public policy analysis literature and teaching, however, have not kept pace with these new developments and this led to the author's decision to embark upon a research programme on the use of strategic management-support technologies in the public sector in order to upgrade the capacity for good governance outcomes, especially in lesser-developed societies.

As far as could be ascertained, there is currently no single overview of the availability of the most state-of-the-art, user-friendly electronic management-support systems for different public policy management purposes in developing countries. At the start of this research programme there were indications that several such systems are available or are under development in highly developed countries, but there was little information about what the real state of the art was in this regard.

This research report is therefore an overview of existing electronic management support initiatives in selected countries in Western Europe, used to facilitate complex, multi-criteria public-sector activities. The results are of practical and academic training value, especially in developing countries like South Africa, and they make an original contribution to public policy analysis and management by identifying and obtaining various new applied 
technologies that have become available for purposes of supporting management processes and outcomes in different stages of the policy process. The research will undoubtedly also stimulate further research into new applications for these technologies in order to improve the service delivery results of public policy decisions.

\section{Research methodology}

The author has been employed as Professor of Public Policy Analysis in the School of Public Management and Planning at the University of Stellenbosch for the past 10 years, specialising in issues relating to the improvement of the public policy process and impact in developing countries. He spent his sabbatical during the second half of 2001 pursuing the first phase of the comparative research programme summarised in this document from a research base at the Catholic University of Leuven in Belgium. The University of Stellenbosch has an academic exchange programme with the University of Leuven and the Public Management Institute at the University agreed to allow the author to use it as a research base and to provide logistical support for this purpose. This defrayed a significant portion of the costs of the research. The intention is to complete the research report by 31 December 2003.

In preparation for the research a background study of the relevant literature available in South Africa and abroad was undertaken before departure to Europe. Additional data gathering then took place on location in selected countries by way of an additional literature compilation for each of the case studies, supplemented by personal empirical observation of public policy decision-support processes, interviews with key selected strategic policy decision experts, as well as discussions with other experts in the fields of both public management and information technology.

The assessment criteria used to analyse and compare the various experiences and systems included their accuracy, relevance, cost, user-friendliness, effectiveness and application potential in different policy planning, decision-making, implementation and 
review contexts in developing countries such as South Africa to assess strategic policy variables, choices, implementation strategies, outputs and outcomes.

At the start of the author's sabbatical, the basic premises underlying the research were tested before a panel of experts in the form of a paper delivered at the 2001 conference of the International Association of Institutes and Schools of Admini-stration (IASIA) in Athens (10 to 12 July 2001). Different conclusions were also subsequently presented the IASIA Conference in Istanbul, Turkey on 17-20 June 2002 and at the IIAS Congress in New Delhi, India, 5-9 November 2002.

\section{Research Schedule}

The research programme was based on a similar empirical research approach and schedule that the author undertook under more difficult circumstances (i.e. with respect to language, cultural and climatic conditions) in South East Asia during the first six months of 1998 , as referred to in the introduction to this proposal. That approach worked well and this current research programme amounted to a logical extension and refinement of that successful approach.

The Public Management Institute at the Catholic University of Leuven in Belgium was used as a research base during the first phase of the programme from July to December 2001. It is centrally located in the middle of Europe, within easy reach of the governmental centres of all the countries selected as case studies. From there periodic field visits to and interviews with key staff were conducted at selected strategic decision-support, management and training units in the public sectors in different countries that were best placed to shed light on the research questions.

The relatively short distances between European capitals and the numerous contacts that the researcher had already established before the start of the programme in every location that was visited contributed to the successful conclusion of the European phase of the 
programme. The fact that the programme could integrate the research with an existing international academic exchange programme also made it very cost effective. The countries selected and the reasons for this selection are outlined below.

\section{Belgium}

The researcher was based in Belgium; the PMI at the Catholic University of Leuven has a reputation in the field as one of the leading institutions in empirical Public Management Research in Europe. The author's research programme also supplemented the activities of the PMI and joint projects will be pursued in future. It was also at an early stage in the research already clear from the literature assessment that had been undertaken that the Flemish government in Belgium is at the cutting edge of technological innovations in public management. This initial hypothesis was verified in the end. The fact that the author could read and speak Flemish well also contributed to better access to research data.

\section{The Netherlands}

The author's initial literature assessment indicated that several academic groups at Dutch universities were active in this field. They included the Technical University of Delft, the European Centre for Policy Management and Development and Institute of Social Studies, both in Maastricht, and the Schools of Public Management at the Universities of LeidenRotterdam, Amsterdam, Tilburgh and Nijmegen. The Technical University of Delft is probably one of the most advanced research institutions in this regard in Europe. The author's ability to read and speak Dutch well also facilitated access to research resources here.

\section{The United Kingdom}

The initial literature review had identified various research groups in the UK that were also actively involved in this field of research. They included the Departments of Management Sciences at the Universities of Strathclyde and Manchester, and also the Operations Research Department of the London School of Economics. Other resources in the UK 
included the Electronic Envoy in the Office of the Prime Minister, the British Cabinet Office and the Centre for Management Development. The British government will be the first European government to have all government services accessible online by the public by 2005. It also has the most extensive list of publications in this field of all European governments and is clearly very far advanced in the field.

\section{France}

The French government is not as far advanced as other European governments in this field, but has a strong, centralised management modernisation programme, and the advantage that it does not have a large electronic legacy system which could be an obstructive factor, as is currently the case in other countries. The country's proximity to the other case study countries and its strong influence in Europe made it a logical choice for this study.

Specific contact persons to be interviewed and additional management support units were identified with the assistance of other experts on location in the respective countries.

Other countries that are also well advanced in terms of technology - and were possible candidates for inclusion here - were Finland and Sweden. They were, however, excluded from the case studies because of their greater distance from the heart of Western Europe, the language barriers involved, and the time and cost constraints that inclusion would have brought about.

The costs of the research were minimised by implementing the following management strategies:

- A preparatory literature study was completed at home before leaving for abroad;

- The author's sabbatical and the existing international academic exchange agreement between the Universities of Stellenbosch and Leuven were utilised to defray the costs of living in Europe; 
- Where overnight stays away from the research base proved to be more costly than daily commuting fares, such costs were minimised.

\section{Research Outputs in Leuven}

The research started on 15 July 2001 at the Public Management Institute of the Catholic University of Leuven. The research strategy was to obtain as much as possible theoretical and empirical data about the current use of electronic back-office management-support systems in the public sector in Belgium, the Netherlands, France and the UK. Data were gathered through specialised library searches, visits to various universities and research institutions, selected interviews with key actors and personal observation of decisionsupport practices in these countries. A total of $60 \mathrm{~kg}$ of documentation was accumulated in this way.

In addition to the above data collection activities, the following academic and research outputs have been achieved during the 6-month sabbatical:

- A chapter on "Political Conflict Management" has been completed for a proposed new book titled Conflict Management: Theory, Analysis \& Practice, editors: Louise Nieuwmeijer \& Fanie Cloete;

- Conference paper: Cloete, Fanie 2001: "Improving Effective Governance Outcomes with Electronic Decision Support Tools", unpublished paper presented at the IIAS CONGRESS ON GOVERNANCE AND ADMINISTRATION IN THE 21ST CENTURY: NEW TRENDS AND NEW TECHNIQUES, 9-13 July 2001, Athens, Greece;

- Conference paper: Cloete Fanie 2001: "Facilitating negotiations through electronic decision support software", unpublished paper presented at the EGPA ANNUAL CONFERENCE ON GOVERNING NETWORKS, 5 - 8 September 2001, Vaasa, Finland; 
- Conference paper: Cloete, Fanie: "Improving Effective Governance Performance with Electronic Management Support Tools", unpublished paper presented at the PUBLICFUTURES 2ND ANNUAL CONFERENCE, 28 September 2001, London;

- Participation in a Workshop on French-South African Co-operation and Development, held in Bordeaux, France, 11 - 14 September 2001;

The following guest lectures were presented:

- PMI Staff: "The use of electronic management support tools for performance monitoring and measurement";

v Course for local government officials on policy design at the PMI on the use of electronic tools in the policy design process;

D Staff of the UK government's Centre of Management and Policy Studies in Sunningdale, UK on "Lessons learnt about the transfer of knowledge";

- Staff of the Department of Public Management at the Erasmus University, Rotterdam, Netherlands, on "Improving good governance through the use of electronic management support tools";

v Students at the University of Nijmegen, in the Netherlands, on "Dynamics of the public policy process in South Africa";

v The Institute of International Development of the Ruhr University of Bochum in Bochum, Germany, on "Political developments in South and Southern Africa".

The following new projects have been initiated during this period:

- Planning has started for a joint assessment with PMI staff of the use of electronic back-office management-support tools in the Flemish government; 
- Preparation of a paper on "The role of electronic management support software in Public Policy Curricula", subsequently delivered at the 2002 IASIA Conference in Istanbul, Turkey, on 17 - 20 June 2002;

- Preparation for participation as a visiting professor in a Summer School of the Institute for Sociological, Political and Juridical Research in Ohrid, Macedonia, on "E-governance and management support systems", 24-29 June 2002. This was postponed to a later date.

- Preparation of a best practices case study presented at the November 2002 IIAS Congress in New Delhi, on "The use of GIS for Electronic Management Support: the case of Tygerberg Municipality in South Africa". 


\section{ANNEXURE 6.2}

\section{INTERVIEWS}

- Ackerman, Fran 2001: Professor, Business School, Strathclyde University, Glasgow, UK, interview: 7 November 2001.

- Aitken, Charlie 2001: International Relations Officer, Office of EU Envoy to the Prime Minister, London, UK, interview: 3 October 2001.

- Behrens, Robert 2001: Director: Training, Centre of Management and Policy Studies, Sunningdale, UK, interview: 4 October 2001.

- Bellamy, Christine 2001: Dean, Graduate School of Economic \& Social Sciences, Nottingham Trent University, Nottingham, UK, interview: 8 July 2001, in Athens, Greece.

- Bouckaert, Geert 2001: Director of \& Professor of Management, Public Management Institute, Catholic University of Leuven, Leuven, Belgium, interview: 20 November 2001.

- Brans, Marleen 2001: Professor of Policy Studies, Public Management Institute, Catholic University of Leuven, Leuven, Belgium, interview: 20 November 2001.

- Courtine, Thierry2001: E-Government Manager, ENA, Paris, France, interview: 24 October 2001.

- DÁrbon, Dominique 2001: Montesqeau IV University, Bordeaux, France, interview: 13 September 2001.

- De Vries, Michiel S 2001: Professor of Public Administration, University of Nijmegen, Netherlands, interview: 15 October 2001.

- Dugget, Michael 2001: Director-General, International Institute of Administrative Sciences (IIAS), Brussels, interview: 29 November 2001. 
- Ehtamo, Dr Harri 2001: Systems Analysis Laboratory, Helsinki University of Technology, Helsinki, Finland, interview: 10 September 2001.

- Field, Tim 2001: Project Manager, E-government, Public Management Service (PUMA), OECD, Paris, France, interview: 30 October 2001

- Goedzeels, Vic 2001: General Controller, Catholic University of Leuven, Leuven, Belgium, interview: 12 December 2001.

- Greenwood, John 2001: Professor of Policy and Public Administration, De Montford University, Leicester, UK, interview: 5 November 2001.

- Gustafsson, Tommy 2001: Systems Analysis Laboratory, Helsinki University of Technology, Helsinki, Finland, interview: 10 September 2001.

- Hamalainen, Raimo 2001: Systems Analysis Laboratory, Helsinki University of Technology, Helsinki, Finland, interview: 10 September 2001.

- Heeks, Richard 2001: Senior Lecturer, Information Systems, Institute of Development Policy and Management (IDPM), University of Manchester, Manchester, UK, interview: 6 November 2001.

- Homburg, VMF 2000: Lecturer, Erasmus University, Rotterdam, Netherlands, interview: 22 October 2001.

- Hondhegem, Annie 2001: Professor of Public Management, Public Management Institute, Catholic University of Leuven, Leuven, Belgium, interview:

20 November 2001.

- Janssen, Ron 2001: Instituut voor Milieuvraagstukken, Free University of Amsterdam, Amsterdam, Netherlands, interview: 28 November 2001.

- Kristensen, Jens 2001: Project Manager, Public Management Service (PUMA), OECD, Paris, France, interview: 25 October 2001.

- Levy, Marc 2001: Researcher, Groupe de researche et déxchanges technologiques (GRET), Paris, France, interview: 25 October 2001. 
- Lootsma, Freerk 2001: Emeritus Professor, University of Delft, Netherlands, interview: 28 November 2001.

- Marechal, Michel 2001: Institute of Public Management and Economic Development, Ministry of Finance, Paris, France, interview: 1 November 2001.

- Matheson, Alex 2001: Head of Budgeting and Management Division, Public Management Service (PUMA), OECD, Paris, France, interview:

23 October 2001.

- Meininger, Marie-Christine 2001: ENA, Paris, France, interview: 24 October 2001.

- Moesen, Wim 2001: Professor in Economics, Centre for Economic Studies, Department of Economics, University of Leuven, Leuven, Belgium, interview:

3 September 2001.

- Perri 6, 2001: Director, Policy Programme, Institute for Applied Health \& Social Policy, King's College, London, UK, interview: 13 November 2001.

- Pollitt, Christopher 2001: Professor of Public Administration, Erasmus University, Rotterdam, Netherlands, interview: 22 October 2001.

- Pratchett, Dr Lawrence 2001: Senior Lecturer, Department of Policy and Public Administration, De Montford University, Leicester, UK, interview:

5 November 2001.

- Roe, Keith 2001: Dean, Faculty of Politics \& Communications, Catholic University of Leuven, Leuven, Belgium, interview: 6 December 2001.

- Salo, Ati 2001: Systems Analysis Laboratory, Helsinki University of Technology, Helsinki, Finland, interview: 10 September 2001.

Silon, Luc 2001: Director of Information Systems, Department of Welfare, Health \& Culture, Flemish Regional Government, Brussels, interview: 18 October 2001.

- Snellen, Ignace 2001: Emeritus Professor, Erasmus University, Rotterdam, Netherlands, interview: 22 October 2001. 
- Taylor, John 2001: Dean, Caledonian Business School, Glasgow Caledonian University, Glasgow, UK, interview: 9 November 2001.

- Van de Donk 2001:, Wim, Professor of Public Administration, University of Nijmegen, Netherlands, interview: 9 September 2001, Vaasa, Finland.

- Van Nispen, Frans 2001: Dean, Student Affairs, Faculty of Management, Erasmus University, Rotterdam, Netherlands, interview: 27 November 2001.

- Van Snick, Paul 2001: Chief Statistics Officer, Department of Planning and Statistics, Flemish Regional Government, Brussels, Belgium, interview: 29 November 2001.

- Wyatt, Andrew 2001: International Relations Officer, Centre of Management and Policy Studies, Sunningdale, UK, interview: 14 November 2001. 
ANNEXURE 6.3

\section{SELECTED ELECTRONIC MANAGEMENT SUPPORT TOOLS}

\begin{tabular}{|c|c|c|}
\hline Software & Cost & Requirements, features \& Comments \\
\hline $\begin{array}{l}\text { Complete Negotiator } \\
\text { www.negotiation.com }\end{array}$ & \multirow[t]{2}{*}{$\$ 25$} & \multirow{2}{*}{$\begin{array}{l}\text { Very useful paper-based negotiation-support model. } \\
\text { Supporting videos also available. Electronic version } \\
\text { planned but not available yet. }\end{array}$} \\
\hline $\begin{array}{l}\text { Paper version: Negotiator's } \\
\text { Library: Complete } \\
\text { Negotiator, How to Read a } \\
\text { Person Like a Book, You're } \\
\text { the Expert, \& Meta-Talk } \\
\text { (based on Nierenberg, G } \\
\text { 1986: The Complete } \\
\text { Negotiator, Nierenberg } \\
\text { Publishing). }\end{array}$ & & \\
\hline \multirow[t]{2}{*}{$\begin{array}{l}\text { Corvu } \\
\text { http://www.corvu.com }\end{array}$} & & $\begin{array}{l}\text { Windows } 3 x, 95,98, N T \text {, Unix, ODBC compliant, OLE DB } \\
\text { for OLAP }\end{array}$ \\
\hline & & $\begin{array}{l}\text { Data Sources: } \\
\text { DB2, Oracle, Informix, SQL server, Progress, ESSBASE, } \\
\text { ASCII, flat files }\end{array}$ \\
\hline CorManage: & & \multirow{3}{*}{$\begin{array}{l}\text { Excellent Enterprise Resource Management package to } \\
\text { link strategic objectives to budgets, action plans, outputs } \\
\text { and outcomes via customised policy indictors, and } \\
\text { monitoring and assessing the results in real time. Very } \\
\text { powerful and sophisticated, fully supported by CORVU } \\
\text { consultants. Price includes training, installation and } \\
\text { maintenance. They guarantee savings covering the cost of } \\
\text { the tool in the short term. Australian product. }\end{array}$} \\
\hline Licence fee per user: & $\$ 3800$ & \\
\hline Annual maintenance fee: & $\begin{array}{l}20 \% \text { of } \\
\text { licence fee }\end{array}$ & \\
\hline \multirow{2}{*}{$\begin{array}{l}\text { Criterion-decision + } \mathbf{3 . 0} \\
\text { http://www.infoharvest .com }\end{array}$} & \multirow[t]{2}{*}{$\$ 695$} & Windows 95,98,NT.4.0. SP3 and higher \\
\hline & & $\begin{array}{l}\text { Very useful qualitative and quantitative MCDA decision- } \\
\text { support package. Comprehensive, user-friendly and } \\
\text { flexible. One of the best on the market in its field. Good } \\
\text { value for money. }\end{array}$ \\
\hline
\end{tabular}




\begin{tabular}{|c|c|c|}
\hline Software & Cost & Requirements, features \& Comments \\
\hline $\begin{array}{l}\text { Decideright } \\
\text { http://www.skyhunter } \\
\text {.com/dr.htm }\end{array}$ & $\$ 110$ & $\begin{array}{l}\text { Windows NT, Windows } 95 \\
\text { Very simple entry level, bottom of the market utility } \\
\text { qualitative MCDA decision-support programme, extremely } \\
\text { user-friendly, colour-coded presentations, automatic report } \\
\text { writing and visual presentation facilities. Restricted } \\
\text { capabilities. }\end{array}$ \\
\hline \multirow{2}{*}{$\begin{array}{l}\text { Decision Explorer } \\
\text { http://www.banxia.com/ }\end{array}$} & & All Microsoft 32-bit operating systems. \\
\hline & & $\begin{array}{l}\text { Excellent qualitative problem identification and structuring } \\
\text { programme to identify causal relationships among } \\
\text { variables. }\end{array}$ \\
\hline $\begin{array}{l}\text { Standard single license } \\
\text { (full package with manuals) }\end{array}$ & $£ 295$ & \multirow{7}{*}{$\begin{array}{l}\text { Effective for creating a visual map of a complex system } \\
\text { with varying relationships at different levels. Best use in } \\
\text { preparation for MCDA exercises. }\end{array}$} \\
\hline $\begin{array}{l}5 \text { user "saver pack" } \\
\text { ( } 5 \text { complete licence, } \\
\text { software \& manual sets) }\end{array}$ & $£ 1180$ & \\
\hline $\begin{array}{l}\text { Licence extensions } \\
\text { (no disks or manuals): }\end{array}$ & & \\
\hline 1 to 9 users, each user & $£ 185$ & \\
\hline 10 to 19 users, each user & $£ 145$ & \\
\hline $20+$ users, each user & $£ 99$ & \\
\hline $\begin{array}{l}\text { Student edition - } \\
\text { up to } 400 \text { concepts }\end{array}$ & $£ 99$ & \\
\hline \multirow{2}{*}{$\begin{array}{l}\text { DecisionPro } \\
\text { http://www.vanguardsw.com }\end{array}$} & & Personal computer with a 386 or higher microprocessor \\
\hline & & $\begin{array}{l}\text { Microsoft } ® \text { Windows } ₫ 95,98, N T 4.0,2000, \text { Me, XP or } \\
\text { later operating system, } 32 \text { MB of memory, Hard disk with at } \\
\text { least } 10 \text { MB of free space, CD-ROM drive, VGA or higher- } \\
\text { resolution video adapter, \& any mouse supported by } \\
\text { Windows }\end{array}$ \\
\hline $\begin{array}{l}\text { DecisionPro } 4.0 \\
\text { Personal }\end{array}$ & $\$ 495$ & \multirow{3}{*}{$\begin{array}{l}\text { Very powerful MCDA programme with many separate } \\
\text { functions in the field of risk assessment, forecasting, etc. } \\
\text { Good value for money }\end{array}$} \\
\hline $\begin{array}{l}\text { DecisionPro } 4.0 \\
\text { Professional }\end{array}$ & $\$ 795$ & \\
\hline $\begin{array}{l}\text { DecisionPro } 4.0 \\
\text { Developer }\end{array}$ & $\$ 995$ & \\
\hline
\end{tabular}




\begin{tabular}{|c|c|c|}
\hline Software & Cost & Requirements, features \& Comments \\
\hline $\begin{array}{l}\text { DEFINITE } \\
\text { http://www.vu.nl/english/oo/ } \\
\text { instituten/IVM/research/ } \\
\text { defenite.htm }\end{array}$ & & Windows 95/98/NT; install on hard disk. \\
\hline Single user version & $€ 1369$ & \multirow[b]{2}{*}{$\begin{array}{l}\text { Excellent MCDA programme developed by the Institute of } \\
\text { Environmental Management at the Free University of } \\
\text { Amsterdam in the Netherlands, in co-operation with the } \\
\text { Netherlands Ministry of Finance, as a decision-support tool } \\
\text { in the public sector. Very user-friendly but powerful and } \\
\text { flexible. One of the best programmes in its class. Available } \\
\text { in English and Dutch. Special educational training module } \\
\text { also available. }\end{array}$} \\
\hline Network version & $€ 2260$ & \\
\hline $\begin{array}{l}\text { Desysion } \\
\text { http://www.decidewise.com/ }\end{array}$ & \multirow[t]{2}{*}{$\mathrm{N} / \mathrm{A}$} & \multirow[t]{2}{*}{$\begin{array}{l}\text { Relatively new product with little information available. No } \\
\text { response to requests for more information. Published } \\
\text { brochures look interesting. }\end{array}$} \\
\hline $\begin{array}{l}\text { Desysion Desktop } \\
\text { Desysion Team }\end{array}$ & & \\
\hline $\begin{array}{l}\text { Expertchoice } \\
\text { www.expertchoice.com }\end{array}$ & & Windows operating system. \\
\hline $\begin{array}{l}\text { Enterprise } 2000 \\
\text { Team } 2000 \\
\text { Professional } 2000\end{array}$ & $\begin{array}{l}\text { Range from } \\
\$ 1195 \\
\text { to } \\
\$ 14995\end{array}$ & $\begin{array}{l}\text { One of the first commercial MCDA decision-support } \\
\text { products. Not as user-friendly as others in this field, but still } \\
\text { very effective and powerful. }\end{array}$ \\
\hline $\begin{array}{l}\text { Group Systems } \\
\text { www.groupsystems.com }\end{array}$ & \multirow[t]{3}{*}{$\mathrm{N} / \mathrm{A}$} & $\begin{array}{l}\text { Windows NT Server } 4.0 \text { (with Service Pack } 5 \text { or higher) or } \\
\text { Windows } 2000 \text { Server }\end{array}$ \\
\hline \multirow{2}{*}{$\begin{array}{l}\text { GroupSystems } \\
\text { MeetingRoom } \\
\text { GroupSystems Work Group } \\
\text { GroupSystems Group } \\
\quad \text { Intelligence }\end{array}$} & & $\begin{array}{l}\text { Pentium Processor, } 64 \text { MB RAM, colour monitor, hard } \\
\text { drive. }\end{array}$ \\
\hline & & $\begin{array}{l}\text { Group decision-making programmes to facilitate complex } \\
\text { decisions in real time. Experienced facilitators required. }\end{array}$ \\
\hline $\begin{array}{l}\text { IDecide } \\
\text { http://www.decisivetools .com }\end{array}$ & $\begin{array}{l}\text { Free online } \\
\text { registration }\end{array}$ & $\begin{array}{l}\text { Creates Influence diagrams using simple drag-n-drop to } \\
\text { represent a decision or model. Then runs Monte Carlo } \\
\text { simulation to explore all possible outcomes. The result is a } \\
\text { statistically accurate representation of the range and } \\
\text { likelihood of all possible outcomes. Restricted functions, } \\
\text { but useful. }\end{array}$ \\
\hline
\end{tabular}




\begin{tabular}{|c|c|c|}
\hline Software & Cost & Requirements, features \& Comments \\
\hline $\begin{array}{l}\text { Impact Explorer } \\
\text { http://www.banxia.com }\end{array}$ & 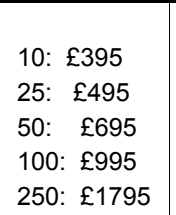 & $\begin{array}{l}\text { Windows operating system } \\
\text { Impact assessment programme for collective decision } \\
\text { support. } \\
\text { Restricted use. }\end{array}$ \\
\hline $\begin{array}{l}\text { Inspire } \\
\text { http://interneg.carleton.ca/ } \\
\text { inspire/ }\end{array}$ & $\begin{array}{l}\text { Available } \\
\text { online }\end{array}$ & Online Negotiation support programme \\
\hline $\begin{array}{l}\text { Joint Gains } \\
\text { www.jointgains.hut.fi }\end{array}$ & $\begin{array}{l}\text { Available } \\
\text { online }\end{array}$ & Online Negotiation support programme \\
\hline $\begin{array}{l}\text { Logical Decisions } \\
\text { www.logicaldecisions.com }\end{array}$ & & Windows operating system \\
\hline $\begin{array}{l}\text { Single Copy } \\
\text { (incl \$15 shipping costs). }\end{array}$ & US $\$ 504$ & $\begin{array}{l}\text { Useful MCDA decision-support programme. Flexible and } \\
\text { good value for money }\end{array}$ \\
\hline LAN or Site License Prices & $\begin{array}{l}\text { Sliding scale } \\
\text { from } \\
\$ 489 \text { to } \\
\$ 195\end{array}$ & \\
\hline Group version: Single Copy & US $\$ 1510$ & \\
\hline Academic Price for LDW 5.0: & $\$ 310$ & \\
\hline Student Version & \$65 per copy & \\
\hline $\begin{array}{l}\text { Palisade Corporation } \\
\text { http://www.palisade.com }\end{array}$ & & Windows operating system \\
\hline $\begin{array}{l}\text { Risk Analysis } \\
\text { Decision Analysis } \\
\text { - Decision Tools Suite }\end{array}$ & $\$ 1295$ & $\begin{array}{l}\text { Powerful MCDA tools, but not as user-friendly as other } \\
\text { tools. Spreadsheet-based applications. }\end{array}$ \\
\hline $\begin{array}{l}\text { Optimisation } \\
\text { Forecasting } \\
\text { Data Analysis } \\
\text { Process Simulation } \\
\text { Industry Solutions }\end{array}$ & $\begin{array}{l}\text { Different } \\
\text { license fee } \\
\text { structures } \\
\text { available }\end{array}$ & \\
\hline
\end{tabular}




\begin{tabular}{|c|c|c|}
\hline Software & Cost & Requirements, features \& Comments \\
\hline $\begin{array}{l}\text { PBViews } \\
\text { http://www.pbviews.com/ }\end{array}$ & & $\begin{array}{l}486 \text { but Pentium recommended, } 32 \text { MB RAM but } 64 \\
\text { recommended, } 35 \text { MB HD space }\end{array}$ \\
\hline Single user licence fee & $£ 3000$ & Windows operating system \\
\hline Network engine & $£ 15000$ & \multirow{7}{*}{$\begin{array}{l}\text { Excellent Enterprise Resource Management package to } \\
\text { link strategic objectives to budgets, action plans, outputs } \\
\text { and outcomes via customised policy indictors, and } \\
\text { monitoring and assessing the results in real time. Very } \\
\text { powerful and sophisticated. Not as comprehensive as } \\
\text { CORVU or QPR. Good value for money, but more } \\
\text { restricted application. Canadian product. }\end{array}$} \\
\hline Network licences: $<50$ & $£ 400 /$ user & \\
\hline Network licences: >50 & $£ 300 /$ user & \\
\hline Enterprise edition: & & \\
\hline Multi-location: & $\begin{array}{l}£ 15000 \\
\text { extra }\end{array}$ & \\
\hline Internet Publishing: & $\begin{array}{l}£ 19000 \\
\text { extra }\end{array}$ & \\
\hline Annual maintenance fee: & $\begin{array}{l}20 \% \text { of } \\
\text { licence fee }\end{array}$ & \\
\hline $\begin{array}{l}\text { QPR } \\
\text { http://www.qprsoftware.com/ }\end{array}$ & & $\begin{array}{l}\text { Application server: Windows NT } 4.0 \text { / } 2000 \\
\text { ODBC support }\end{array}$ \\
\hline QPR ScoreCard: & $\begin{array}{l}\text { Available } \\
\text { online }\end{array}$ & $\begin{array}{l}\text { Database server: Any of the following supported RDMS } \\
\text { running: Oracle } 7.3,8.0,8 \mathrm{i} \text {; MS SQL } 6.5,7.0,2000 \text {; DB2 } \\
5.2 / 6.1 \text { for Windows NT }\end{array}$ \\
\hline $\begin{array}{l}\text { Basic solution licence fee: } \\
(1 \text { Appl server, } 5 \\
\text { development clients, } 50 \\
\text { browser clients, } 2 \text { days } \\
\text { training) }\end{array}$ & $£ 30000$ & $\begin{array}{l}\text { Access } 97 \text { or } 2000 \\
\text { (Recommended only for stand-alone usage) } \\
\text { Application web server: } \\
\text { Windows NT } 4.0 \text { / } 2000\end{array}$ \\
\hline Annual maintenance fee: & $\begin{array}{l}20 \% \text { of } \\
\text { licence fee }\end{array}$ & $\begin{array}{l}\text { Web server: Windows NT } 4.0 \text { / } 2000 \\
\text { CGI 1.1-compliant web server software } \\
\text { Stand-alone application or client/server system, Database } \\
\text { systems: Oracle } 8 . x, \text { MS SQL Server } 7.0 \text { or } 2000, \text { MS } \\
\text { Access } 97 \text { or } 2000\end{array}$ \\
\hline QPR ProcessGuide & & $\begin{array}{l}\text { Excellent Enterprise Resource Management package to } \\
\text { link strategic objectives to budgets, action plans, outputs } \\
\text { and outcomes via customised policy indictors, and } \\
\text { monitoring and assessing the results in real time. Very } \\
\text { powerful and sophisticated. Finnish product. }\end{array}$ \\
\hline
\end{tabular}




\begin{tabular}{|c|c|c|}
\hline Software & Cost & Requirements, features \& Comments \\
\hline $\begin{array}{l}\text { SIMUL8 } \\
\text { http://www.visualt.com/ }\end{array}$ & & $\begin{array}{l}\text { Windows } 95,98, \mathrm{ME}, \mathrm{NT} 4,2000, \mathrm{XP} \text { or higher, } 486 / 66 \mathrm{MHz} \\
\text { Processor, } 24 \mathrm{MB} \text { of available RAM but only } 16 \mathrm{MB} \text { for } \\
\text { Windows } 95 / 98,70 \mathrm{MB} \text { of available hard-disk space, mouse } \\
\text { or equivalent pointing device, CD-ROM drive for installation } \\
\text { of boxed edition. }\end{array}$ \\
\hline SIMUL8 Standard & $\$ 995$ & BPR simulation. Very user-friendly. Good value for money. \\
\hline SIMUL8 Professional & $\$ 6995$ & \\
\hline $\begin{array}{l}\text { Smartsettle } \\
\text { www.smartsettle.com }\end{array}$ & $\begin{array}{l}\text { Online } \\
\text { Access }\end{array}$ & Online negotiation support tool. \\
\hline $\begin{array}{l}\text { STRADSPAN } \\
\text { http://www.btinternet.com/ } \\
\text { حstradspan/ }\end{array}$ & & $\begin{array}{l}\text { Microsoft Windows, Windows software } \\
\text { Excellent qualitative problem identification and structuring } \\
\text { programme to identify causal relationships among variables. }\end{array}$ \\
\hline Single user licence & $\begin{array}{l}£ 360 \\
\$ 540 \\
€ 576\end{array}$ & $\begin{array}{l}\text { Effective for creating a visual map of a complex system with } \\
\text { varying relationships at different levels. Best use in } \\
\text { preparation for MCDA exercises. }\end{array}$ \\
\hline $\begin{array}{l}\text { Thinktools } \\
\text { http://www.thinktools.com }\end{array}$ & $\mathrm{N} / \mathrm{A}$ & $\begin{array}{l}\text { Windows operating system. Very powerful but extremely } \\
\text { expensive knowledge management system. }\end{array}$ \\
\hline \multirow[t]{2}{*}{$\begin{array}{l}\text { V.I.S.A. } \\
\text { http://www.visualt.com/ }\end{array}$} & \multirow[t]{2}{*}{$\$ 199$} & $\begin{array}{l}\text { Windows } 95,98, \mathrm{ME}, \mathrm{NT} 4,2000, \mathrm{XP} \text { or higher, Pentium } \\
300 \mathrm{MHz} \text { Processor, } 64 \mathrm{MB} \text { of available RAM (only } 32 \mathrm{MB} \text { for } \\
\text { Windows } 95 / 98 \text { ), } 120 \mathrm{MB} \text { of available hard-disk space, } \\
\text { mouse or equivalent pointing device }\end{array}$ \\
\hline & & $\begin{array}{l}\text { Excellent MCDA decision support package. Very user- } \\
\text { friendly and interactive. Good value for money. }\end{array}$ \\
\hline \multirow{2}{*}{$\begin{array}{l}\text { WebNS } \\
\text { http://eclab.business. } \\
\text { mcmaster.ca/WebNS/ } \\
\text { Default.html/ }\end{array}$} & \multirow[t]{2}{*}{$\begin{array}{l}\text { Access } \\
\text { online }\end{array}$} & $\begin{array}{l}\text { WebNS can run only on Microsoft Internet Explorer } 4 . x \text { or } \\
\text { Netscape Communicator } 4 . x \text { at present. }\end{array}$ \\
\hline & & Online negotiation support software \\
\hline $\begin{array}{l}\text { WinSquared } \\
\text { www.winXwin.con }\end{array}$ & & $\begin{array}{l}\text { Windows } 95 / 98 / \mathrm{Me} / 2000 / \mathrm{XP} \text { or NT } 4.0 \text { Pentium processor or } \\
\text { equivalent ( } 133 \mathrm{MHz} \text { or higher recommended) } 16 \mathrm{MB} \text { RAM } \\
\text { (32 MB RAM recommended) } 20 \mathrm{Mb} \text { Hard disk space. } \\
\text { Display with resolution of at least } 640 \times 480.256 \text { colour } \\
\text { display or better (true colour recommended) small font mode } \\
\text { standard Windows colour scheme). }\end{array}$ \\
\hline
\end{tabular}




\section{Select Electronic Software Bibliography}

Gustafsson Tommy: A Comparison of Prime Decisions with other tools for decision analysis, Systems Analysis Laboratory, Helsinki University of Technology (http://www.hut.fi/units/sal/).

LYNCH Thomas \& LYNCH Cynthia E 2001: Revolution in Teaching?, unpublished paper presented at the IASIA CONFERENCE ON GOVERNANCE AND ADMINISTRATION IN THE $21^{\text {ST }}$ CENTURY: NEW TRENDS AND NEW TECHNIQUES,

9-13 July 2001, Athens, Greece.

Netherlands 2001b: ICT en besluitvorming: Een verkenning naar software-toepassingen ter ondersteuning van besluitvormingsprocessen, Report of the Institute for Social Innovation of Leiden University, Leiden, Netherlands, to the Netherlands Minister of the Interior (www.xpin.nl/materiaal/110318ict en besluitvorming.pdf).

OR/MS TODAY 2000: 2000 Decision Analysis Software Survey, OR/MS TODAY, October 2000:1-10

Wyatt R, 1999, COMPUTER-AIDED POLICYMAKING: LESSONS FROM STRATEGIC PLANNING SOFTWARE, E \& FN Spon, London.

WOOLDRIDGE Blue 2001: Teaching the Master's Level Course in Public Policy Formulation, Analysis and Implementation: a multi-disciplinary approach using advanced information technology, unpublished paper presented at the IASIA CONFERENCE ON GOVERNANCE AND ADMINISTRATION IN THE $21^{\text {ST }}$ CENTURY: NEW TRENDS AND NEW TECHNIQUES, 9-13 July 2001, Athens, Greece.

Zapatero E G, Smith C H \& Weistroffer H R 1997: Evaluating multiple attribute decision support systems, JOURNAL OF MULTI-CRITERIA DECISION ANALYSIS 6:201-214 
ANNEXURE 6.4

OUTLINE FOR INTERACTIVE MASTERS-LEVEL TRAINING COURSE ON ELECTRONIC MANAGEMENT SUPPORT TOOLS FOR CAPACITY BUILDING IN THE PUBLIC SECTOR

\section{NEED FOR ELECTRONIC MANAGEMENT SUPPORT TO ACHIEVE GOOD GOVERNANCE IN THE 21ST-CENTURY PUBLIC SECTOR}

Issues

- global information management trends

- global public sector management trends

- nature of management decisions

- multi-criteria decision issues

- linkage between back-office and front-office technologies

- types of electronic management support for sustainable governance

\section{Literature}

\begin{tabular}{|c|c|c|c|}
\hline • & Clapper \& Greyling 2001 & • & Cloete 2002 \\
\hline • & Jennings \& Wattam 1998 & > & Kirkwood 1997 \\
\hline • & Lauden \& Lauden 1998 & • & Lotfi \& Pegels 1996 \\
\hline • & Marakas 1999 & • & Nagel 1991 \\
\hline > & Nagel \& Teasley 1998 & • & OECD 1998 \\
\hline • & PCIP 2002 & • & Pollitt \& Bouckaert 2000 \\
\hline • & Snellen \& Van de Donk 1998 & > & Turban \& Aronson 2001 \\
\hline • & UN Millennium Declaration & • & Wyatt 1999 \\
\hline
\end{tabular}




\section{Assignment}

Design motivated policy spending priorities for a development budget which aims at achieving the following policy objectives: optimal economic growth, a more equitable distribution of opportunities and resources among ethnic and gender groups, a rise in the quality of life of people, a sustainable use of resources, a better quality of service provision to the public, and maximum societal stability. Prepare a visual presentation of your results with the aid of presentation software.

\section{ELECTRONIC PROBLEM-STRUCTURING SUPPORT}

Issues

1 issue structuring and analysis

v determining positive or negative causal linkages

Tools: Decision Explorer, STRADSPAN, Thinktools, Desysion.

Literature: Friend; Netherlands 2001b; Rosenhead 1996; Wyatt 1999.

Assignment: Design, with the aid of one of the above tools, a visual representation of the main elements of a policy issue, indicating linkages between causes and consequences.

\section{ELECTRONIC DECISION SUPPORT}

\section{Issues}

> issue prioritisation

, option identification

1 criteria identification

> criteria weighting/ranking

- option scoring against criteria and assessment

- decision support vs expert systems

b international experiences 
Tools: Criterion-decision+, Decideright, DecisionPro, Definite, e, Idecide, Logicaldecision, Palisade Decision Tools Suite, Prime Decisions, Thinktools, V.I.S.A, Ventana Group Support Systems, Expert Choice.

Literature: Belton; De Vreede; Jones \& Mgaya 1998; Dennis, Valacich, Connolly \& Wynne 1996; Gustafsson, Janssen, Lootsma 2000; Mabin, Menzies, King \& Joyce 1997; Parkinson 1995; Regan \& Holtzman 1995; Salo 1995; Snellen, Van de Donk \& Baquiast 1989; Watson Houdeshel \& Rainer 1997; Wyatt 1999.

Assignment: Design, with the aid of one of the above tools, a visual comparison and analysis of a policy issue with alternatives and attributes against which the alternatives are measured. Also do a sensitivity analysis to determine and assess choice thresholds.

\section{ELECTRONIC NEGOTIATION SUPPORT}

\section{Issues}

- Psychological profiling

- Negotiation strategies

- Negotiation tactics

- Negotiation outcome assessment

Tools: Inspire, Joint Gains, Smartsettle, The-art-of-negotiating, WebNS, WinSquared.

Literature: Ehtamo, Kettunen \& Hamalainen 1999 \& 2001; Teich, Wallenius Kuula \& Zionts 1995; Metcalfe \& Metcalfe 2001; Nierenberg 1986; Kersten \& Noronha 1999; Madanmohan Kersten, Noronha Kersten \& Cray 2000; Salo 1995.

Assignment: Develop, with the aid of one of the above tools, a negotiation plan for a public sector negotiation context of your choice, including a psychological profile of the two main negotiating parties involved. 


\section{INTEGRATED GEOGRAPHIC INFORMATION SYSTEMS}

\section{Issues}

1 History of GIS

- Characteristics and types of GISs

- GIS applications

Tools: ArcInfo/Arcview, etc.

Literature: Aangeenbrug 1991; Bernhardsen 1992; Batty \& Xie 1994; Calkins 1991; Cloete 2002; Da Villa \& Panizzolo 1996; Grimshaw 1994; Hawkins 1994; Hirschfield Brown \& Bundred 1995; Karnavou \& Mikelis 1994; Maguire 1991; McIntire 1994 ; Snellen 2000; Taylor 1991; Walker \& Young 1997; Yeh \& Li 1997.

Assignment: Develop, with the aid of GIS logic, the broad outlines of a feasible, spatiallybased management information system for a public sector organisation of your choice.

\section{ELECTRONIC MANAGEMENT IMPLEMENTATION SUPPORT}

\section{Issues}

- Electronic processing and dissemination of documents

- Electronic recording and archiving of transactions and documents

- Electronic planning \& monitoring of management implementation processes (project management)

- International best practices

Tools: MS Project and other project management and document processing and archival tools.

Assignment: Develop, with the aid of project management logic, a systematic implementation strategy for a public sector policy project of your choice. 


\section{ELECTRONIC MANAGEMENT ASSESSMENT SUPPORT}

\section{Issues}

- What should be assessed?: management assessment models

- Policy indicators to link objectives to strategies, resources, outputs and outcomes

- Comparative experiences and best practices

Tools: Corvu, PBViews, QPR, SIMUL8, Impact Explorer, etc.

Literature: Cloete 2002; Corvu; Hart 1999; Impact Explorer; OECD 2000; Publicfutures 1998; PBViews; QPR; SIMUL8.

Assignment: Develop feasible and sustainable policy performance assessment indicators for a public sector policy project of your choice.

\section{ELECTRONIC SERVICE DELIVERY AND DEMOCRACY}

\section{Issues}

Dimensions and levels of online service delivery

- E-communications

- E-voting

- International best practices

Tools: Interactive TV, E-mail, Internet (e.g. www.ecitizen.gov.sq), Smart cards, etc.

Literature: Accenture 2001; Van de Donk \& Meyer 1995; Feldman \& Sarbaugh-Thompson 1996.

Assignment: Develop a systematic internet sitemap to improve e-communication with a grassroots policy community over a public sector policy project of your choice. 


\section{INTEGRATED MANAGEMENT IN THE PUBLIC SECTOR}

\section{Issues}

- Integrated public management and good governance

- Automation

- Informatisation

- Transformation

- Strategies to maximise good governance

- Criteria for the selection of electronic support systems

Tools: Computerisation, Digital Networks, E-mail, Business process re-engineering (BPR), Enterprise Resource Management (ERM), Business Intelligence (BI)Tools.

Literature: Brittain 1992; Enzweiler; Frissen 1998; OR/MS TODAY 2000; Peterson 1998a \& 1998b; Pollitt 1999; Sanders \& Courtney 1985.

Assignment: Design a feasible lobbying strategy to lower the resistance against informatisation initiatives in a public sector organisation of your choice. 


\section{BIBLIOGRAPHY}

Accenture 2001: E-GOVERNMENT LEADERSHIP: RHETORIC VS REALITY - CLOSING THE GAP, http://www.accenture.com/xdoc/en/industries/government/final.pdf, 18 February 2003.

Ackerman, Fran 2001: Professor, Business School, Strathclyde University, Glasgow, UK, interview: 7 November 2001.

Aitken, Charlie 2001: International Relations Officer, Office of EU Envoy to the Prime Minister, London, UK, interview: 3 October 2001.

Alavi, M \& Joachimsthaler, EA 1992: "Revisiting DSS implementation research", MIS QUARTERLY 16(1).

Ayers, Jim 2001: Is supply chain management the same as ERP?, INFORMATION STRATEGY, 2001, 17(3):43-46.

Bannister, Frank 2001a: Clashing Cultures: Vision and Verve versus Inertia and Indifference in Public Sector ICT, unpublished paper presented at the EGPA ANNUAL CONFERENCE ON GOVERNING NETWORKS, 5 - 8 September 2001, Vaasa, Finland.

Bannister, Frank 2001b: Dismantling the silos: extracting new value from IT investments in public administration, INFORMATION SYSTEMS JOURNAL 11:65-84.

Batty, M \& Xie, Y 1994: Urban analysis in a GIS environment: population density modelling using ARC/INFO, in Fotheringham $S$ \& Rogerson P (eds): SPATIAL ANALYSIS AND GIS, Taylor \& Francis, New York.

Behrens, Robert 2001: Director: Training, Centre of Management and Policy Studies, Sunningdale, UK, interview: 4 October 2001.

Benjamin, Peter 1999: in Heeks, R (ed): REINVENTING GOVERNMENT IN THE INFORMATION AGE: INTERNATIONAL PRACTICE IN IT-ENABLED PUBLIC SECTOR REFORM, Routledge, London. 
Bekaert, Patrick 1997: Naar een nieuwe geintegreerde budgettaire en algemene Vlaamse overheidsboekhouding, VLAAMSE TIJDSCHRIFT VOOR OVERHEIDSMANAGEMENT 1997(3):27-31.

Bekkers, V \& Frissen, P 1992: Informatization and administrative modernisation: A comparative analysis, in Frissen, PHA; Bekkers, VJJM; Brussaard, BK; Snellen, IThM \& Wolters, M (eds) 1992: EUROPEAN PUBLIC ADMINISTRATION \& INFORMATIZATION: A COMPARATIVE RESEARCH PROJECT INTO POLICIES, SYSTEMS, INFRASTRUCTURES AND PROJECTS, IOS Press, Amsterdam, 479-489.

Bell, Simon \& Moore, Stephen 2000: SUSTAINABILITY INDICATORS: MEASURING THE IMMEASURABLE, Earthscan, London.

Bellamy, C \& Taylor, JA 1998: GOVERNING IN THE INFORMATION AGE, Open University Press, Buckingham.

Bellamy, Christine 2000: Implementing Information Age Government: principles, progress and paradox, PUBLIC POLICY AND ADMINISTRATION 15(1):29-42.

Bellamy, Christine 2001: Dean, Graduate School of Economic \& Social Sciences, Nottingham Trent University, Nottingham, UK, interview: 8 July 2001, in Athens, Greece.

Belton, V 1999: "Multi-criteria problem structuring and analysis in a value theory framework", in Stewart, T; Gal, T \& Hanne, T (eds): ADVANCES IN MULTI-CRITERIA DECISION MAKING, Kluwer, Amsterdam.

Berman, BJ \& Tettey, WJ 2001: African states, bureaucratic culture and computer fixes, PUBLIC ADMINISTRATION AND DEVELOPMENT 21(1):1-13.

Bernhardsen, Tor 1992: GEOGRAPHIC INFORMATION SYSTEMS, Viak, Norway, chpts $1,4,8,11,12,14$ (GEOG 910.285 BER). 
Bhatnagar, S 2001: The future of e-government in developing countries, paper presented at a World Bank/Development Gateway Conference on E-government in developing countries: Achievements and Prospects, held on 11-12 June 2001 in Washington, DC, http://www1.worldbank.org/publicsector/egov/June01conference.htm/

30 March 2002.

Blunt, Peter 1990: Strategies for enhancing organisational effectiveness in the third world, PUBLIC ADMINISTRATION AND DEVELOPMENT 10:299-313.

Bouckaert, G \& Auwers, T 1999: PRESTATIES METEN IN DE OVERHEID, Die Keure, Brugge.

Bouckaert, G; Hoet, D \& Ulens, W 2000: PRESTATIEMEETSYSTEMEN IN DE OVERHEID: EEN INTERNATIONALE VERGELIJKING, Die Keure, Brugge.

Bouckaert, G \& Vandeweyer, S 1999: KWALITEIT IN DE OVERHEID, Die Keure, Brugge.

Bouckaert, Geert: Director of \& Professor of Management, Public Management Institute, Catholic University of Leuven, Leuven, Belgium, interview: 20 November 2001.

Brans, Marleen: Professor of Policy Studies, Public Management Institute, Catholic University of Leuven, Leuven, Belgium, interview: 20 November 2001.

Bridges 2003: http://www.bridges.org/, 6 March 2003.

Brinkerhoff, DW 1992: Promoting the sustainability of development institutions: a framework for strategy, WORLD DEVELOPMENT 20(3):369-383.

Brittain, Michael (ed) 1992: INTEGRATED INFORMATION SYSTEMS, Taylor Graham, London.

Brown, Deryck, R 1998: Evaluating institutional sustainability in development programmes: beyond dollars and cents, JOURNAL OF INTERNATIONAL DEVELOPMENT 10:55-69. 
Bruggeman, Werner \& Vereecken, Luc 1999: De balanced scorecard: ook voor overheidsorganisaties?, VLAAMSE TIJDSCHRIFT VOOR OVERHEIDSMANAGEMENT 1999(1):26-34.

Calkins, HW 1991: GIS and public policy, in Maguire, DJ; Goodchild, MF \& Rhind, DW (eds): GEOGRAPHICAL INFORMATION SYSTEMS: PRINCIPLES AND APPLICATIONS, Longman, London, 233-245 (GEOG 910.285 GEOG).

Cape Town 2002: Towards a smart city strategy for Cape Town, briefing paper by Unicity of Cape Town.

Clapper, Valiant A \& Greyling, Francilene 2001: In Pursuit of Improved Public Management Education and Training in an Electronic Era, unpublished paper presented at the IASIA CONFERENCE ON GOVERNANCE AND ADMINISTRATION IN THE $21^{\text {ST }}$ CENTURY: NEW TRENDS AND NEW TECHNIQUES, 9-13 July 2001, Athens, Greece.

Clarke, Steve 2001: INFORMATION SYSTEMS STRATEGIC MANAGEMENT- AN INTEGRATED APPROACH, Routledge, London.

Cloete, F \& Wissink, H 2000: IMPROVING PUBLIC POLICY, Van Schaik Publishers, Pretoria.

Cloete, F 1991: Negotiating Political Change, in Nieuwmeijer, L and Cloete, F (eds): THE DYNAMICS OF NEGOTIATIONS IN SOUTH AFRICA, HSRC, Pretoria, 1991, pp. 45-74.

Cloete, F 2000: AT FULL SPEED THE TIGER CUBS STUMBLED, HSRC, Pretoria.

Cloete, F 2001a: IMPROVING EFFECTIVE GOVERNANCE OUTCOMES WITH ELECTRONIC DECISION SUPPORT TOOLS, unpublished paper presented at the IIAS Conference on Governance and Administration in the $21^{\text {st }}$ century: new trends and new techniques, 9-13 July 2001, Athens, Greece.

Cloete, F 2001b: Facilitating Negotiations Through Electronic Decision Support Software, unpublished paper presented at the European Group on Public Administration (EGPA) Annual Conference on Governing Networks, held on 5-8 September 2001 in Vaasa, Finland. 
Cloete, F \& Needham, H 2002: Fulfilling the promise?: Spatial technologies and local government management in South Africa, IIAS Conference, 5 - 9 November 2002, New Delhi, India.

Cooper, Terry L; Musso, Juliet A \& Oztas, Nail 2001: The New Sciences of SelfOrganization: a model for implementation of governance reform, unpublished paper presented at the IIAS CONFERENCE ON GOVERNANCE AND ADMINISTRATION IN THE $21^{\text {ST }}$ CENTURY: NEW TRENDS AND NEW TECHNIQUES, 9-13 July 2001, Athens, Greece.

Corvu: Software Programme, http://www.corvu.com

Council of Europe 1997: THE USE OF PERFORMANCE INDICATORS IN LOCAL PUBLIC SERVICES, Council of Europe Study Series: Local and Regional Authorities in Europe, No. 63, Strasbourg.

Courtine, Thierry: E-Government Manager, ENA, Paris, France, interview: 24 October 2001.

CPP 2002: GLOBAL E-GOVERNMENT, Center for Policy Study, Brown University, Providence, Rhode Island, USA.

Criterion-decision+: The Weigted Decision Object, Software Programme, http://www.infoharvest.com, 3 April 2002.

Da Villa, F \& Panizzolo, R 1996: An empirical study of the adoption and implementation of advanced technologies in the Italian public sector, INTERNATIONAL JOURNAL OF TECHNOLOGY MANAGEMENT 12(2): 181-198.

DÁrbon, Dominique 2001: Montesquieu IV University, Bordeaux, France, interview: 13 September 2001.

Davis, GB \& Naumann, JD 1999: Knowledge Work Productivity, in Kendall, Kenneth (ed): EMERGING INFORMATION TECHNOLOGIES: IMPROVING DECISIONS, CO-OPERATION AND INFRASTRUCTURE, Sage, London, 343-357. 
De Vreede, G, Jones N \& Mgaya, J 1998: "Exploring the Application and Acceptance of Group Support Systems in Africa" ,JOURNAL OF MANAGEMENT INFORMATION SYSTEMS, Vol. 15, No. 3, pp. 196-234.

De Vries, Michiel 1992: Stepwise multi-criteria evaluation, QUALITY AND QUANTITY 26:61-76.

De Vries, Michiel 1994: Establishing priorities: technocratic policy-making in the Netherlands, INTERNATIONAL REVIEW OF ADMINISTRATIVE SCIENCES 60:483-503.

De Vries, Michiel, S 2001: Professor of Public Administration, University of Nijmegen, Netherlands, interview: 15 October 2001.

Deblaere, Guido \& Vander Auwera, C 2000: Op weg naar een performanter WVC, VLAAMSE TIJDSCHRIFT VOOR OVERHEIDSMANAGEMENT 2000(2/3):12-18.

Decideright: Software Programme, http://www.avantos.com, 3 April 2002.

Decision Explorer: BANXIO Software: Decision Support and Meeting tools, Software Programme, http://www.banxia.com, 3 April 2002.

DecisionPro: Vanguard Software Programme: http://www.vanguardsw.com, 3 April 2002.

Definite 2001: Impact assessment software package, developed by the Institute of Environmental Issues at the Free University of Amsterdam, and the Ministry of Finance in the Netherlands.

Dennis, AR; Valacich, JS; Connolly, T \& Wynne, BE 1996: "Process Structuring in Electronic Brainstorming", INFORMATION SYSTEMS RESEARCH, Vol. 7, No. 2, pp. 268-277.

Desysion: DesideWise ICT Solution for decision management, Software Programme, http://www.decidewise.com, 3 April 2002.

DPSA 2002: E-GOVERNMENT GATEWAY CONCEPT PAPER, Department of Public Service and Administration, Pretoria. 
Duffy, NM 1998: EIS in Context, in Berkeley, D; Widmeyer, GR; Brezillon, P \& Rajkovic, V: CONTEXT SENSITIVE DECISION SUPPORT SYSTEMS, Chapman \& Hall, London.

Dugget, Michael 2001: Director-General, International Institute of Administrative Sciences (IIAS), Brussels, interview: 29 November 2001.

Durant, Robert F 1998: Agenda-setting, the 'third wave', and the administrative state, ADMINISTRATION AND SOCIETY 30(3):211-247.

Dutta, S; Wieranga, B \& Dalebout, A 1997: "Designing Management Support Systems Using an Integrative Perspective", COMMUNICATIONS OF THE ACM, Vol. 40, No. 6, pp. 70-79.

Easton, GK; George, JF; Nunamaker, JF, Jr. \& Pendergast, MO 1990: "Using Two Different Electronic Meeting System Tools for the Same Task: An Experimental Comparison ", JOURNAL OF MANAGEMENT INFORMATION SYSTEMS, Vol. 7, No. 1, pp. 87-100.

Egov4dev 2003: e-Government for Development, Homepage: http://www.egov4dev.org, 3 April 2002.

Ehtamo, Harri 2001: Systems Analysis Laboratory, Helsinki University of Technology, Helsinki, Finland, interview: 10 September 2001.

Ehtamo, Harri; Kettunen, Eero \& Hamalainen, Raimo P 1999: Searching for Joint Gains in Multi-party Negotiations, EUROPEAN JOURNAL OF OPERATIONAL RESEARCH 130:54-69.

EIU 2002: THE 2002 E-READINESS RANKINGS, Economist Intelligence Unit, THE ECONOMIST, London.

Enzweiler, AL: How ERP systems solve the too many systems problem, FOCUS MAGAZINE FOR THE PERFORMANCE MANAGEMENT PROFESSIONAL, http://focusedmanagement.com/focus magazine/

Estabrooks, M 1995: ELECTRONIC TECHNOLOGY, CORPORATE STRATEGY AND WORLD TRANSFORMATION, Quorum Books, London. 
European Commission 2002: WEB-BASED SURVEY ON ELECTRONIC PUBLIC SERVICES, summary report by Cap Gemini Ernst \& Young, 2002, Brussels.

Evans, Karen G 1996: "Chaos as opportunity: grounding a positive vision of management and society in the new physics", PUBLIC ADMINISTRATION REVIEW 56(5):491-494.

Expertchoice: Advanced decision support software programme, www.expertchoice.com, 3 April 2002.

Feldman, MS \& Sarbaugh-Thompson, M 1996: Electronic communication and decisionmaking, INFORMATION INFRASTRUCTURE AND POLICY, 1996, 5(1):1-15.

Fidler, Christine \& Rogerson, Simon 1996: STRATEGIC MANAGEMENT SUPPORT SYSTEMS, Pitman Publishing, London.

Field, Tim 2001: Project Manager, E-government, Public Management Service (PUMA), OECD, Paris, France, interview: 30 October 2001

Finer, S 1997: THE HISTORY OF PUBLIC ADMINISTRATION, Oxford University Press, London.

Finlay, Paul 1994: INTRODUCING DECISION SUPPORT SYSTEMS, Blackwell, Oxford.

Flanders 2000: VRIND 2000: VLAAMSE REGIONALE INDIKATOREN, Administration Planning and Statistics, Department of General Affairs and Finances, Ministry of the Flemish Community, Brussels, Belgium.

Flanders 2001: Official Flanders websites: http://www.vlaanderen.be, and http://fred.vlaanderen.be/statistieken/statistiek.htm

Foroughi, A; Jelassi, T \& Perkins, WC 1991: An empirical study of an interactive, sessionoriented computerized negotiation support system, INSEAD WORKING PAPER 29/1999, INSEAD Fontainebleau.

Frissen, PHA \& Snellen, IThM (eds) 1990: INFORMATIZATION STRATEGIES IN PUBLIC ADMINISTRATION, Elsevier, Amsterdam. 
Frissen, PHA 1998: PUBLIC ADMINISTRATION IN CYBERSPACE: A POST-MODERN PERSPECTIVE, in Snellen, IThM \& Van de Donk WBHJ (eds) 1998: Public Administration in an Information Age: A Handbook, I O S Press, Amsterdam, 33-46.

Goedzeels, Vic 2001: General Controller, Catholic University of Leuven, Leuven, Belgium, interview: 12 December 2001.

Goodwin, Paul \& Wright, George 1991: DECISION ANALYSIS FOR MANAGEMENT JUDGEMENT, Wiley, New York, 201-211.

Gorry, A \& Scott Morton, MS 1971: A Framework for Information Systems Design, SLOAN MANAGEMENT REVIEW 13(1):55-70.

Gray, Paul 1999: Data Warehousing, in Kendall, Kenneth (ed): EMERGING INFORMATION TECHNOLOGIES: IMPROVING DECISIONS, CO-OPERATION AND INFRASTRUCTURE, Sage, London, 99-116.

Gray, Paul \& Watson, Hugh J 1998: DECISION SUPPORT IN THE DATA WAREHOUSE, Prentice-Hall, Upper Saddle River, NJ.

Greany, V \& Kellaghan, T 1996: MONITORING THE LEARNING OUTCOMES OF EDUCATION SYSTEMS, World Bank Directions in Development Series, World Bank, Washington DC.

Greenwood, John 2001: Professor of Policy and Public Administration, De Montford University, Leicester, UK, interview: 5 November 2001.

Grimshaw, DJ 1994: BRINGING GEOGRAPHICAL INFORMATION SYSTEMS INTO BUSINESS,

Grindle, MS \& Hildebrand ME 1995: Building sustainable capacity in the public sector: what can be done?, PUBLIC ADMINISTRATION AND DEVELOPMENT 15:441-463.

Gurowka, J 2001: ABC Software - Is there a future for ABC software?, FOCUS MAGAZINE FOR THE PREFORMANCE MANAGEMENT PROFESSIONAL, www.focusedmanagement.com, 3 April 2002.

Gustafsson, Tommy: A COMPARISON OF PRIME DECISIONS WITH OTHER TOOLS FOR DECISION ANALYSIS, Systems Analysis Laboratory, Helsinki University of Technology. 
Gustafsson, Tommy 2001: Systems Analysis Laboratory, Helsinki University of Technology, Helsinki, Finland, interview: 10 September 2001.

Hamalainen, Raimo 2001: Professor \& Head: Systems Analysis Laboratory, Helsinki University of Technology, Helsinki, Finland, interview: 10 September 2001.

Hart, Maureen 1999: GUIDE TO SUSTAINABLE COMMUNITY INDICATORS, Hart Environmental data, North Andover, Mass.

Hawkins, AM 1994: Geographical information systems: Their use as decision support tools in public libraries and the integration of GIS with other computer technology, NEW LIBRARY WORLD 95(1117):4-13.

Heath, William 2001: Address at the European E-government Conference on 29 November 2001 in Brussels, Belgium.

Heeks, R \& Bhatnagar, S 1999: Understanding success \& failure in information age reform, in Heeks, R (ed): REINVENTING GOVERNMENT IN THE INFORMATION AGE:

INTERNATIONAL PRACTICE IN it-ENABLED PUBLIC SECTOR REFORM, Routledge, London, 49-74.

Heeks, R \& Davies, Anne 1999: Different approaches to information age reform, in Heeks, R (ed): REINVENTING GOVERNMENT IN THE INFORMATION AGE: INTERNATIONAL PRACTICE IN it-ENABLED PUBLIC SECTOR REFORM, Routledge, London, 22-48.

Heeks, R (ed) 1999: REINVENTING GOVERNMENT IN THE INFORMATION AGE:

INTERNATIONAL PRACTICE IN it-ENABLED PUBLIC SECTOR REFORM, Routledge, London.

Heeks, Richard 2001: Senior Lecturer, Information Systems, Institute of Development Policy and Management (IDPM), University of Manchester, Manchester, UK, interview: 6 November 2001.

Heirbrant, Serge 1999: Nabeschouwingen bij het eerste VIOM-ICT symposium, VLAAMSE TIJDSCHRIFT VOOR OVERHEIDSMANAGEMENT 1999(3):33-37. 
Hensmans, M 1999: Overheden in het elekronische tijdperk: de provincie Vlaams-Brabant als cybermediair, VLAAMSE TIJDSCHRIFT VOOR OVERHEIDSMANAGEMENT 1999(4):27-43.

Hirschfield, A; Brown, PJB \& Bundred, P 1995: The spatial analysis of community health services on Wirral using geographic information systems, JOURNAL OF THE OPERATIONAL RESEARCH SOCIETY 46(2):147-159.

Homburg, VMF 2000: Lecturer, Erasmus University, Rotterdam, Netherlands, interview: 22 October 2001.

Hondhegem, Annie: Professor of Public Management, Public Management Institute, Catholic University of Leuven, Leuven, Belgium, interview: 20 November 2001.

Hood, Christopher 1995: Contemporary public management: a new global paradigm?, PUBLIC POLICY AND ADMINISTRATION 10(2):104-117.

Humphries, Fay 2002: E-government: From standing in line to going online, http://www.itweb.co.za , 20 May 2002.

IDecide: Software Programme, http://www.decisivetools.com, 3 April 2002.

Impact Explorer: BANXIA Software Programme, http://www.banxia.com, 3 April 2002.

Inspire: Web-based Negotiation Support Software Programme:

http://interneg.carleton.ca/inspire, 3 April 2002.

Janssen, R: On the use of multi-criteria analysis in environmental impact assessment in the Netherlands, JOURNAL OF MULTI-CRITERIA DECISION-MAKING.

Janssen, R 1991: MULTI-OBJECTIVE DECISION SUPPORT FOR ENVIRONMENTAL PROBLEMS, Elinkwijk Drukkerij, Netherlands.

Janssen, R \& Van Herwijnen, M: Beslissingsondersteuning voor complexe keuzevraagstukken: BOSDA voor Windows, BELEIDSANALYSE 99(4):4-19. 
Janssen, Ron 2001: Instituut voor Milieuvraagstukken, Free University of Amsterdam, Amsterdam, Netherlands, interview: 28 November 2001.

Jee, M \& Or, Z 1999: HEALTH OUTCOMES IN OECD COUNTRIES: A FRAMEWORK OF HEALTH INDICATORS FOR OUTCOME-ORIENTED POLICYMAKING, OECD Working Paper VII:3.

Jennings, David, \& Wattam, Stuart 1998: DECISION MAKING: AN INTEGRATED APPROACH, Pitman, London.

Jensen, Mike 1999: The state of African Information Infrastructure, research report for the First Meeting of the Committee on Development Information (CODI), of the Economic Commission for Africa (ECA), held 28 June to 2 July 1999, in Addis Ababa, Ethiopia (http://www.africanet.com)

Joint Gains: Negotiation Support Software Programme: www.jointgains.hut.fi, 3 April 2002

Karnavou, E \& Mikelis, D 1994: A menu-driven environment for automated urban and regional analysis: a GIS application for educational purposes, EUROPEAN JOURNAL OF INFORMATION SYSTEMS 3(1):70-82.

Kersten, GE \& Noronha SJ 1999: Supporting international negotiation with a WWW-based system, DECISION SUPPORT SYSTEMS 25:135-154.

Kettl, DF \& Milward, HB (eds) 1996: THE STATE OF PUBLIC MANAGEMENT, Johns Hopkins University Press, Baltimore.

Kettl, Donald F 2001: CENTRAL GOVERNMENTS IN 2010: A GLOBAL PERSPECTIVE, Paper presented at a Strategic Thinkers Seminar, Performance and Innovation Unit, Cabinet Office, London.

Kiel, LD 1994: MANAGING CHAOS AND COMPLEXITY IN GOVERNMENT: A NEW PARADIGM FOR MANAGING CHANGE, INNOVATION AND ORGANISATIONAL RENEWAL, Jossey Bass, San Francisco. 
Kirkwood, CW 1997: STRATEGIC DECISION MAKING: MULTIOBJECTIVE DECISION ANALYSIS WITH SPREADSHEETS, Duxbury Press, Boston.

Klein, MR \& Methlie, LB 1998: KNOWLEDGE-BASED DECISON SUPPORT SYSTEMS WITH APPLICATIONS IN BUSINESS, John Wiley. New York.

Kooiman, Jan 1993: MODERN GOVERNANCE: NEW GOVERNMENT-SOCIETY INTERACTIONS, Sage, London.

KPMG 2001, E-GOVERNMENT FOR ALL: THE KPMG CONSULTING E-GOVERNMENT SURVEY 2001, http://www.kpmgconsulting.co.uk/research/reports/ps egov0401.html 18 February 2003.

Kristensen, Jens 2001: Project Manager, Public Management Service (PUMA), OECD, Paris, France, interview: 25 October 2001.

Kroon, Nicole 1997: EUROPESE INFORMATIESYSTEMEN: GRENSVERLEGGEND?, Eburon, Delft.

Lauden, KC \& Lauden, JP 1998: MANAGEMENT INFORMATION SYSTEMS: NEW APPROACHES TO INFORMATION AND TECHNOLOGY, Prentice-Hall, New Jersey.

Leftwich, A 1993: Governance, Democracy and Development in the Third World, THIRD WORLD QUARTERLY 14:605-624.

Leftwich, A 1994: Governance, the state and the politics of development, DEVELOPMENT AND CHANGE, 25:363-386.

Levin, Alan 2002: Director Cape Online, Cape Provincial Government, Cape Town, South Africa, interview 8 May 2002.

Levy, Marc 2001: Researcher, Groupe de researche et déxchanges technologiques (GRET), Paris, France, interview: 25 October 2001.

Logicaldecisions: Software Programme, www.logicaldecision.com, 3 April 2002. 
Lootsma, FA 1997: FUZZY LOGIC FOR PLANNING AND DECISION-MAKING, Kluwer, Dordrecht.

Lootsma, FA 1999a: MULTI-CRITERIA DECISION ANALYSIS VIA RATIO AND DIFFERENCE JUDGEMENT, Kluwer, Dordrecht.

Lootsma, FA 1999b: The assignment of scores for output-based research funding, JOURNAL OF MULTI-CRITERIA DECISION ANALYSIS 8:44-50.

Lootsma, FA 2000a: Decision support in the public sector, JOURNAL OF MULTI-CRITERIA DECISION ANALYSIS 9:1-6.

Lootsma, FA 2000b: GETELD, GETELD, GEWOGEN , GEBROKEN, Afscheidsrede 13 October 2000, Faculteit Informatietechnologie en Systemen, Technische Universiteit Delft, Netherlands.

Lootsma, Freerk 2001: Emeritus Professor, University of Delft, Netherlands, interview: 28 November 2001.

Lotfi, V \& Pegels, CC 1996: DECISION SUPPORT SYSTEMS FOR OPERATIONS MANAGEMENT AND MANAGEMENT SCIENCE, Irwin, Chicago.

Lynch, Thomas \& Lynch, Cynthia E 2001: Revolution in Teaching?, unpublished paper presented at the IASIA CONFERENCE ON GOVERNANCE AND ADMINISTRATION IN THE $21^{\text {ST }}$ CENTURY: NEW TRENDS AND NEW TECHNIQUES, 9-13 July 2001, Athens, Greece.

Mabin, V; Menzies, M; King, G \& Joyce, K 1997: Electronic meeting support and multicriteria decision analysis as tools to assist decision-making in the public sector, PUBLIC SECTOR 20(2):13-18.

Madanmohan, TR; Kersten, GE; Noronha, SJ; Kersten, M \& Cray, D 2000: Inspire: Learning negotiations with web-based systems: the base of IIMB (Indian Institute of Management, Bangalore), in Kersten, GE; Mikolajuk, Z \& Yeh AG: DECISION SUPPORT SYSTEMS FOR SUSTAINABLE DEVELOPMENT: A RESOURCE BOOK OF METHODS AND APPLICATIONS, Kluwer Academic, Boston, Mass, 215-238. 
Maguire, DJ 1991: An overview and definition of GIS, in Maguire, DJ; Goodchild, MF \& Rhind, DW (eds): GEOGRAPHICAL INFORMATION SYSTEMS: PRINCIPLES AND APPLICATIONS, Longman, London, 9-20 (GEOG 910.285 GEOG).

Malabie, Aubrey 1998: The use of information technology in the public sector, in Presidential Review Commission: DEVELOPING A CULTURE OF GOOD GOVERNANCE, Department of Public Service and Administration, Pretoria, Annexure 8.

Malema, Francis 2002: ICT IN THE PUBLIC SERVICE, presentation at the School of Public Management \& Planning, University of Stellenbosch, South Africa, SITA, Pretoria.

Mandell, Myrna P \& Steelman, Toddi A 2001: The Impact of Networks on Issues of Governance: developing strategies for the future, unpublished paper presented the IIAS CONFERENCE ON GOVERNANCE AND ADMINISTRATION IN THE $21^{\text {ST }}$ CENTURY: NEW TRENDS AND NEW TECHNIQUES, 9-13 July 2001, Athens, Greece.

Marakas, GM 1999: DECISION SUPPORT SYSTEMS IN THE $21^{\text {ST }}$ CENTURY, Prentice-Hall, Upper Saddle River, New Jersey.

Marechal, Michel 2001: Institute of Public Management and Economic Development, Ministry of Finance, Paris, France, interview: 1 November 2001.

Margetts, H 1999: INFORMATION TECHNOLOGY IN GOVERNMENT: BRITAIN AND AMERICA, Routledge, London.

Margetts, Helen 1995: The Automated State, PUBLIC POLICY AND ADMINISTRATION $10(2): 88-103$.

Marr, B; Erlhoefer, F \& Neely, Andy 2000: Weighing the options: Balanced Scorecard Software, Centre for Business Performance, Cranfield School of Management \& the Gartner Group, Stamford, Connecticut.

Martin, David 1991: GEOGRAPHIC INFORMATION SYSTEMS AND THEIR SOCIO-ECONOMIC APPLICATIONS, Routledge, London.

Matheson, Alex 2001: Head of Budgeting and Management Division, Public Management Service (PUMA), OECD, Paris, France, interview: 23 October 2001. 
McGee, JV \& Prusak, L 1993: MANAGING INFORMATION STRATEGICALLY, Wiley, New York.

McIntyre, John A 1994: Using GIS technology in economic development, ECONOMIC DEVELOPMENT REVIEW 12(3):72-74.

Meininger, Marie-Christine 2001: ENA, Paris, France, interview: 24 October 2001.

Metcalfe, Les \& Metcalfe, David 2001: Tools for Good Governance: managing international negotiations more effectively, unpublished paper presented at the IIAS CONFERENCE ON GOVERNANCE AND ADMINISTRATION IN THE $21^{\text {ST }}$ CENTURY: NEW TRENDS AND NEW TECHNIQUES, 9-13 July 2001, Athens, Greece.

Milner, EM 2000: MANAGING INFORMATION AND KNOWLEDGE IN THE PUBLIC SECTOR, Routledge, London.

Moesen, Wim 2001: Professor in Economics, Centre for Economic Studies, Dept of Economics, University of Leuven, Leuven, Belgium, interview: 3 September 2001.

Nagel, Stuart S \& Teasley III, CE 1998: Diverse Perspectives for Public Policy Analysis, in Rabin, Jack; Hildreth, WB \& Miller, GJ: HANDBOOK OF PUBLIC ADMINISTRATION, 507-533.

Nagel, Stuart S 1991: DECISION AIDING SOFTWARE, Macmillan, London.

Negotiator Pro: Software Programme, www.negotiatorpro.com, 3 April 2002.

Netherlands 1999: ACTIEPROGRAMMA ELEKTRONISCHE OVERHEID, Ministry of the Interior, Netherlands, 1999 (http://www.postbus51.nl).

Netherlands 2000a: CONTRACT MET DE TOEKOMST: EEN VISIE OP DE ELEKTRONISCHE RELATIE OVERHEID-BURGER, Minstry of the Interior, Netherlands, 19 May 2000.

Netherlands 2000b: VOORTGANGSRAPPORTAGE: DE DIGITALE DELTA, Ministry of the Interior, Netherlands, October 2000. 
Netherlands 2001a: DE ELEKTRONISCHE OWERHEID AAN DE BEGIN VAN DE 21STE EEU, Ministry of the Interior, Netherlands, 2001.

Netherlands 2001b: ICT EN BESLUITVORMING: EEN VERKENNING NAAR SOFTWARETOEPASSINGEN TER ONDERSTEUNING VAN BESLUITVORMINGSPROCESSEN, Report of the Institute for Social Innovation of Leiden University, Leiden, Netherlands, to the Netherlands Minister of the Interior, www.xpin.nl/materiaal/110318ict en besluitvorming.pdf, 12 March 2002.

Netherlands 2001c: INSTELLINGSBESCHIKKING: ADVIESCOMMISSIE ICT EN OVERHEID, Minister van Binnelandse Zaken, 13 Februarie 2001.

Newell, S; Swan, JA \& Galliers, RD 2000: A knowledge-focused perspective on the diffusion and adoption of complex information technologies: the BPR example, INFORMATION SYSTEMS JOURNAL 10:239-259.

Nierenberg, G 1986: THE COMPLETE NEGOTIATOR, Nierenberg Publishing www.negotiation.com

Nordbotten, JC \& Crosby, ME 1999: The effect of graphic style on data model interpretation, INFORMATION SYSTEMS JOURNAL 9:139-155.

Norris, Pippa 2000: The worldwide digital divide, paper prepared for the Annual Meeting of the Political Studies Association of the UK, 10 - 13 April 2000 at the LSE, London, UK.

NUA Netherlands 2002: Survey of internet access in the Netherlands, www.nua.com/surveys/how many online/europe.html, 13/4/02.

OECD 1997: PERFORMANCE INDICATORS FOR THE ROAD SECTOR, OECD Road Transport Research Series, Paris.

OECD 1998: INFORMATION TECHNOLOGY AS AN INSTRUMENT OF PUBLIC MANAGEMENT REFORM: A STUDY OF FIVE OECD COUNTRIES, Working Paper PUMA (98)14, OECD, Paris.

OECD 1999: PERFORMANCE MANAGEMENT AND FINANCIAL MANAGEMENT - HOW TO INTEGRATE THEM?, Working Paper PUMA/SBO (99)4, OECD, Paris. 
OECD 2000a: FRAMEWORKS TO MEASURE SUSTAINABLE DEVELOPMENT, OECD, Paris.

OECD 2000b: TOWARDS SUSTAIANBLE DEVELOPMENT: INDICATORS TO MEASURE PROGRESS, OECD, Paris.

OR/MS TODAY 2000: 2000 Decision Analysis Software Survey, OR/MS TODAY, October 2000:1-10.

Overman, E Sam 1996: The new sciences of administration: chaos and quantum theory, PUBLIC ADMINISTRATION REVIEW 56(5):487-491.

Owes, I; Welson, T \& Abell, A 1996: INFORMATION AND BUSINESS PERFORMANCE: A STUDY OF INFORMATION SYSTEMS AND SERVICES IN HIGH PERFORMING COMPANIES, Bowker/SAUR, London.

Palisade Corporation: Software Programme, http://www.palisade.com, 3 April 2002.

Parkinson, Chris 1995: What if?: decision shaping systems, CMA MAGAZINE 69(2):10-15.

Pascale, RT 1999: Surfing the edge of chaos, MIT Sloan Management Review, Spring: 83-94.

PBViews: Software Programme, http://www.pbviews.com, 3 April 2002.

PCIP 2002: ROADMAP FOR E-GOVERNMENT IN THE DEVELOPING WORLD, WORKING GROUP ON E-GOVERNMENT IN THE DEVELOPING WORLD, Pacific Council on International Policy, Los Angeles, USA, http://www.pacifficcouncil.org

Peppard, J 2001: Bridging the gap between the IS organization and the rest of the business: plotting a route, INFORMATION SYSTEMS JOURNAL 11:249-270.

Perri 6 2001a: TOMORROW'S GOVERNMENT - HOLISTIC, DIGITAL, SYNDICATED, paper presented at a Strategic Thinkers Seminar, Performance and Innovation Unit, Cabinet Office, London.

Perri 6 2001b: Director, Policy Programme, Institute for Applied Health \& Social Policy, King's College, London, UK, interview: 13 November 2001. 
Peterson, SB 1998: Saints, demons, wizards and systems: why information technology reforms fail or underperform in public bureaucracies, PUBLIC ADMINISTRATION AND DEVELOPMENT 18(1/2):37-60.

PGWC 2001a: PREPARING THE WESTERN CAPE FOR THE KNOWLEDGE ECONOMY OF THE $21^{\text {ST }}$ CENTURY, White Paper, Department of Economic Affairs, Agriculture and Tourism, Provincial Government of the Western Cape, Cape Town, May 2001.

PGWC 2001b: THE CAPE ONLINE PROGRAMME BUSINESS PLAN, Department of Economic Affairs, Agriculture and Tourism, Provincial Government of the Western Cape, Cape Town, August 2001.

Pollitt, C \& Bouckaert, G 2000: PUBLIC MANAGEMENT REFORM - A COMPARATIVE ANALYSIS, OUP, Oxford.

Pollitt, C 1999: PERFORMANCE MANAGEMENT AND FINANCIAL MANAGEMENT: HOW TO INTEGRATE THEM?, OECD Working Paper, vol VII:19.

Pollitt, Christopher: Professor of Public Administration, Erasmus University, Rotterdam, Netherlands, interview: 22 October 2001.

Pratchett, Lawrence 2001: Senior Lecturer, Department of Policy and Public Administration, De Montford University, Leicester, UK, interview: 5 November 2001.

Pratchett, Lawrence 1999: New Technologies and the modernisation of local government: an analysis of biases and constraints, PUBLIC ADMINISTRATION 77(4):731-750.

Prime Decisions: Software Programme, www.hut.fi/units/sal, 3 April 2002.

Publicfutures 1998: PUBLIC SERVICE EXCELLENCE MODEL: IMPROVING PERFORMANCE, Publicfutures Ltd, Llantilio, Wales, http://www.publicfutures.com

QPR: Software Programme, http://www.qprsoftware.com, 3 April 2002.

Ragsdale, Cliff T 1995: SPREADSHEET MODELING AND DECISION ANALYSIS: A PRACTICAL INTRODUCTION TO MANAGEMENT SCIENCE, Course Technology Inc, International Thompson Publishing Co, Boston. 
Regan, PJ \& Holtzman, S 1995: R \& D Decision Advisor: An interactive approach to normative decision system model construction, EUROPEAN JOURNAL OF OPERATIONAL RESEARCH 84:116-133.

Rhodes, RAW 1997: UNDERSTANDING GOVERNANCE: POLICY NETWORKS, GOVERNANCE, REFLEXIVITY AND ACCOUNTABILITY, Open University Press Buckingham.

Robson, Wendy 1997: STRATEGIC MANAGEMENT AND INFORMATION SYSTEMS: AN INTEGRATED APPROACH, Pitman Publishing, London.

Roe, Keith: Dean, Faculty of Politics \& Communications, Catholic University of Leuven, Leuven, Belgium, interview: 6 December 2001.

Rosenhead, Jonathan (ed) 1996: What's the problem?: An introduction to problem structuring methods, INTERFACES 26(6):117-131.

RVA 2001: Presentation by the Director-General of the Federal Labour Bureau, Belgian Government, Brussels, Belgium.

Salo, AA 1995: Interactive decision aiding for group decision support, EUROPEAN JOURNAL OF OPERATIONAL RESEARCH 84:134-149.

Salo, Ati 2001: Systems Analysis Laboratory, Helsinki University of Technology, Helsinki, Finland, interview: 10 September 2001.

Sanders, GL \& Courtney, JF 1985: A field study of organisational factors influencing DSS success, MIS QUARTERLY, March.

Sauter, Vicki L 1997: DECISION SUPPORT SYSTEMS: AN APPLIED MANAGERIAL APPROACH, John Wiley, New York.

Savitch, HV 1998: Global challenge and institutional capacity: Or, how we can refit local administration for the next century, ADMINISTRATION AND SOCIETY 30(3):248-273.

Schuuring, J and Feenstra, R 1998: THE APPLICATION OF GROUP SUPPORT SYSTEMS IN SOUTH AFRICA, Delft University of Technology, Delft. 
Scott Morton, M (ed) 1991: THE CORPORATION OF THE NINETIES: INFORMATION TECHNOLOGY AND ORGANIZATIONAL TRANSFORMATION, Oxford University Press, Oxford.

Silon, Luc 2001: Director of Information Systems, Department of Welfare, Health \& Culture, Flemish Regional Government, Brussels, interview: 18 October 2001.

SIMUL8: Software Programme, http://www.visualt.com, 3 April 2002.

Smartsettle: Software Programme, www.smartsettle.com, 3 April 2002.

Smith, Matin J 1998: Reconceptualizing the British State: Theoretical and empirical challenges to central government, PUBLIC ADMINISTRATION 76:45-72.

Snellen, IThM 2000: Territorialising governance and the state: policy dimensions of geographic information systems, INFORMATION INFRASTRUCTURE AND POLICY, 2000, 6(3):131-139.

Snellen, IThM; Van de Donk, WBJH \& Baquiast, J-P 1989: EXPERT SYSTEMS IN PUBLIC ADMINISTRATION, Elsevier, Amsterdam.

Snellen, IThM \& Van de Donk, WBHJ 1998: Introduction, in Snellen, IThM \& Van de Donk, WBHJ (eds) 1998: PUBLIC ADMINISTRATION IN AN INFORMATION AGE: A HANDBOOK, I O S Press, Amsterdam, 1-19.

Snellen, Ignace 2001: Emeritus Professor, Erasmus University, Rotterdam, Netherlands, interview: 22 October 2001.

SOS: Software Programme, http://www.staff.uiuc.edu/ s-nagel , http://www.ureform.org , Nagel, SS \& Bievenue, L: TEACH YOURSELF DECISION-AIDING SOFTWARE, 1992, University Press of America, New York.

Sprague, Jr, RH \& Watson, HJ (eds) 1986: DECISION SUPPORT SYSTEMS: PUTTING THEORY IN PRACTICE, Prentice-Hall, Englewood Cliffs, New Jersey.

STRADSPAN: Software Programme, http://www.btinternet.com/ stradspan, 3 April 2002. 
Svensson, Jörgen S 2001: Legal expert systems in general assistance, unpublished paper presented at the EGPA ANNUAL CONFERENCE ON GOVERNING NETWORKS, 5 - 8 September 2001, Vaasa, Finland.

Taylor, JA; Snellen, IThM \& Zuurmond, A (eds) 1997: BEYOND BPR IN PUBLIC ADMINISTRATION: INSTITUTIONAL TRANSFORMATION IN AN INFORMATION AGE, I O S Press, Amsterdam.

Taylor, DRF 1991: GIS and developing nations, in Maguire, DJ; Goodchild, MF \& Rhind, DW (eds): GEOGRAPHICAL INFORMATION SYSTEMS: PRINCIPLES AND APPLICATIONS, Longman, London, 71-84.

Taylor, John 2001: Dean, Caledonian Business School, Glasgow Caledonian University, Glasgow, UK, interview: 9 November 2001.

Teich, JE; Wallenius, H; Kuula, M \& Zionts, S 1995: A decision support approach for negotiation with an application to agricultural income policy negotiations, EUROPEAN JOURNAL OF OPERATIONAL RESEARCH 81:76-87.

The-art-of-negotiating: Nierenburg's Art of Negotiating: www.negotiation.com, 3 April 2002.

Thinktools: http://www.thinktools.com

THRIP (Technology and Human Resources for Industry Programme) 2000, GUIDE FOR THE EVALUATION AND PRIORITISATION OF THRIP PROJECTS USING MCDM , Vol. 7, No. 3, pp. 107-135.

Toonen, Theo AJ 1998: Networks, Management and Institutions: Public Administration as 'normal science', PUBLIC ADMINISTRATION 76:229-252.

Turban, E \& Aronson, JE 2001: DECISION SUPPORT SYSTEMS AND INTELLIGENCE SYSTEMS, Prentice-Hall, Upper Saddle River, New Jersey.

UK Cabinet Office 1999: MODERNISING GOVERNMENT, White Paper, Modernising Government Secretariat, Cabinet Office, London. 
UK Cabinet Office 2000a: ADDING IT UP - IMPROVING ANALYSIS \& MODELLING IN CENTRAL GOVERNMENT, Performance \& Innovation Unit, Cabinet Office, London.

UK Cabinet Office 2000b: e.gov - ELECTRONIC GOVERNMENT SERVICES FOR THE 21ST CENTURY, Performance \& Innovation Unit, Cabinet Office, London.

UK Cabinet Office 2000c: E-GOVERNMENT: A STRATEGIC FRAMEWORK FOR PUBLIC SERVICES IN THE INFORMATION AGE, Central IT Unit, Cabinet Office, London.

UK Cabinet Office 2001a: A FUTURIST'S TOOLBOX - METHODOLOGIES IN FUTURES WORK, Performance and Innovation Unit, Cabinet Office, London.

UK Cabinet Office 2001b: UNDERSTANDING BEST PRACTICE IN STRATEGIC FUTURES, Performance and Innovation Unit, Cabinet Office, London.

UK Cabinet Office 2001c: BETTER POLICY DELIVERY AND DESIGN: A DISCUSSION PAPER, Performance \& Innovation Unit, Cabinet Office, London.

UK Cabinet Office 2001d: BETTER POLICY-MAKING, Government's Centre for Management and Policy Studies, Cabinet Office, London.

UK Cabinet Office 2001e: E-GOVERNMENT INTEROPERABILITY FRAMEWORK, Office of the E-Envoy, Cabinet Office, London.

UK Cabinet Office 2001f: SUMMARY REPORT OF THE STRATEGIC THINKERS SEMINAR ON FUTURE STRUCTURES FOR CENTRAL GOVERNMENTS, 15 June 2001, Performance \& Innovation Unit, Cabinet Office, London.

UN-CEPA 2002a: CAPACITY OF THE PUBLIC SECTOR TO SUPPORT THE CREATION AND APPLICATION OF KNOWLEDGE, INNOVATION AND TECHNOLOGY FOR DEVELOPMENT, Committee of Experts on Public Administration, UN Social \& Economic Council, E/C.16/2002/5, 10 May 2002, http://www.unpan.org/conf groupexperts.asp

UN-CEPA 2002b: REPORT OF THE FIRST MEETING OF THE COMMITTEE OF EXPERTS ON PUBLIC ADMINISTRATION, Committee of Experts on Public Administration, UN Social \& Economic Council, E/2002/84, 26 July 2002, http://www.unpan.org/conf groupexperts.asp 
UN-DPEPA 2001: BENCHMARKING E-GOVERNMENT: A GLOBAL PERSPECTIVE, United Nations Division for Public Economics and Public Administration, New York.

UN-HDR 2001: MAKING TECHNOLOGIES WORK FOR DEVELOPMENT: 2001 Human Development Report, United Nations, OUP, New York.

UN 2000: MILLENIUM DECLARATION, United Nations Summit, 6-8 September 2000, New York.

V.I.S.A: Software programme, http://www.simul8.com, 3 April 2002.

Van de Donk, WBJH \& Meyer, OMT 1995: Digitalising decision-making in a democracy: For better or for worse, in Van de Donk, WBJH; Snellen, IThM \& Tops, PW 1995: ORWELL IN ATHENS: A PERSPECTIVE ON INFORMATIZATION AND DEMOCRACY, I O $S$ Press, Amsterdam, 225-248.

Van de Donk, Wim, Professor of Public Administration, University of Nijmegen, Netherlands, interview: 9 September 2001, Vaasa, Finland.

Van Nispen, Frans 2001: Dean, Student Affairs, Faculty of Management, Erasmus University, Rotterdam, Netherlands, interview: 27 November 2001.

Van Os, Jerry A 1994: Emerging applications of computer graphics in support of managerial decision making, in Khosrowpour Mehdi: INFORMATION TECHNOLOGY AND ORGANIZATIONS: CHALLENGES OF NEW TECHNOLOGIES, Idea Group Publishing, London, 103-130.

Van Snick, Paul 2001: Chief Statistics Officer, Department of Planning and Statistics, Flemish Regional Government, Brussels, Belgium, interview: 29 November 2001.

Van Sprundel, Paul 2000: De doelmatigheidsanalyse als evaluatie-instrument binnen de Vlaamse Gemeenschap, VLAAMSE TIJDSCHRIFT VOOR OVERHEIDSMANAGEMENT 2000(2/3):33-46.

Ventana: Group Systems Products 2003, Software Programme, www.groupsystems.com, 3 April 2002. 
Verbeken, D \& Pallemans, G 2000: Surfen na die 21ste eeu binne een 19de eeuws kader: een onmogelijke opdracht?, VLAAMSE TIJDSCHRIFT VOOR OVERHEIDSMANAGEMENT 2000(1):15-18.

Verdonck, Willie 1996: Informatie stuurplannen: wegwijser na die toekomst, VLAAMSE TIJDSCHRIFT VOOR OVERHEIDSMANAGEMENT 1996(3):5-13.

Verdonck, Willy \& Van Wayenberge, Inge 1999: Informatie- en Communicatietechnologie (ICT) in Vlaanderen: een overzicht, VLAAMSE TIJDSCHRIFT VOOR OVERHEIDSMANAGEMENT 1999(3):9-22.

Walker, Paul A \& Young, Michael D 1997: Using integrated economic and ecological information to improve government policy, INTERNATIONAL JOURNAL OF GEOGRAPHICAL INFORMATION SCIENCE 11(7):619-632.

Watson, HJ; Houdeshel, G \& Rainer, RK 1997: BUILDING EXECUTIVE INFORMATION SYSTEMS AND OTHER DECISION SUPPORT APPLICATIONS, Wiley, New York.

WebNS: Online Software Programme, http://webNS.mcmaster.ca, 3 April 2002.

Wijnmalen, D J D: Wikken en wegen met TOPSYS, evalueren van alternatieven met behulp van criteriumhierarchiën, BELEIDSANALYSE 99(4):20-35.

Williams, D \& Young, T 1994: Governance, the World Bank and liberal theory, POLITICAL STUDIES 42:84-100.

WinSquared: Software Programme, www.winXwin.com, 3 April 2002.

Winston, Wayne L \& Albright, S C 1997: PRACTICAL MANAGEMENT SCIENCE: SPREADSHEET MODELING AND APPLICATIONS, Duxbury Press, Boston.

Wolfensohn, James 2001: Speech at World Bank / Development Gateway Conference on E-Government in Developing Countries, 11 June 2001, Washington, DC.

Wooldridge, Blue 2001: Teaching the Master's Level Course in Public Policy Formulation, Analysis and Implementation: a multi-disciplinary approach using advanced information technology, unpublished paper presented at the IASIA CONFERENCE ON GOVERNANCE 
AND ADMINISTRATION IN THE $21^{\text {ST }}$ CENTURY: NEW TRENDS AND NEW TECHNIQUES, 9-13 July 2001, Athens, Greece.

Workbench: Prototype experimental impact assessment software package, under development by Environmentek, Strategic Environmental Analysis specialists, Council for Scientific \& Industrial Research, Stellenbosch, South Africa.

World Bank 1994: GOVERNANCE, World Bank, Washington, DC.

Wyatt, R 1999: COMPUTER-AIDED POLICYMAKING: LESSONS FROM STRATEGIC PLANNING SOFTWARE, E \& FN Spon, London.

Wyatt, Andrew 2001: International Relations Officer, Centre of Management and Policy Studies, Sunningdale, UK, interview: 14 November 2001.

Yeh, Anthony Gar-on \& Li, Xia 1997: An integrated and remote sensing and GIS approach in the monitoring and evaluation of rapid urban growth for sustainable development in the Pearl River Delta, China, INTERNATIONAL PLANNING STUDIES 2(2):193-210.

Zapatero, EG; Smith, CH \& Weistroffer, HR 1997: Evaluating multiple attribute decision support systems, JOURNAL OF MULTI - CRITERIA DECISION ANALYSIS 6:201-214.

Zeleny, Milan 1982: MULTIPLE CRITERIA DECISION MAKING, McGraw-Hill, New York, 21-27, 85-94, 473-493. 


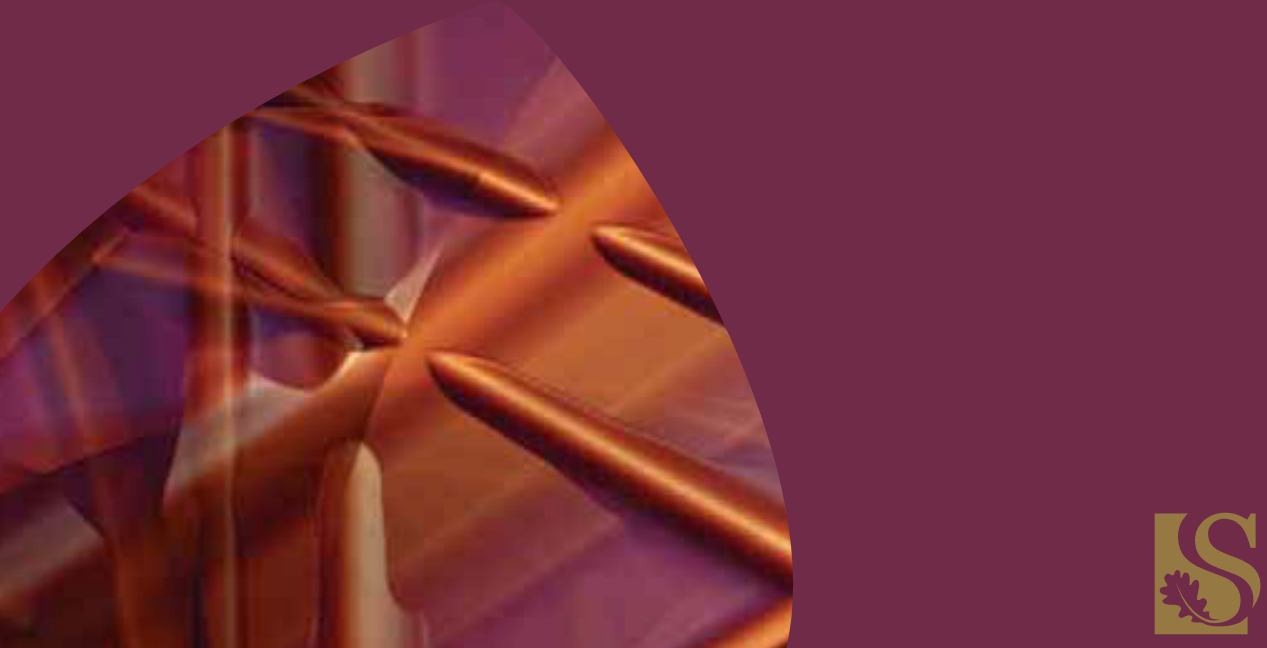

UNIVERSITEIT.STELLENBOSCH.UNIVERSITY jou kennisvennoot your knowledge partner 